UNIVERSIDADE DE SÃO PAULO

FACULDADE DE FILOSOFIA CIÊNCIAS E LETRAS DE RIBEIRÃO PRETO DEPARTAMENTO DE PSICOLOGIA

PROGRAMA DE PÓS-GRADUAÇÃO EM PSICOBIOLOGIA

Alterações eletrofisiológicas coliculares induzidas pela interrupção da administração crônica de Cetamina

ROBERTA MONTEIRO INCROCCI

Ribeirão Preto

- 2017 - 
UNIVERSIDADE DE SÃO PAULO

FACULDADE DE FILOSOFIA, CIÊNCIAS E LETRAS DE RIBEIRÃO PRETO

DEPARTAMENTO DE PSICOLOGIA

PROGRAMA DE PÓS-GRADUAÇÃO EM PSICOBIOLOGIA

\section{Alterações eletrofisiológicas coliculares induzidas pela interrupção da administração crônica de Cetamina}

Dissertação apresentada à Faculdade de Filosofia, Ciências e Letras de Ribeirão Preto USP, como parte das exigências para obtenção do título de Mestre em Ciências. Área: Psicobiologia

Orientação: Prof. Dr. Manoel Jorge Nobre do Espírito Santo 
AUTORIZO A REPRODUÇÃO E DIVULGAÇÃO TOTAL OU PARCIAL DESTE TRABALHO, POR QUALQUER MEIO CONVENCIONAL OU ELETRÔNICO, PARA FINS DE ESTUDO E PESQUISA, DESDE QUE CITADA A FONTE.

\section{FICHA CATALOGRÁFICA}

Incrocci, R.M.

Alterações eletrofisiológicas coliculares induzidas pela interrupção da administração crônica de Cetamina. 84 p.; $30 \mathrm{~cm}$.

Dissertação de mestrado apresentada à Faculdade de Filosofia, Ciências e Letras de Ribeirão Preto - USP. Área de concentração: Psicobiologia.

Orientador: Prof. Dr. Manoel Jorge Nobre do Espírito Santo.

1. Cetamina. 2. Colículo inferior. 3. Glutamato. 4. Potencial evocado. 5. Córtex préfrontal. 
Nome: Roberta Monteiro Incrocci

Título: Alterações eletrofisiológicas coliculares induzidas pela interrupção da administração crônica de Cetamina

Dissertação apresentada à Faculdade de Filosofia, Ciências e Letras de Ribeirão Preto USP, como parte das exigências para obtenção do título de Mestre em Ciências.

Aprovada em: 22 de junho de 2017

Banca Examinadora:

Prof. Dr. Manoel Jorge Nobre (orientador)

Departamento: Departamento Psicologia

Instituição/Unidade: Uni - Facef

Prof. Dra. Kelly Jacqueline Barbosa

Departamento: Faculdade de medicina

Instituição/Unidade: Uni - Facef

Prof. Dr. Norberto Cysne Coimbra

Professor Titular

Departamento: Departamento de Farmacologia.

Instituição/Unidade: FMRP-USP

Prof. Dra Júlia Maria dos Santos

Professor Adjunto

Departamento: Fisioterapia

Instituição/Unidade: Universidade Federal de Uberlândia 
Dedico ao meu filho Nicolas e aos meus pais pela confiança e apoio irrestritos. 
É precisamente na fronteira do conhecimento que a imaginação tem seu papel mais importante; o que ontem foi apenas um sonho, amanhã poderá se tornar realidade.

Marcelo Gleiser 


\section{AGRADECIMENTOS}

Ao Prof. Dr. Manoel Jorge Nobre pela sólida orientação neste trabalho, confiança e oportunidade.

À Dra. Paula Santos por ter me incentivado e por ter me indicado o caminho que deveria prosseguir.

Ao Rafael Miranda pelo incentivo e apoio inicial.

Ao pessoal do laboratório pelo convívio diário e apoio sempre que preciso.

Aos que dedicaram um tempo para poder me ensinar técnicas laboratoriais: Adriano Reimer, Fernando Reis, Renata Ferreira, Milene Carvalho e Viviane Saito.

Ao meu filho, que por algumas vezes teve que me acompanhar no laboratório.

À todos aqueles que de forma direta ou indireta contribuíram.

À CAPES, pelo apoio financeiro. 


\section{RESUMO}

INCROCCI, R.M. Alterações eletrofisiológicas coliculares induzidas pela interrupção da administração crônica de Cetamina. 2017. 84 p. Dissertação (Mestrado) - Faculdade de Filosofia, Ciências e Letras, Universidade de São Paulo, Ribeirão Preto, 2017.

A Cetamina, antagonista não competitivo de receptores de glutamato do tipo NMDA, é uma substância com propriedades dissociativas originalmente utilizada como anestésico que apresenta a característica de intensificar as experiências sensoriais. Apesar de seus conhecidos efeitos sobre os aspectos cognitivos e comportamentais, poucos estudos préclínicos foram conduzidos para tentar detectar os efeitos físicos e/ou comportamentais da abstinência de Cetamina após consumo prolongado. Partindo do princípio de que os efeitos da Cetamina sobre a neurotransmissão glutamatérgica induzem alguns dos sintomas observados durante surtos esquizofrênicos, como as alucinações auditivas, e sabendo que o colículo inferior tem sua função ligada ao processamento da informação sensorial a estímulos sonoros, neste estudo avaliamos os efeitos da modulação glutamatérgica na área cortical pré-límbica (PrL) sobre os potenciais evocados auditivos eliciados (PEAs) no colículo inferior. As medidas foram realizadas no fim do tratamento, ou seja, no $14^{\circ}$ dia, 24 horas e 6 dias após a retirada da cetamina. Em nossos resultados obtivemos que a administração local de NMDA, foi capaz de diminuir a amplitude dos PEAs, os quais foram recuperados 24 horas após. A cetamina sistêmica não foi capaz de diminuir os PEAs, uma provável consequência da interação com outros receptores além do NMDA. Os testes realizados 6 dias após a interrupção ao tratamento crônico de cetamina, demonstraram uma forma inesperada de "U", diferente da curva padrão de "U" invertido. Além disso, encontramos que as alterações provocadas pela cetamina são dependentes dos níveis dos mecanismos dopaminérgico e glutamatérgicos. Estes resultados demonstram que o processamento auditivo no colículo inferior está sob controle direto no Pré límbico e permitem ampliar o conhecimento atual da neurobiologia por evidenciar novas informações do efeito crônico da cetamina.

Palavras chave: Cetamina, Colículo inferior, Glutamato, Potencial evocado auditivo, Córtex pré-frontal. 


\begin{abstract}
Ketamine is a non-competitive NMDA receptor antagonist. It is a substance with dissociative properties originally used as anesthetic, which can intensify sensory experiences, being also capable of accentuating the psychotic state in patients with schizophrenia. Despite its known effect on cognitive aspects and behavior, there are few preclinical studies conducted to identify physical and behavioral effects of ketamine withdrawal after its long-term use. Moreover, little is known about the impact of repetitive use of ketamine on brain structures and their functioning. The inferior colliculus, part of the midbrain tectum, is mainly related to auditory information processing, sending information to the motor centers and participating in the modulation and expression of specific behaviors, such as attack and predatory. Therefore, it is related to the biological importance of sounds to survival. The auditory hallucinations induced by schizophrenic psychotic crisis has as neural correspondent the activation of inferior colliculus and cortical areas. It is not yet known which cortical area is connected to the modulation of alterations induced by electrophysiological potential registered in inferior colliculus. Considering that the effects of ketamine on glutamate neurotransmission induces the symptoms observed during schizophrenic psychotic crisis, such as auditory hallucinations, and that inferior colliculus is related to the sensory information processing and auditory pathways, the present work evaluates the effects of glutamate modulation on pre-limbic cortical area on auditory evoked potential startle in inferior colliculus of rats tested during and after interruption of chronic treatment with ketamine.
\end{abstract}

Keywords: Ketamine, Inferior Colliculus, Glutamate, Auditory Evoked Potential, Prefrontal Cortex. 


\section{LISTA DE ABREVIATURAS}

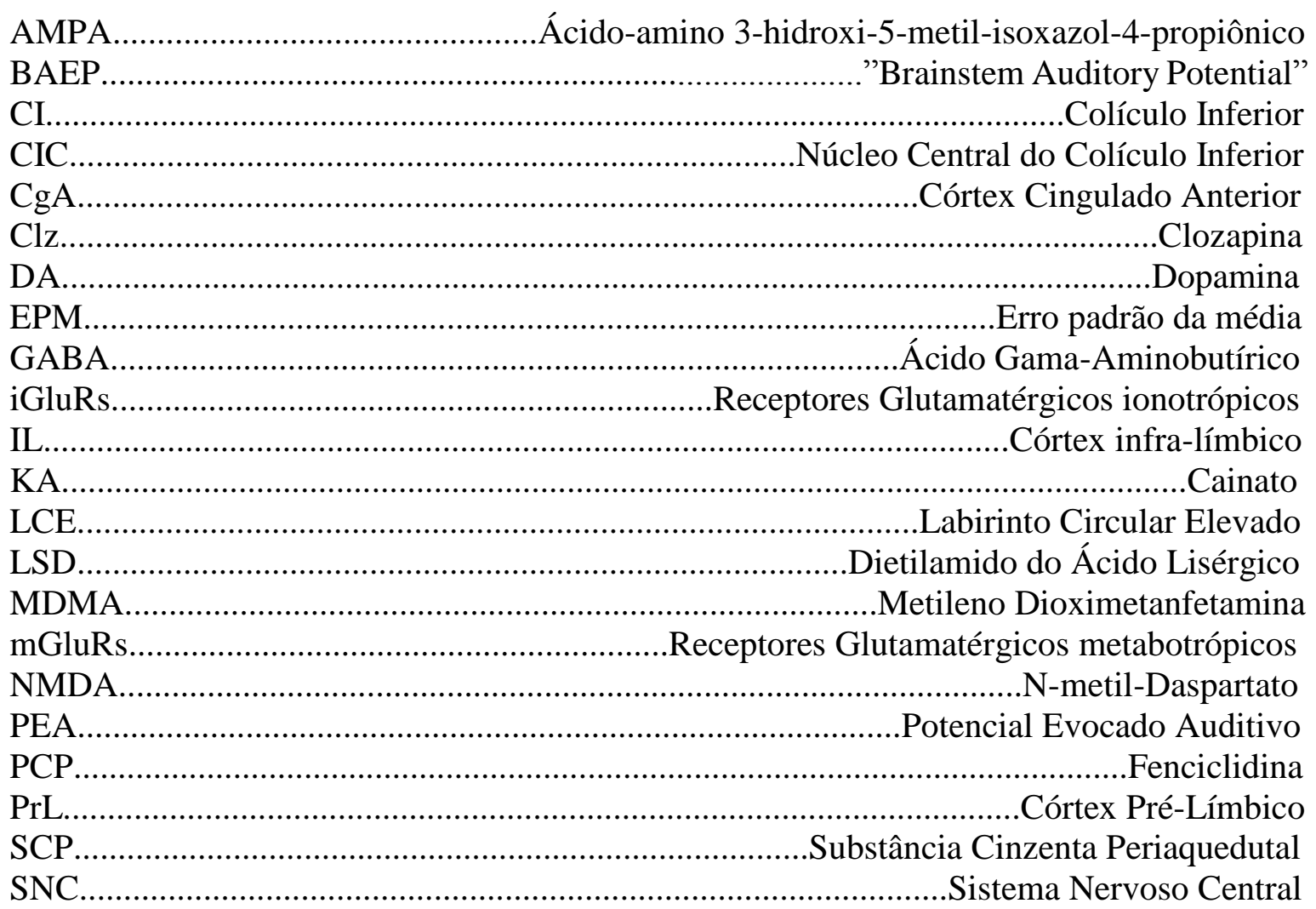


1.1 Cetamina

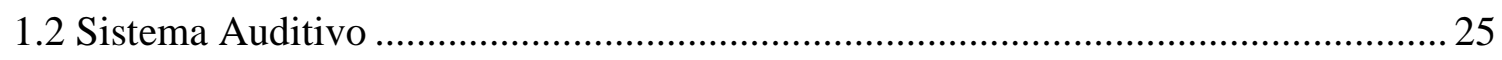

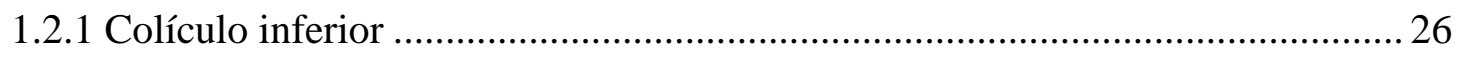

1.2.2 Modulação dopaminérgica dos substratos neurais da aversão no colículo inferior .

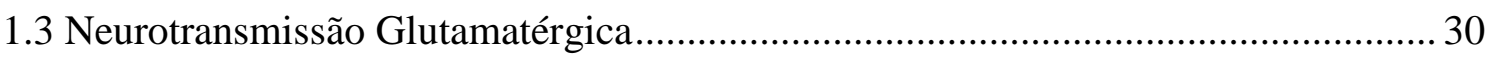

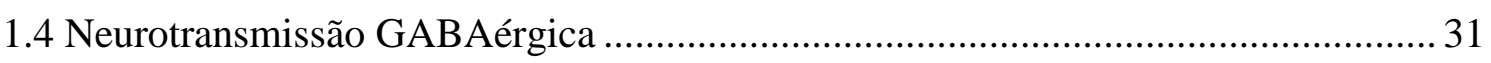

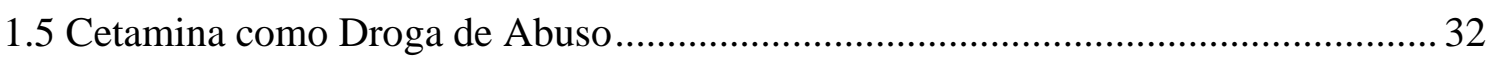

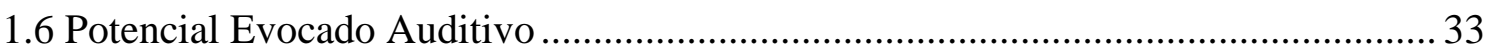

2. OBJETIVOS ....................................................................................................................... 34

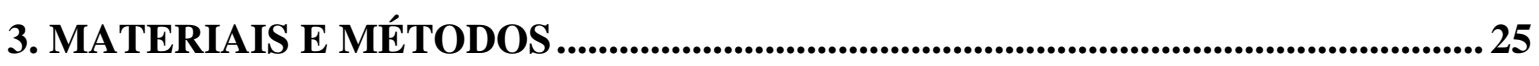

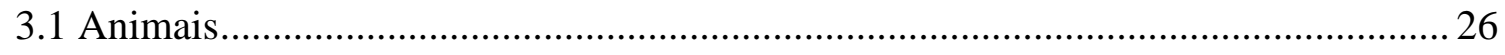

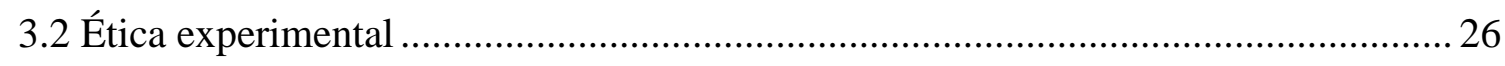

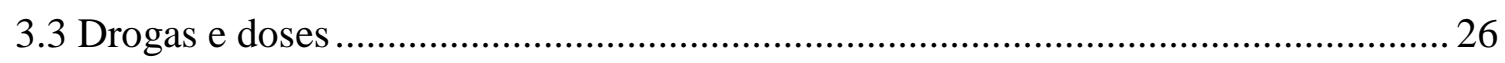

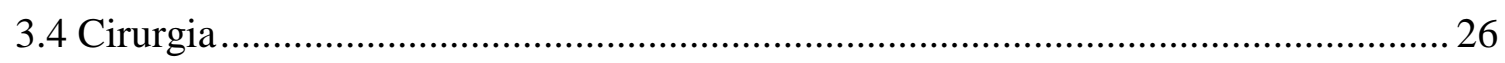

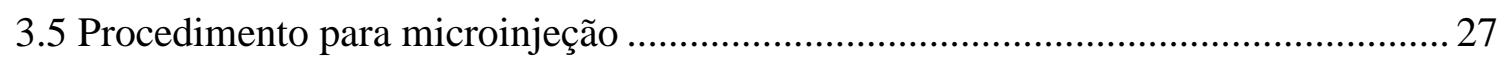

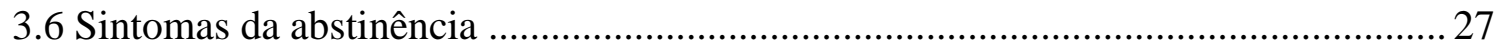

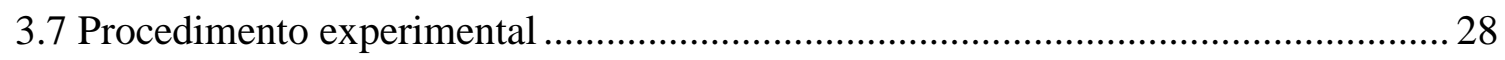

3.7.1 Registro dos potenciais evocados auditivos (PEAs) ........................................ 28

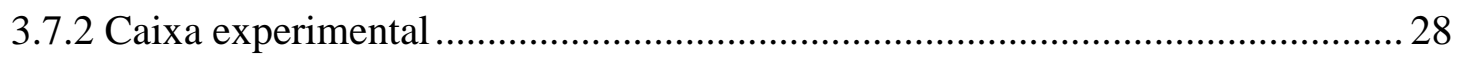

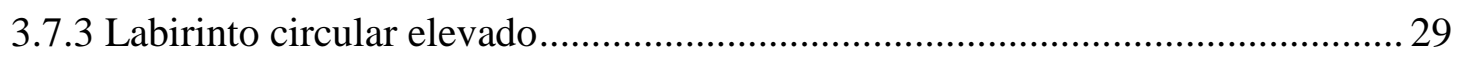

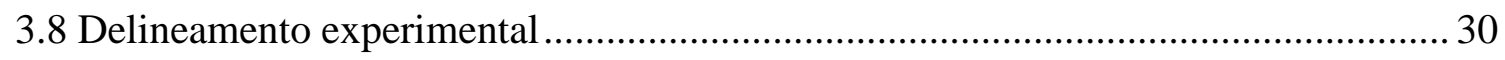

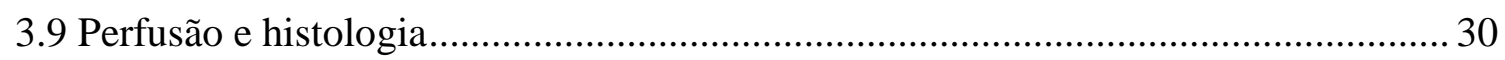

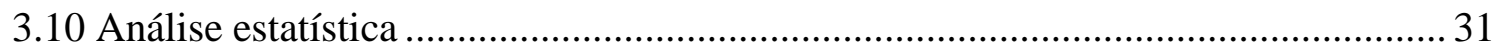

4. RESULTADOS ….............................................................................................................. 32

5. DISCUSSÃO .............................................................................................................. 41

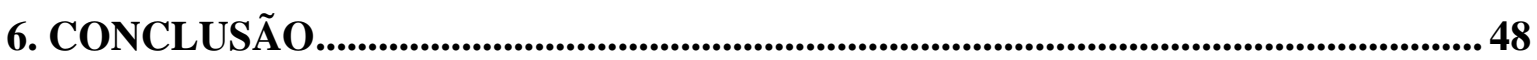

7. REFERÊNCIAS BIBLIOGRÁFICAS ..................................................................50

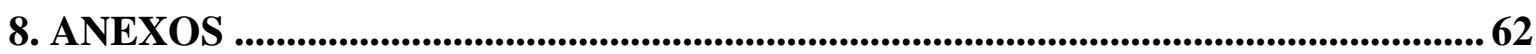


1. INTRODUÇÃO 
A utilização de substâncias psicotrópicas é uma prática universal e milenar. Nas diversas sociedades, substâncias eram utilizadas para fins religiosos, culturais e medicinais. Não obstante, seu uso não ficou limitado somente para estes fins, ampliando para a forma recreativa e, então, padrões anormais de uso têm sido descritos pelo menos desde a morte por excesso de álcool de Alexandre, o Grande, em 323 a.C. (FERREIRA; MARTINI, 2001).

A relação entre o ser humano e os psicotrópicos é moldada por diversos fatores, entre eles, culturais (sociedade), religiosos e, atualmente, ambientais, tais como: os "clubs drugs" e "Raves". Nestes ambientes, são realizados festivais com músicas eletrônicas que podem durar dias, e os frequentadores fazem uso de substâncias psicotrópicas, sobretudo as estimulantes, para que tolerem demasiadas horas acordados e dançando (JANSEN, 2004). As principais drogas encontradas neste contexto são cocaína, anfetamina, metanfetamina, metilenodioximetanfetamina (MDMA), LSD e Cetamina.

A Cetamina é procurada pela sua capacidade de intensificar as experiências sensoriais (DILLON et al., 2003) e sexuais, elevação do humor, euforia, distorções visuais e auditivas, sensações eróticas, empatia, sensação de flutuação sobre o próprio corpo. Portanto, vem se tornando popular entre os jovens (JANSEN, 2004).

\subsection{Cetamina}

O cloridato de Cetamina foi sintetizado em 1962 por Calvin Stevens com o objetivo de substituir a fenciclidina (PCP), um anestésico dissociativo (SMITH et al., 2002). Na prática clínica, a Cetamina era considerada um fármaco que levava à quase anestesia completa, pois fornecia alívio de dor, imobilidade, amnésia e rebaixamento de consciência (ANNETTA et al., 2005; CORAZZA et al., 2013).

A Cetamina também apresenta efeitos psicomiméticos tanto em seres humanos quanto em animais. Sua biodisponibilidade administrada por via oral é de $16 \%$, devido ao metabolismo de primeira passagem; porém, quando administrada por via intramuscular, sublingual, aérea ou endovenosa, é consideravelmente maior (KRYSTAL et al., 1994).

Em termos farmacodinâmicos, a Cetamina é, sobretudo, um antagonista não competitivo dos receptores glutamatérgicos do tipo N-metil-Daspartato (NMDA), podendo agir também, como antagonista de receptores muscarínicos, agonista GABAérgico (MORGAN et al., 2012) e dopaminérgico (DA) (RABINER, 2007), além de também ser considerado um agonista fraco de receptores opióides $\mu$ (OYE et al., 1992). Estudos mostram 
que a ação da droga em receptores diferentes do NMDA pode ser observada em concentrações plasmáticas bastante elevadas, de 10 a 100 vezes maior que a dose utilizada para a anestesia (250-1000 $\mu \mathrm{g} / \mathrm{L})$ (BRAU et al., 2010; BERGMAN, 1999).

Em doses anestésicas, a Cetamina pode apresentar sintomas que alteram a percepção, tais como: alucinações, sonhos vívidos, distorções do tempo, espaço e imagem corporal (MORGAN et al., 2012). A tolerância aos seus efeitos sedativos já é conhecida (TOBIAS, 2000). Em dose subanestésica, em animais de laboratório, induz uma série de sinais, dentre os quais perturbações sensório-motoras (MANSBACH \& GEYER, 1991), déficits de memória (IMRE et al., 2006; KOS et al., 2006), hipermotilidade (CARLSSON, 1993), estereotipia e ataxia (TRICKLEBANK et al., 1989).

Estudos mais recentes mostram que este fármaco apresenta um potencial efeito antidepressivo, principalmente em pacientes refratários aos tratamentos de depressão maior (OWOLABI et al., 2014). Porém, seu uso continuado produz uma série de efeitos físicos e psicológicos dentre os quais cistite ulcerativa (SHAHANI et al., 2007), dor abdominal (MUETZELFELDT et al., 2008), depressão (MORGAN et al., 2010) e psicose (KRYSTAL et al., 1994), além de danos cognitivos (MORGAN; CURRAN, 2006) e alterações neurológicas (LIAO et al., 2011).

Além disso, estudos mostram que a Cetamina é indutora de sintomas positivos e negativos semelhantes aos sintomas associados à esquizofrenia em animais de laboratório e, por isso, vem sendo utilizada como um modelo clínico e animal de esquizofrenia (GEYER, 1998). Em seres humanos, apresenta a característica de acentuar o estado psicótico de pacientes esquizofrênicos (LAHTI et al., 1995).

\subsection{Sistema Auditivo}

As formas utilizadas pelos diversos organismos para sobreviver em seu ambiente natural envolvem dois aspectos principais: alimentação e defesa. A busca por alimento e a necessidade de proteção demandam do indivíduo mecanismos apurados, os sentidos, tais como, por exemplo, a visão e a audição (LANG et al., 1998).

No que remete à proteção, o sistema auditivo exerce um importante papel por permitir a codificação e o processamento de variados sons ambientais, facilitando a detecção, localização e identificação da aproximação de um predador em potencial (POPPER; FAY, 1997; FAY; POPPER, 2000; GANS, 1992; CASSEDAY; COVEY, 1996). 
Por outro lado, disfunções dos circuitos auditivos geram uma séria de alterações funcionais levando ao aparecimento de respostas mal adaptativas (crises audiogênicas), perturbações na expressão de respostas adaptativas (orientação em direção a uma fonte sonora, prejuízo da resposta de sobressalto) e ao surgimento de respostas bizarras decorrente de hiperexcitação dos circuitos auditivos (JANE et al., 1965; LI et al., 1998; GARCIACAIRASCO, 2002).

O sistema encefálico auditivo é um sistema complexo, composto por uma série de estruturas, muitas delas localizadas no mesencéfalo (AITKIN, 1983). As fibras mesencefálicas que carreiam informações de natureza acústica compreendem uma gama de corpos neuronais e feixes de axônios, dispostos paralelamente ou em série, que convergem, em grande parte, para uma área comum (POLLAK et al., 2003), o colículo inferior (CI); estrutura que consiste basicamente de uma massa neuronial central de células circundadas por um córtex (MOREST; OLIVER, 1984; FAYE-LUND; OSEN, 1985). Na literatura, a maioria dos trabalhos sobre o CI versa sobre o papel dessa estrutura na transmissão e modulação da informação auditiva para estruturas superiores.

Sugere-se que a Cetamina pode também influenciar os sistemas sensoriais auditivos do tronco cerebral (KRYSTAL et al., 1994; HONEY et al., 2005; MOGHADDAM, 2007; MORGAN et al., 2012). Corroborando esse fato, um dos efeitos tóxicos da Cetamina envolve a sensibilidade exacerbada do sistema auditivo.

Muito embora não existam trabalhos que liguem diretamente os efeitos crônicos da Cetamina ao desenvolvimento de psicose, na qual alucinações auditivas surgem como um dos sintomas principais, é provável que sua ingestão crônica leve a alterações no circuito neural auditivo. Neste contexto, uma importante estrutura destaca-se por sua capacidade de atuar como gatilho sensório - motor para estímulos auditivos - o Colículo Inferior, no qual o glutamato cumpre importante papel (MELO et al., 1995; NOBRE et al., 2010)

\subsubsection{Colículo inferior}

O colículo inferior (do latim collis; "colina"), tradicionalmente conhecido como "relé" das vias auditivas, é uma estrutura bilateral mesencefálica que possui três divisões principais, as quais, segundo os critérios citoarquitetônicos, são: o núcleo central (essencial para funções auditivas normais), o córtex externo (multissensorial; integrando informações tanto auditivas quanto somatossensoriais) e, por fim, o córtex dorsal, o qual recebe a maioria 
de suas aferências do córtex cerebral, cuja função no sistema auditivo ainda não foi claramente esclarecida (WINE; SHREINER, 2005).

O colículo inferior envia informações para os centros motores que participam da modulação e expressão de comportamentos específicos relacionados à importância biológica dada ao som (CASSEDAY; COVEY, 1996), apresentando um padrão eletrofisiológico característico que pode ser alterado pela exposição a estímulos auditivos condicionados ou incondicionados (NOBRE et al., 2010; NOBRE, 2013).

A estimulação elétrica no núcleo central do CI (CIC) incita o comportamento de defesa relacionado a um estado de perigo iminente, tais como estados de alerta, congelamento e fuga. Além disso, se aumentarmos a intensidade acústica de natureza aversiva, propicia a sensibilização do CIC, podendo resultar no aumento da amplitude do potencial induzido por um estímulo auditivo (NOBRE et al., 2003). Então, sugere-se que o CI faz a mediação entre a informação sensorial auditiva e a resposta motora para produzir o comportamento defensivo (MELO; BRANDÃO, 1995).

Já as eferências se dirigem principalmente para a parte ventral do núcleo geniculado medial do tálamo. Todas estas projeções que ascendem em direção às áreas corticais auditivas mantém uma incrível similaridade em uma ampla gama de mamíferos (MOORE et al., 1977).

O núcleo central do $\mathrm{CI}$ recebe as principais eferências auditivas ascendentes provenientes dos núcleos coclear dorsal e ventral, do complexo olivar superior e dos núcleos do lemnisco lateral (WOOLARD; HARPMAN, 1940; MOORE; GOLDBERG, 1963; ROTH et al., 1978). Do CI as fibras da via auditiva se dirigem para o núcleo geniculado medial talâmico e daí para o córtex auditivo (OSEN, 1973).

Porém, nem todos os núcleos do CI recebem aferências diretamente dos circuitos auditivos, muito embora Moore \& Goldberg (1963) tenham verificado que o núcleo central é o principal alvo das fibras auditivas provenientes dos núcleos cocleares (dorsal e ventral) e do complexo olivar superior, grande parte das aferências provém do próprio CI, ou seja, das conexões intranucleares e coliculares contralaterais.

Ao contrário do núcleo central, o córtex externo recebe escassas aferências contralaterais cocleares e do complexo olivar superior, sendo que suas principais aferências provêm das áreas cerebrais de Brodmann 39 e 40, ipsilaterais, do núcleo da coluna dorsal (“inputs" somatosensoriais), do núcleo central (“inputs” auditivos), do núcleo parabraquial, 
núcleo cuneiforme, grácil, trigeminal e da parte lateral da substância negra (COLEMAN; CLERICI, 1987).

Em relação às eferências, o córtex externo envia maciças projeções bilaterais para o núcleo coclear, parte medial do corpo geniculado medial do tálamo (LEDOUX et al., 1987) e núcleo pontino dorsolateral (KAWAMURA et al., 1974). O córtex externo também apresenta conexões com estruturas envolvidas na gênese e modulação de comportamentos defensivos como a substância cinzenta periaquedutal (Scp), camadas profundas do colículo superior, hipotálamo e complexo amigdaloide (via tálamo) (ADAMS, 1980; LEDOUX et al., 1985; LEDOUX et al., 1990).

O córtex dorsal também apresenta conexões com a substância cinzenta periquedutal e a substância negra. Em relação às suas aferências, o córtex dorsal recebe substanciais aferências corticais ipsilaterais de várias regiões, como as áreas 20, 36 e 41, e do globo pálido (MORIIZUMI; HATTORI, 1991), e diferentemente do córtex externo, envia a maioria das suas projeções para a divisão dorsal do corpo geniculado medial. Devido a essas diferentes conexões entre os núcleos do CI, Tokunaga (1984) propôs uma dualidade funcional dessa estrutura: o núcleo central seria, primordialmente, uma estação relé das vias auditivas, enquanto que os córtices dorsal e externo, recebendo informações não só auditivas, mas também visuais e somáticas, seriam núcleos participantes da integração sensorial-motora.

Corroborando esta sugestão, Moriizumi \& Hattori (1991) verificaram que a maioria das fibras que se originam no globo pálido, estrutura envolvida no controle motor, e que se dirigem para o CI, apresentam seus terminais no núcleo dorsal.

\subsubsection{Modulação dopaminérgica dos substratos neurais da aversão no colículo} inferior

A dopamina (DA) é um neurotransmissor da família das catecolaminas conhecida por exercer papel de regulação da atividade motora, dos processos cognitivos e, principalmente, no sistema de recompensa. Poucos trabalhos na literatura investigaram seu papel na mediação do comportamento defensivo eliciado por estimulação do CI. Já foi demonstrado que os neurônios do CI expressam grande quantidade de RNA mensageiro para receptores dopaminérgicos D2, mas não para D1 (HURD et al., 2001), o que confirma achados anteriores que indicam uma alta concentração de receptores D2, mas não de D1, nessa estrutura (WAMSLEY et al., 1989). Sabe-se que há um aumento na liberação de DA 
no córtex pré-frontal de ratos submetidos a condições graduais de estresse (FEENSTRA et al., 1995).

De forma similar, a estimulação elétrica aversiva do CI aumenta significativamente os níveis de DA e de seu metabólico, a DOPAC, no córtex pré-frontal de ratos (CUADRA et al., 2000). Embora o papel preciso dos neurônios mesocorticais permaneça obscuro, estudos farmacológicos e neuroquímicos apontam um vínculo funcional entre mecanismos dopaminérgicos pré-frontais e respostas comportamentais induzidas por estímulos aversivos (CUADRA et al., 1999; ESPEJO; MINANO, 1999; MORROW et al., 1999). Foi demonstrado que a produção de fuga ou congelamento, induzidos pela estimulação elétrica aversiva do CI, aumenta a expressão da proteína c-Fos, um marcador de atividade neuronial no córtex frontal (LAMPREA et al., 2002).

Desse modo, é provável que o circuito envolvido no processamento da informação auditiva de natureza aversiva seja composto de projeções que se originem do núcleo central do CI em direção ao córtex pré-frontal, passando pelo corpo geniculado medial, amígdala e tálamo dorsomedial (FUSTER, 1989; BRODAL, 1992; MAISONNETTE et al., 1996; BRANDÃO et al., 1999). Uma provável participação de mecanismos dopaminérgicos nestes processos é sugerida com base no fato de que a administração de apomorfina (agonista de receptores dopaminérgicos do tipo D2) aumenta a amplitude do potencial evocado induzido por sons muito intensos (BRANDÃO et al., 2001; SANDNER et al., 2002).

Do ponto de vista anátomo-funcional, o CI pode estar associado ao processamento da informação condicionada aversiva e, por extensão, com o medo condicionado (BRANDÃO et al., 2001; CASTILHO; BRANDÃO, 2001). Dessa forma, ratos aprendem rapidamente a evitar um estímulo aversivo (estimulação elétrica do CI) quando confrontado num paradigma de "switch-off" no qual é utilizada uma luz como estímulo condicionado (BRANDÃO et al., 1997).

Além disso, a administração de apomorfina em baixa dose $(0,5 \mathrm{mg} / \mathrm{kg})$, porém não exemplos em altas concentrações $(2,0 \mathrm{mg} / \mathrm{kg})$, potencializou os efeitos aversivos induzidos pela estimulação elétrica do CI, diminuindo a latência para a resposta no procedimento de fuga-esquiva, assim como aumentando o número de respostas de esquiva. No mesmo estudo, o autor sugere o envolvimento dos receptores dopaminérgicos no CI nesse efeito, já que a administração sistêmica de clorpromazina (antagonista de receptores D2) na dose de 2,0 $\mathrm{mg} / \mathrm{kg}$ bloqueou os efeitos aversivos da apomorfina (TRONCOSO et al., 2003). 
De maneira geral, esses trabalhos abrem uma nova linha de investigação, relacionando os substratos neurais do medo e da ansiedade com mecanismos dopaminérgicos originados no CI.

\subsection{Neurotransmissão Glutamatérgica}

O glutamato é o principal e mais abundante neurotransmissor excitatório do SNC, exercendo um importante papel em mecanismos como a cognição, aprendizado e memória (IZQUIERDO, 1994). Os receptores glutamatérgicos são divididos em dois grandes grupos: os ionotrópicos (iGluRs) e os metabotrópicos (mGluRs).

Os mGluRs são receptores acoplados à proteína $\mathrm{G}$ e estão localizados em ambos os terminais pré e pós-sinápticos. Os iGluRs são canais iônicos, cuja ativação leva à despolarização neuronial. Estes receptores podem ser divididos de acordo com suas propriedades farmacológicas e fisiológicas em três tipos: N-metil-D-aspartato (NMDA), ácido-amino 3-hidroxi-5-metil-isoxazol-4-propiônico (AMPA) e cainato (KA) (OZAWA et al., 1998).

Os receptores do subtipo AMPA são encontrados no SNC e predominantes nas regiões do hipocampo (CA1 e CA3 do giro denteado) e estão envolvidos com o aumento da excitabilidade neuronial por meio de sua alta permeabilidade ao $\mathrm{Na}^{+}$e $\mathrm{K}^{+}$. A função dos receptores KA ainda não está claramente esclarecida, porém, sabe-se que, ao contrário dos AMPA, são altamente permeáveis aos íons $\mathrm{Ca}^{2+}$ (OZAWA et al., 1998).

Os receptores NMDA são encontrados em todo o SNC, possuem alta permeabilidade aos íons $\mathrm{Ca}^{2+}$ e estão envolvidos na modulação da neurotransmissão excitatória e podem mobilizar uma grande quantidade desse íon para dentro das células, resultando na ativação de diversas vias intracelulares. Porém, na ocorrência de um grande influxo de $\mathrm{Ca}^{2+}$ devido à ativação excessiva desse receptor, pode levar à morte celular pelo mecanismo de excitotoxicidade (LÉVEILLÉ et al., 2008) o que pode ocasionar doenças neuropatológicas, como, por exemplo, Huntington, Parkinson e esquizofrenia.

A utilização de antagonistas de receptores NMDA pode alterar a atividade neuronial em diversas estruturas encefálicas, como amígdala, hipocampo e córtex pré-frontal medial (O’DONNELL; GRACE, 1998). Os efeitos agudos do uso desses antagonistas sobre a atividade pré-frontal são comparáveis àqueles encontrados em pacientes esquizofrênicos, particularmente nas regiões pré e infralímbica (NEILL et al., 2010) que aparecem como 
importante alvo, já que suas eferências exercem uma regulação top-down, direta (através de projeções glutamatérgicas) ou indireta, através da modulação de neurônios dopaminérgicos para estas regiões (VERTES, 2006; FLORESCO et al., 2009).

Desse modo, uma das áreas cerebrais mais afetadas pelo uso de Cetamina (antagonista NMDA) é o córtex pré-frontal, particularmente suas regiões fronto-medial (córtex pré-límbico - PrL) e inferior (córtex infra-límbico - IL) (HOLCOMB et al., 2001). Além disso, outros estudos mostram que o desempenho em tarefas dependentes da atividade cortical destas regiões é profundamente afetado pela administração aguda de Cetamina em seres humanos (HONEY et al., 2004).

De fato, um estudo utilizando a técnica de imagem por ressonância magnética mostrou que os efeitos subjetivos (dissociativos) da Cetamina se correlacionam significativamente com uma redução na atividade cortical ventromedial mediada por glutamato (DEAKIN et al., 2008).

Portanto, apesar das já demonstradas alterações cognitivas e comportamentais induzidas pela exposição subcrônica de antagonistas de receptores NMDA, poucos estudos pré-clínicos foram conduzidos para tentar detectar potenciais efeitos físicos e/ou comportamentais de sua abstinência após consumo prolongado.

\subsection{Neurotransmissão GABAérgica}

O ácido gama-aminobutírico (GABA) é o principal neurotransmissor inibitório do SNC amplamente distribuído nas estruturas do teto mesencefálico (BORMANN, 2000). A administração local de agonistas GABAérgicos em estruturas relacionadas ao processamento da informação aversiva promovem efeitos ansiolíticos similares aos benzodiazepínicos (BRANDÃO et al., 1982; AUDI; GRAEFF, 1987). Estes medicamentos atuam através de um sítio específico para a droga encontrados em receptores $\mathrm{GABA}_{\mathrm{A}}$. Estudos em modelos animais demonstram, consistentemente, sua interação entre as ações antiaversivas com receptores GABAérgicos do teto mesencefálico (BRANDÃO et al., 1982; BRANDÃO et al., 1985; GRAEFF et al., 1986).

Em laboratório, resultados obtidos por Nobre et al. (2003) mostram que microinjeções de semicarbazida, um inibidor da síntese de GABA, diretamente no CI eliciam a resposta de congelamento e aumento na amplitude dos potenciais evocados (amplitude da onda P1) associado a uma redução na amplitude da resposta de sobressalto. 
A inibição das funções GABAérgicas no CI por meio da semicarbazida parece afetar também a reatividade dos neurônios do CI a estímulos auditivos. Brandão et al. (2001) verificaram que a microinjeção unilateral de glutamato no CI, em uma dose que causa o comportamento de congelamento, em ratos com eletrodos implantados bilateralmente, produziu aumento ipsilateral dos potenciais registrados nessa região, sugerindo que o aumento da estimulação aversiva promove aumento na reatividade dos neurônios do CI aos estímulos auditivos.

A medida dos potenciais evocados auditivos (PEA) também é utilizada em estudos para análise de alterações neuronais associadas ao uso agudo ou contínuo de drogas como o diazepam (CABRAL et al., 2009) e o álcool (CHU et al., 1990; BEGLEITER et al., 1981).

\subsection{Cetamina como Droga de Abuso}

Posteriormente ao domínio do uso de anfetaminas, a busca de drogas com efeitos alucinógenos aumentou consideravelmente, então o consumo de Cetamina tem se tornado cada vez mais comum, principalmente em festas de longa duração - "Raves". Na literatura, o primeiro caso a ser descrito foi em 1971 nos Estados Unidos; porém, tornou-se tão intenso nos anos 90, sobretudo no Reino Unido, que o FDA (Food Drug Administration) classificou a Cetamina como droga de abuso. Entre os usuários a droga é conhecida como "Special K", "Vitamina K” ou apenas “K” (GLABE, 2004).

Estudos relacionam a ação da Cetamina com a ação de outras drogas de abuso, tais como, cocaína e anfetamina, pela sua capacidade de induzir sensibilização após a administração repetida (ROBINSON; BERRIGE, 2003). Estudos recentes demonstraram que a administração repetida de Cetamina leva a prejuízos na expressão da resposta condicionada de medo e a uma redução de longo prazo nos potenciais evocados auditivos (MAXWELL et al., 2006; AMANN et al., 2009). Entretanto, a técnica utilizada nestes estudos mediu o potencial evocado auditivo encefálico como um todo, não sendo possível determinar qual região específica foi afetada pelos efeitos da droga e, portanto, qual a área responsável pela redução na amplitude destes potenciais.

Ademais, além das interações já mencionadas, a Cetamina interage também na neurotransmissão colinérgica, inibindo a transmissão da acetilcolina, o que pode estar relacionado aos efeitos adversos do comportamento dos usuários (DUVAL, 2004). Este quadro se agrava levando em consideração que boa parte dos indivíduos que fazem uso de 
Cetamina são poliusuários (LANKENAU; SANDERS, 2007; LANKENAU et al., 2007a; 2007b). Aliam-se a isso os efeitos secundários do uso serem intensos e preocupantes, dentre os quais se incluem o estabelecimento de dependência, risco de "overdose" e comprometimento físico decorrente de intoxicação aguda (JANSEN, 2004).

\subsection{Potencial Evocado Auditivo}

O potencial evocado auditivo do tronco cerebral é uma medida eletrofisiológica da resposta do grupo de neurônios que circundam a área de registro de um eletrodo após um estímulo de natureza auditiva (NOBRE, 2013). Estes potenciais refletem a atividade neural das regiões do complexo auditivo, particularmente o núcleo coclear, o complexo olivar superior e o colículo inferior (CI) (LONG; ALLEN, 1984).

As aplicações práticas de medida de potencial evocado auditivo têm sido usadas para propósitos clínicos. Biacabe et al. (2001) publicaram uma revisão com o objetivo de descrever a anatomia funcional de estruturas auditivas do tronco encefálico nas quais são gerados potenciais evocados auditivos (BAEP, "brainstem auditory evoked potential"), e propuseram sua aplicação clínica para a identificação de neurinomas acústicos (tumores) ou lesões, diagnóstico precoce de problemas auditivos em crianças e para pacientes que não respondem a testes audiométricos tradicionais.

Sabe-se que as alucinações auditivas induzidas durante surtos esquizofrênicos têm como correspondente neural uma ativação pronunciada do CI, além de outras áreas corticais e subcorticais como a ínsula, o córtex cingulado anterior $(\mathrm{CgA})$, o córtex temporal, o tálamo e o hipocampo (SHERGILL et al., 2000).

Tendo em vista o mecanismo de ação da cetamina e a sua utilização como modelo de esquizofrenia, esta investigação foi conduzida pela hipótese de que o uso crônico desta droga pode alterar a percepção do estímulo sonoro mesmo após 6 dias de retirada da droga. Além disso, tivemos o interesse em investigar se há uma interação direta entre o PrL e o Ci. 


\section{OBJETIVOS}


Partindo do princípio que os efeitos da Cetamina sobre a neurotransmissão glutamatérgica induz alguns dos sintomas observados durante surtos esquizofrênicos, como as alucinações auditivas, e sabendo que o colículo inferior (CI) tem sua função ligada ao processamento da informação sensorial a estímulos sonoros, neste estudo avaliamos os efeitos da modulação glutamatérgicas no córtex pré-límbico (PrL) sobre os potenciais evocados auditivos eliciados no CI de ratos testados após a interrupção do tratamento crônico com Cetamina. 


\section{MATERIAIS E MÉTODOS}




\subsection{Animais}

Foram utilizados 96 ratos Wistar, com peso inicial aproximado de $180 \mathrm{~g}$, provenientes do Biotério Central da USP-RP. Os animais foram mantidos em número de quatro em caixas de polipropileno de $45 \mathrm{~cm}$ de largura x $65 \mathrm{~cm}$ de comprimento x $30 \mathrm{~cm}$ de altura, nas quais foram adicionadas raspas de madeira e ração, dentro de uma estante ventilada com controle de temperatura $\left(23 \pm 1^{\circ} \mathrm{C}\right)$, ventilação, exaustão, luminosidade e umidade, em um ciclo claro-escuro de 12 horas, com as luzes acesas às 7 horas da manhã.

\section{2 Ética experimental}

Os experimentos foram realizados sob a anuência do Comitê de Ética Animal (CEUA) da USP-RP (processo 2016.5.738.59.4) e de acordo com as recomendações do Manual de Utilização de Animais da FIOCRUZ $\left(2008,1^{\text {a }}\right.$ Ed. http://www.castelo.fiocruz.br/vpplr/comissoes_camarastecnicas/Manual_procedimentos.pd f) e U.S. National Institutes of Health Guide for the Care and Use of Laboratory Animals (National Academic Press, Washington D.C. $8^{\text {a }}$. Ed., 2011). Todo o cuidado foi tomado para reduzir ao mínimo o número de animais utilizados, assim como seu sofrimento, sem comprometer, no entanto, a viabilidade dos dados coletados.

\subsection{Drogas e doses}

Foram utilizados o antagonista de receptores de glutamato do tipo NMDA, cloridrato Cetamina (cloridrato, Agener União, Brasil) nas doses de 20, 40 e 80 mg/Kg (CHATTERJEE et al., 2011), o antipsicótico atípico clozapina (CLZ) (Sigma-Aldrich, USA $5 \mathrm{mg} / \mathrm{kg}$ i.p.) (CHATTERJEE et al., 2011) e o agonista de receptores de glutamato do tipo NMDA N-metil-D-aspartato (NMDA - Sigma-Aldrich, USA) na dose de 7 nmoles/0.2 $\mu 1$ (NOBRE et al., 2004). Os testes foram realizados 10 minutos após a $14^{\mathrm{a}}$ injeção subcutânea de Cetamina, 24 horas e 6 dias após a última dose. As drogas em estudo (CLZ-IP e NMDAintra-PrL) foram administradas 30 e 5 minutos antes dos testes, respectivamente.

\subsection{Cirurgia}

Os animais testados com NMDA intra-PrL, receberam um implante de duas cânulas, uma direcionada ao PrL e outra ao CI, ipsilateralmente. Metade dos animais recebeu o 
implante no CI oposto (lado contralateral). Já os animais tratados com clozapina (i.p.), estes receberam somente a cânula direcionada ao CI, e a metade destes, receberam o implante no lado oposto.

Para tal, os animais foram anestesiados com xilazina $(0.25 \mathrm{mg} / \mathrm{kg})+$ Cetamina $(0.25$ $\mathrm{mg} / \mathrm{kg}$ ) por via intramuscular e levados a um aparelho estereotáxico digital (Insight, Brasil) onde tiveram o crânio fixado pelo rochedo temporal e incisivos superiores, e foi feita a tricotomia, aplicada na área de incisão o anestésico local lidocaína a 2\% (Harvey, Brasil) em dose subcutânea de $0.2 \mathrm{~mL}$. Feito isso, o tecido subcutâneo e o periósteo foram retirados com o auxílio de pinça, algodão e hastes flexíveis com ponta de algodão. Já com a superfície craniana exposta e ajustada em posição horizontal, entre o bregma e lambda, orifícios foram feitos nos ossos parietais através de uma broca elétrica (Foredom, EUA) para fixação da cânula guia e de parafusos para ancorar a prótese. As coordenadas utilizadas tomaram como base o atlas de Paxinos \& Watson (2008). Ao término da cirurgia cada animal recebeu, por via intramuscular, uma injeção de pentabiótico (60.000 UI, $0.2 \mathrm{ml}$ ) e uma injeção subcutânea do analgésico e anti-inflamatório banamine ( $2.5 \mathrm{mg} / \mathrm{K})$. Depois disso, cada cânula guia foi selada com um fio de aço inoxidável para protegê-la de entupimento.

\subsection{Procedimento para microinjeção}

Na intenção de evitar ao mínimo o dano neuronial promovido pela introdução de uma agulha no tecido encefálico, as drogas foram administradas através de uma agulha gengival curta (30G) localizada, quando introduzida, $1 \mathrm{~mm}$ abaixo da ponta da cânula guia. A agulha de injeção foi acoplada a uma seringa Hamilton ( $5 \mu \mathrm{L}$, EUA) por meio de um fino tubo flexível de polietileno. O volume microinjetado foi de $0.2 \mu \mathrm{L}$ de agonista de receptores de glutamato do tipo NMDA N-metil-D-aspartato diretamente no PrL, com o auxílio de uma bomba eletrônica de infusão (“Insight”, Brasil).

\subsection{Sintomas da abstinência}

Para avaliação da presença de possíveis sintomas de abstinência associados à retirada de Cetamina, os animais foram submetidos aos testes do labirinto circular elevado, para avaliação das respostas emocionais. A porcentagem de tempo e entradas nos braços aberto e número de entradas nos braços fechados foram as variáveis em estudo. 


\subsection{Procedimento experimental}

\subsubsection{Registro dos potenciais evocados auditivos (PEAs)}

A apresentação dos estímulos foi produzida e controlada por um sistema de aquisição e controle de dados (Sysdin, Lynx, São Paulo, Brasil). Os dados individuais foram coletados ao longo da sessão, sendo posteriormente promediados.

Foram apresentados 100 estímulos auditivos, registrados individualmente como a diferença de potencial existente entre a parte não isolada (ponta do eletrodo em contato com o tecido neural) de aço inoxidável $(150 \mu \mathrm{m}$ o.d.) inserido dentro de um tubo de aço inoxidável, sendo a ponta deste último o segundo polo, implantado previamente no CI. A diferença de potencial existente entre estes dois polos foi registrada e amplificada (Lynx, TX001, frequências passal alta e baixa 20 e $200 \mathrm{~Hz}$, respectivamente) através de cabos condutores isolados por uma passagem no topo da gaiola de Faraday.

Apesar de que estudos prévios de nosso laboratório apontam para a ausência de diferenças inter-hemisféricas no registro dos PEAs utilizando este nosso setting experimental (NOBRE et al., 2003), metade dos animais de cada grupo recebeu o implante no CI direito e a outra metade no CI esquerdo. A saída do amplificador de sinais foi conectada a um dos 4 canais de um conversor analógico/digital (CAD 12/36) ligado a um PC. Os PEAs foram amostrados a uma taxa de $0.33 \mathrm{~Hz}$ (1 a cada 3 seg.) e posteriormente filtrados $(20-200 \mathrm{~Hz})$.

A aquisição de dados foi iniciada $10 \mathrm{~ms}$ antes do início da apresentação do estímulo sonoro, continuando até $200 \mathrm{~ms}$ após seu término A primeira onda negativa (N1) assim como a primeira onda positiva (P1) foram identificadas visualmente. A onda P1 é considerada o componente inicial da resposta colicular. Sua amplitude deve ser medida pico-a-pico, sendo a latência para seu pico situada por volta de 5 e 8 ms (HALL; MARK, 1967; MARK; HALL, 1967). Os PEAs eliciados foram registrados a partir das porções ventro-caudais do CI, assim como realizado em outros estudos utilizando protocolos similares (SZCZEPANIAK; MOLLER, 1995; NOBRE et al., 2003; 2010). As amplitudes de pico foram definidas como as amplitudes máximas medida entre N1 e P1, como em outros trabalhos (BRANDÃO et al., 2001; NOBRE et al., 2003; 2010).

\subsubsection{Caixa experimental}


Os registros dos PEAs foram conduzidos com os animais mantidos dentro de uma gaiola de contenção de acrílico $(19$ × 9 x $49 \mathrm{~cm})$ com piso, tampa, frente e fundo compostos de barras de aço inoxidável espaçadas $1,5 \mathrm{~cm}$ entre si, e laterais de acrílico com vazamento de $5 \times 1 \mathrm{~cm}$, para acomodação do focinho/cauda. Esta gaiola de contenção estava situada dentro de uma caixa de isolamento acústico $(64$ x 60 x $40 \mathrm{~cm})$ cujas partes internas (paredes, piso e teto) foram compostas por uma malha de metal (gaiola de Faraday) com aterramento para isolamento das interferências induzidas pelo ambiente externo, particularmente aquelas na faixa de frequência de $60 \mathrm{~Hz}$, que pudessem adicionar ruído ao sinal registrado do CI. Vale ressaltar que este é um experimento realizado com animais não sedados (“awake”).

Os estímulos sonoros (cliques) foram produzidos por dois “tweeters” (12 $\Omega, 200 \mathrm{~W}$, LeSon, Brasil) localizados nas laterais da caixa de isolamento acústico, $15 \mathrm{~cm}$ acima do piso. Estes estímulos tiveram a seguinte configuração: tom puro de $3000 \mathrm{~Hz}$, com $50 \mathrm{~ms}$ de duração e 95 dB de intensidade (SPL). Dado o tamanho da gaiola de contenção, apesar de não totalmente contidos, os animais ficaram impossibilitados de dar meia-volta, ficando, no entanto, com uma pequena margem de espaço para movimentação da cabeça ( $\pm 5^{\circ}$ direitaesquerda-acima-abaixo). Esta variação pode induzir alterações de até $5 \mathrm{~dB}$ na intensidade sonora. Portanto, os animais foram submetidos à estimulação sonora com intensidade entre 92.5 e $95 \mathrm{~dB}$.

\subsubsection{Labirinto circular elevado}

O labirinto circular elevado utilizado neste experimento segue o modelo previamente descrito no trabalho de Shepherd et al. (1994). Neste trabalho, não utilizamos o labirinto em cruz elevado para este fim, particularmente pelo viés induzido nos resultados pelo tempo que os animais permanecem no centro do aparato. Foram registradas as porcentagens de entradas e tempo de permanência nos braços abertos, assim como o número de entradas nos braços fechados (BRAUN et al., 2010). Os valores em percentuais foram calculados, para cada fator (entradas ou tempo), segundo a fórmula:

$$
\%=\underline{100 \times \mathrm{TA} / \mathrm{EA}}
$$

$$
\mathrm{TA} / \mathrm{EA}+\mathrm{TF} / \mathrm{EF}
$$

sendo, $\mathrm{TA}=$ tempo no aberto, $\mathrm{EA}=$ entradas no aberto, $\mathrm{TF}=$ tempo no fechado, $\mathrm{EF}=$ entradas no fechado. 


\subsection{Delineamento experimental}
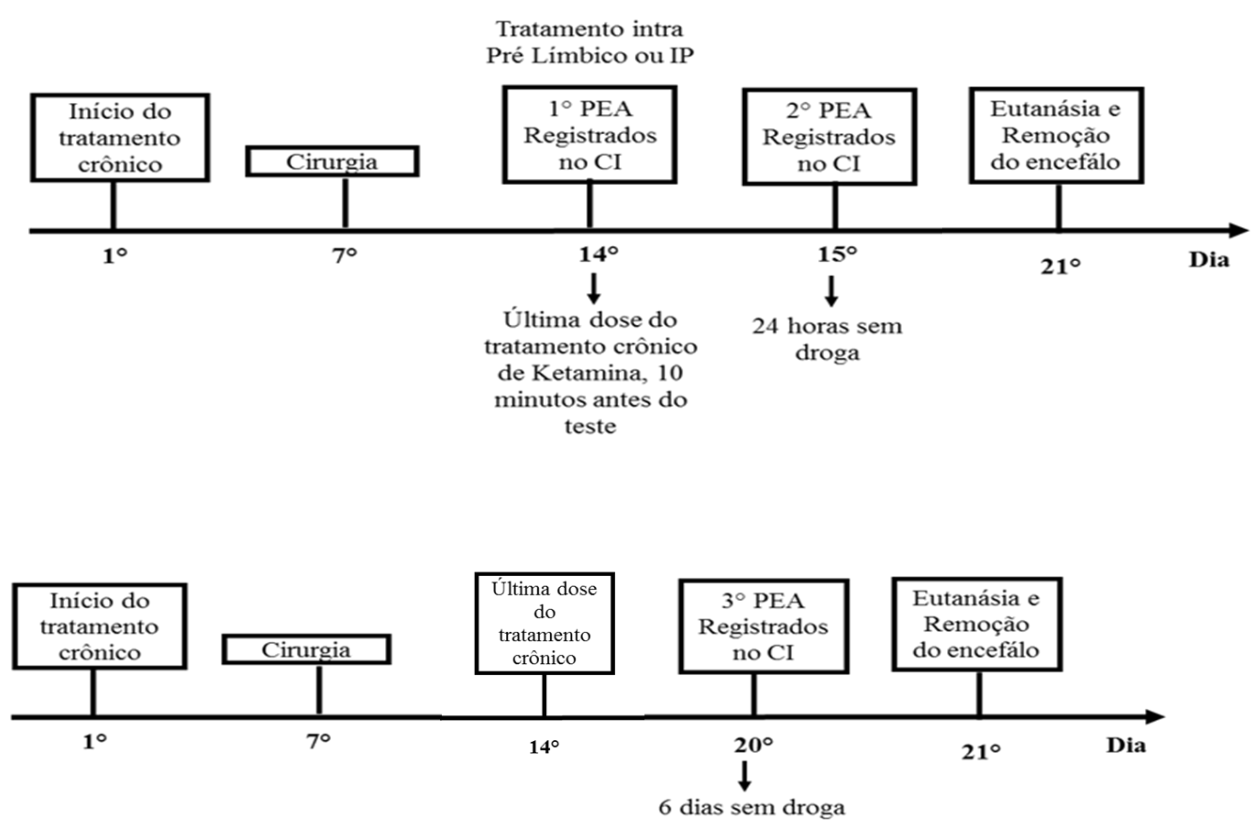

Figura 1: Desenho experimental dos PEAs.

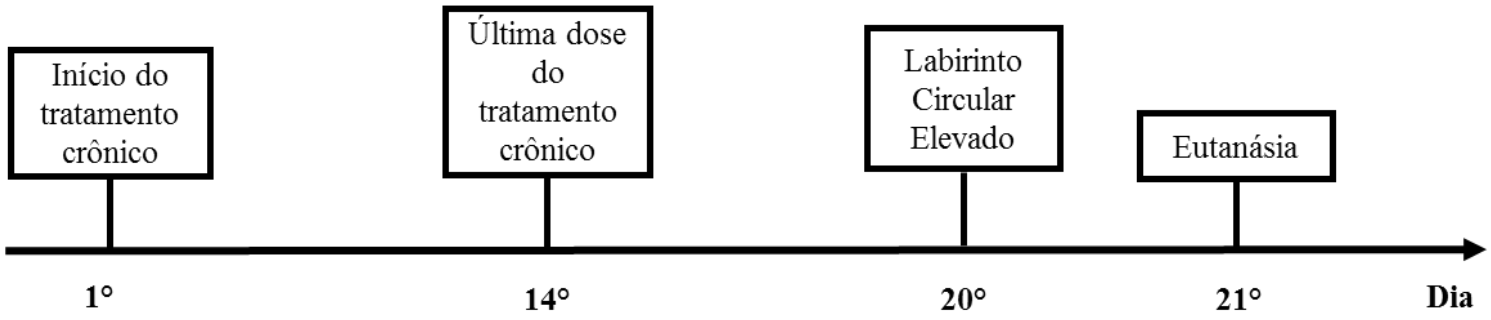

Figura 2: Desenho experimental do labirinto circular elevado.

\subsection{Perfusão e histologia}

Ao final dos experimentos, os animais foram anestesiados profundamente com hidrato de cloral à $25 \%(0.1 \mathrm{~g} / \mathrm{Kg}$ ip). A confirmação de morte foi dada pelo rompimento do diafragma, e em seguida foi realizado a perfusão cardíaca $(150 \mathrm{ml}$ de PBS seguido de 150 $\mathrm{ml}$ de paraformaldeído a 4\%). Posteriormente, os animais foram decapitados para retirada 
dos encéfalos, que foram mantidos numa solução de formalina por no máximo 2 horas, sendo a seguir mergulhados numa solução de sacarose (30\%) a menos $4^{\circ} \mathrm{C}$ até seu processamento. Os encéfalos foram então fatiados em cortes de $80 \mu \mathrm{m}$ de espessura, coletadas em tampão fosfato (0.1M, pH 7.4) de acordo com o atlas de Paxinos \& Watson (2008).

\subsection{Análise estatística}

As ondas do potencial evocado auditivo (PEA) foram demarcadas como em trabalhos anteriores (BAGRI et al., 1989; BRANDÃO et al., 2001b; 2005; NOBRE, 2013). Os dados experimentais estão como média \pm erro padrão da média $(\mathrm{EPM})$. Os efeitos das drogas na latência para a primeira negativa (N1) e a segunda onda positiva (P1), e na amplitude do PEA foram analisados por two way ANOVA (tratamento $\mathrm{x}$ tempo) com medidas repetidas. Quando necessário, outras comparações foram realizadas com one way ANOVA. Comparações a posteriori foram feitas utilizando o teste t-Student. A probabilidade de significância foi estabelecida em $\mathrm{p} \leq 0.05$ para todas as comparações. 
4. RESULTADOS 
A microfotografia do sítio de microinjeção está representada na figura 3.

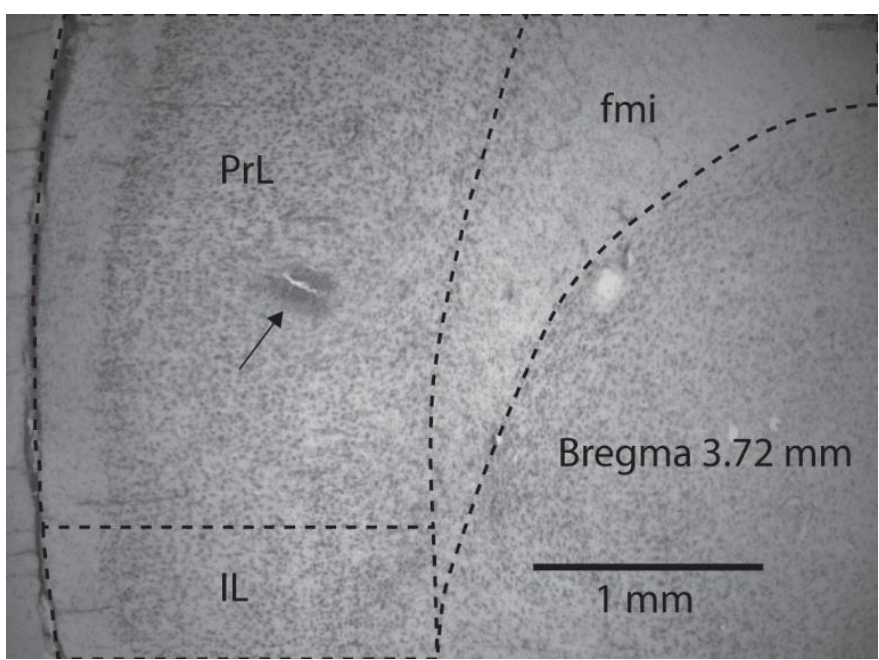

Figura 3: Esta é uma micrografia representativa de um corte transversal do cérebro de um rato Wistar, passando pelos córtices pré limbico (PrL) e infralimbico (IL), a seta demonstra o sitio de injeção de drogas realizadas no PrL.

Para analisar os efeitos da administração diária da Cetamina na latência e na amplitude dos PEAs, foi utilizado two-way ANOVA. A análise estatística mostrou que os efeitos ou a retirada da Cetamina não alteraram a latência, em nenhuma das doses (N1: $\mathrm{F}_{3,98}=1.66, \mathrm{p}=0.08 ; \mathrm{P} 1: \mathrm{F}_{3,98}=1,90, \mathrm{p}=0.21$ ) (figura 4).

Os animais testados sob efeito da Cetamina $\left(\mathrm{F}_{3,31}=1.059 ; \mathrm{p}=0.38\right)$ não demonstraram diferenças na amplitude dos PEAs. Após 24 horas da retirada, houve alteração significativa nos PEAs $\left(\mathrm{F}_{3,27}=3.52 ; \mathrm{p}<0.03\right)$. O mesmo foi encontrado após 6 dias do término do tratamento de Cetamina $\left(\mathrm{F}_{3,32}=6.14 ; \mathrm{p}<0.002\right)$. O teste pos-hoc t-Student revelou que a Cetamina nas doses de 20 e $80 \mathrm{mg} / \mathrm{kg}$ diminui os PEAs após 24 horas da sua retirada. Além disso, os PEAs do grupo controle são recuperados de forma significativa neste ponto e pode ser a explicação da dose de $40 \mathrm{mg} / \mathrm{kg}$ parecer diminuir esta medida. Foi observado, após 6 dias, o efeito rebote na amplitude induzida pelas doses 20 e $80 \mathrm{mg} / \mathrm{kg}$. Apesar do histograma 
apresentar a tendência da clozapina alterar a latência da P1 do grupo $80 \mathrm{mg} / \mathrm{kg}$, a diferença não foi significante $\left(\mathrm{N} 1: \mathrm{F}_{4,67}=1.35, \mathrm{p}=0.25 ; \mathrm{P} 1: \mathrm{F}_{4,67}=2.51, \mathrm{p}=0.14\right)$ (figura 5).

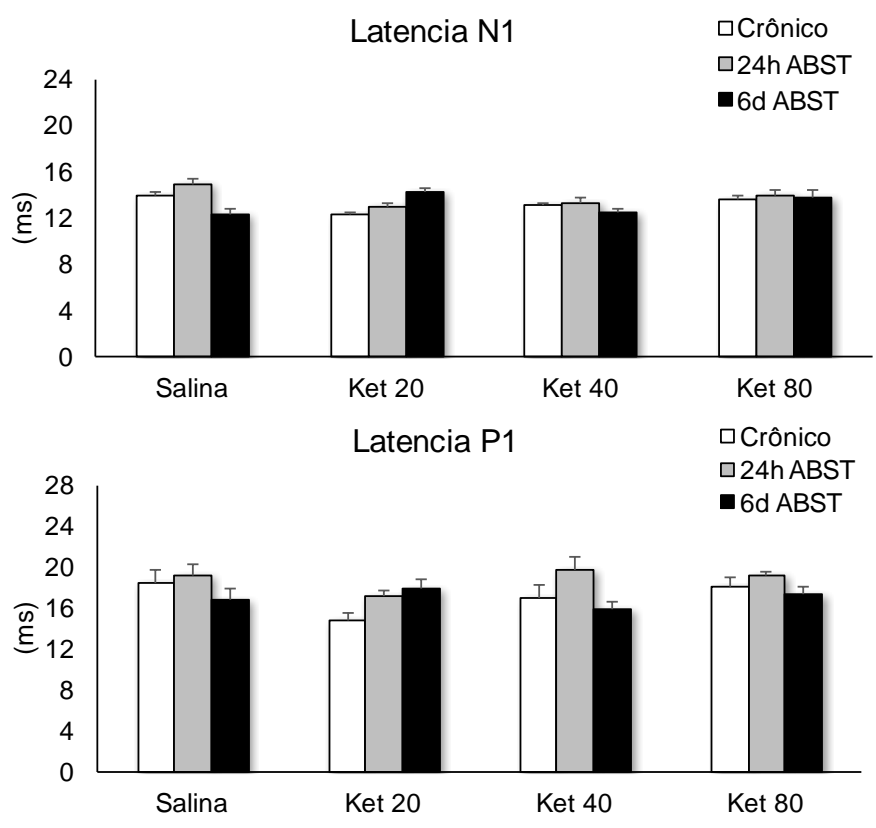

Figura 4: Latência da primeira negativa $\mathrm{w}$ da primeira positiva do potencial evocado auditivo registrada no colículo inferior, em milissegundos (ms). Foram utilizadas três doses de Cetamina, os animais foram testados sob efeito, 24 horas e 6 dias após a última injeção. 

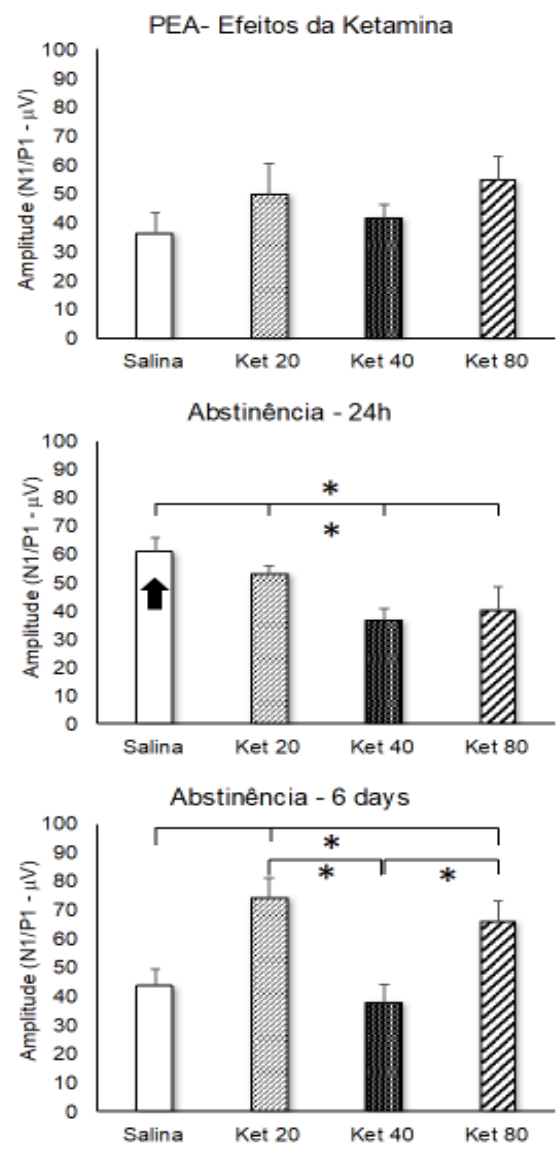

Figura 5: EPM da amplitude do potencial evocado auditivo (PEA) registrado no colículo inferior. As amplitudes são mostradas como um pico entre as medidas P1 e N1. Foram utilizadas três doses de Cetamina, os animais foram testados sob efeito, 24 horas e 6 dias após a última injeção.

Os PEAs foram seletivamente afetados pela clozapina. Alterações entre os grupos Cetamina $\left(\mathrm{F}_{4,35}=2.18, \mathrm{p}=0.09\right)$ e Cetamina após 24 horas de retirada $\left(\mathrm{F}_{4,33}=1.98, \mathrm{p}=0.12\right)$ não foram encontradas (figura 6). Contudo, a clozapina facilita a recuperação da amplitude nos grupos controle e $20 \mathrm{mg} / \mathrm{kg}$, testados após 24 horas do término do tratamento (figura 7). 

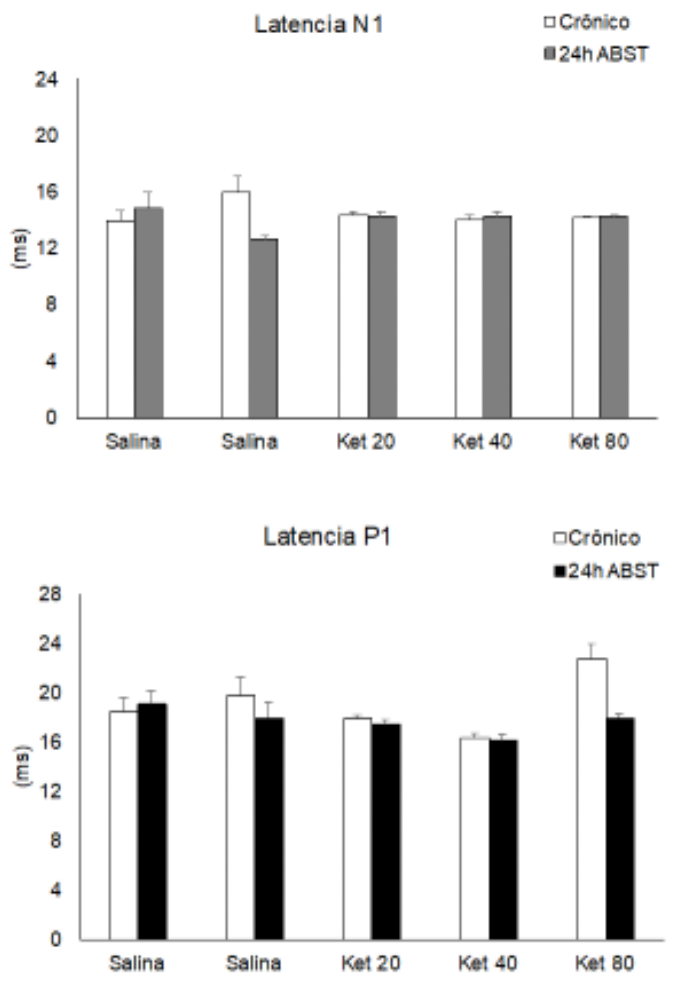

Figura 6: Latência da primeira negativa (N1) da primeira positiva (P1) do potencial evocado auditivo registrada no colículo inferior, em milissegundos (ms). Foram utilizadas três doses de Cetamina. O efeito crônico da Cetamina foi desafiado de forma sistêmica (intraperitoneal) com o antipsicótico Clozapina.Os animais foram testados sob efeito e 24 horas após os tratamentos.

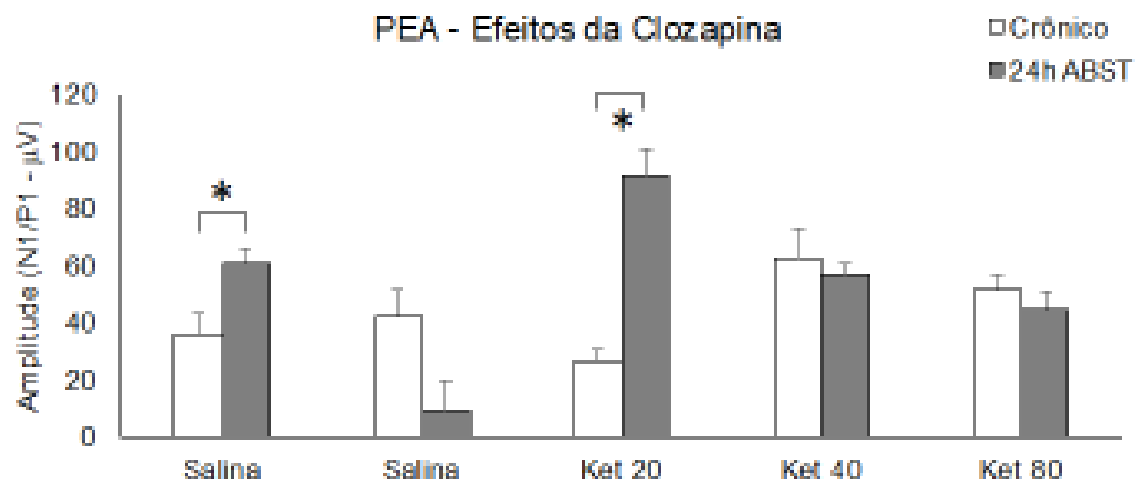

Figura 7: Média EPM da amplitude do potencial evocado auditivo (PEA) registrado no colículo inferior. As amplitudes são mostradas como um pico entre as medidas P1 e N1. Foram utilizadas três doses de Cetamina. O efeito crônico da Cetamina foi desafiado de forma sistêmica (intraperitoneal) com o antipsicótico Clozapina.Os animais foram testados sob efeito e 24 horas após os tratamentos. 
O antagonismo de NMDA no CI não demonstrou influência na latência da N1 ( $\mathrm{F}_{4,56}=$ 0.844.85, $\mathrm{p}=0.51)$ ou na latência da $\mathrm{P} 1\left(\mathrm{~F}_{4,56}=1.20, \mathrm{p}=0.63\right)$ (figura 8). A ANOVA revelou diferenças significativas $\left(\mathrm{F}_{4,59}=6.68, \mathrm{p}<0.005\right)$, esta diferença é devido, principalmente, a diminuição dos PEAs quando o antagonista é desafiado pelos efeitos da Cetamina. Ademais, NMDA quase bloqueou completamente o PEA do grupo $40 \mathrm{mg} / \mathrm{kg}$ testado 24 horas após o término do tratamento crônico (figura 9).

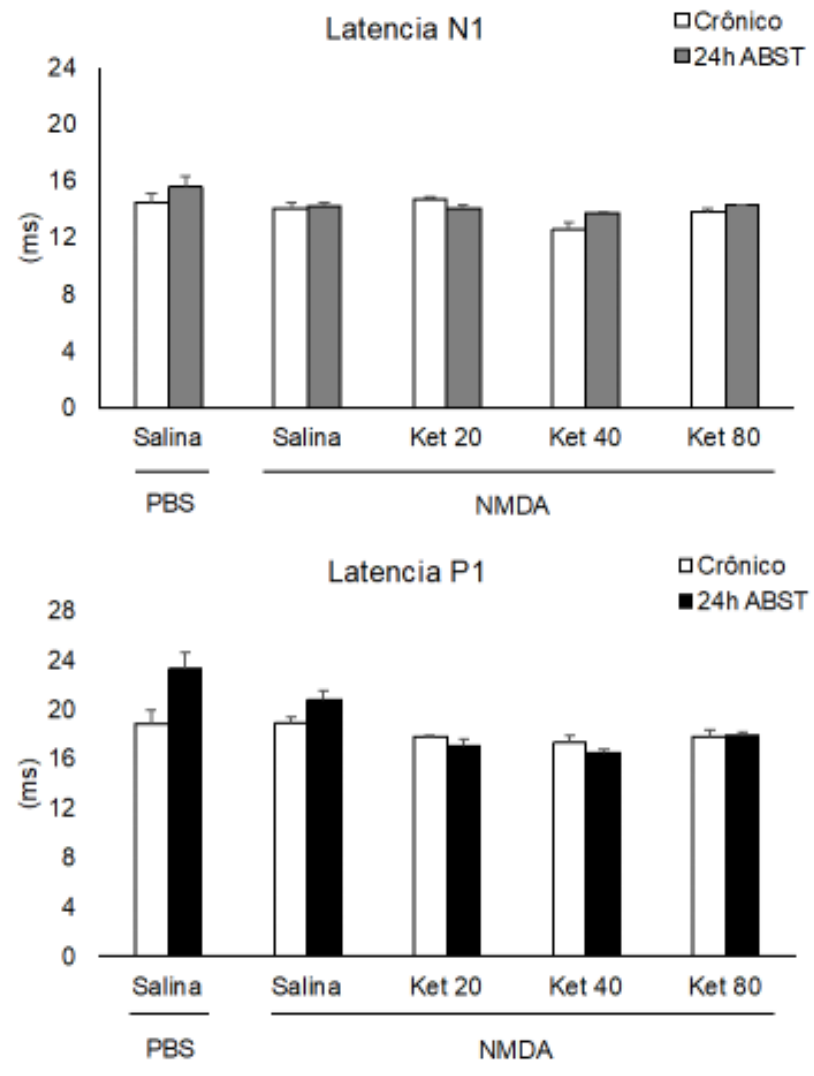

Figura 8: Latência da primeira negativa $(\mathrm{N} 1)$ da primeira positiva $(\mathrm{P} 1)$ do potencial evocado auditivo registrada no colículo inferior, em milissegundos (ms). Foram utilizadas três doses de Cetamina. O efeito crônico da Cetamina foi desafiado de forma com injeção local intra-PrL de NMDA. Os animais foram testados sob efeito e 24 horas após os tratamentos. 


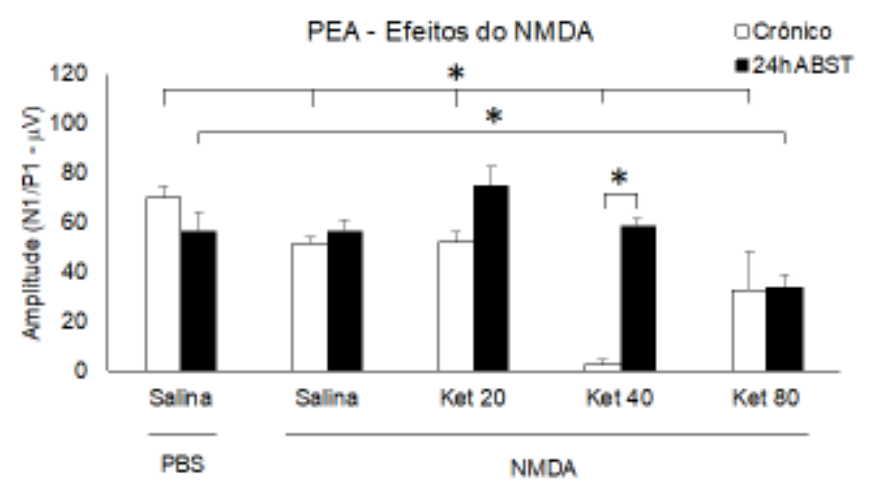

Figura 9: Média EPM da amplitude do potencial evocado auditivo (PEA) registrado no colículo inferior. As amplitudes são mostradas como um pico entre as medidas P1 e N1. Foram utilizadas três doses de Cetamina. O efeito crônico da Cetamina foi desafiado de forma com injeção local intra-PrL de NMDA. Os animais foram testados sob efeito e 24 horas após os tratamentos.

\subsection{Representação esquemática dos potencias evocados auditivos}

O potencial evocado auditivo do tronco cerebral é uma medida eletrofisiológica da resposta do grupo de neurônios que circundam a área de registro de um eletrodo após um estímulo de natureza auditiva, abaixo representações esquemáticas do teste

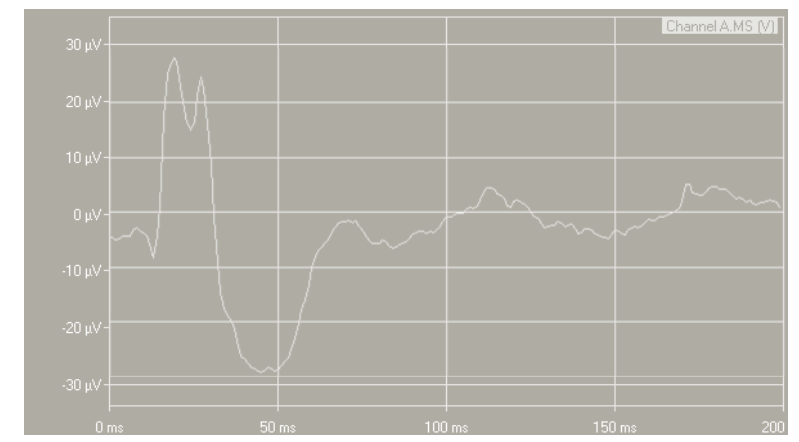

Figura 10: Representação esquemática de um potencial evocado auditivo registrado no colículo inferior de um animal tratado durante 14 dias com salina. O teste foi realizado 10 minutos após a última dose do tratamento crônico, subcutânea.

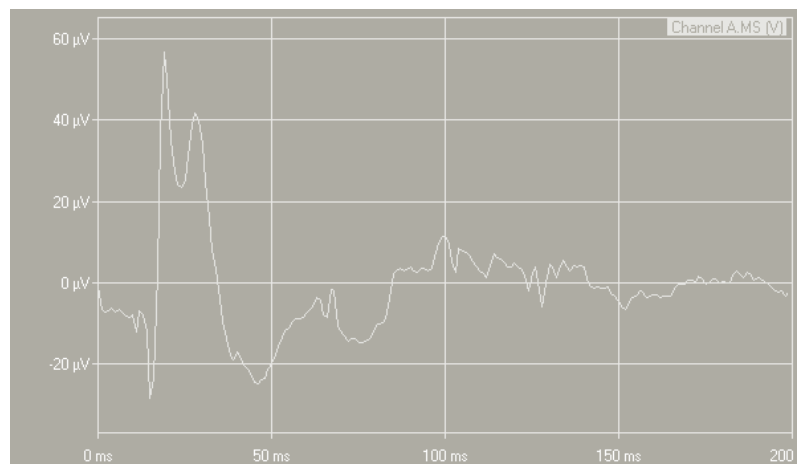


Figura 11: Representação esquemática de um potencial evocado auditivo registrado no colículo inferior de um animal tratado durante 14 dias com Cetamina $(20 \mathrm{mg} / \mathrm{kg})$. O teste foi realizado 10 minutos após a última dose do tratamento crônico, subcutânea.

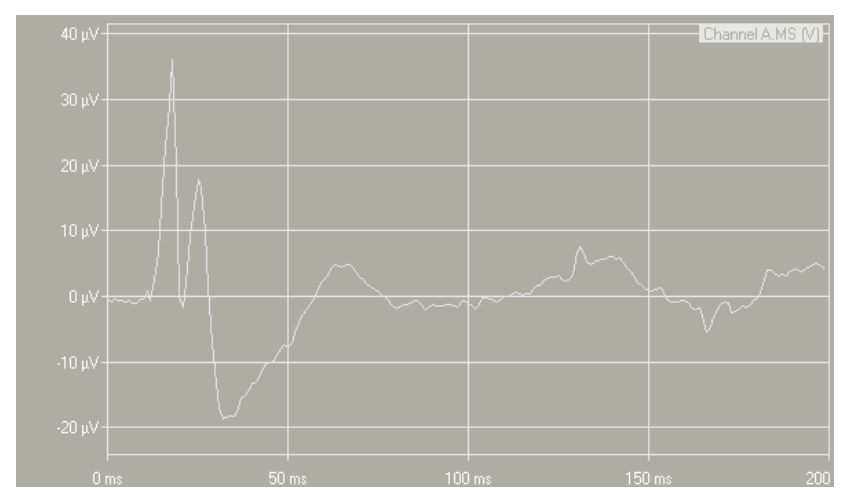

Figura 12: Representação esquemática de um potencial evocado auditivo registrado no colículo inferior de um animal tratado durante 14 dias com Cetamina $(40 \mathrm{mg} / \mathrm{kg}$ ). O teste foi realizado 10 minutos após a última dose do tratamento crônico, subcutânea.

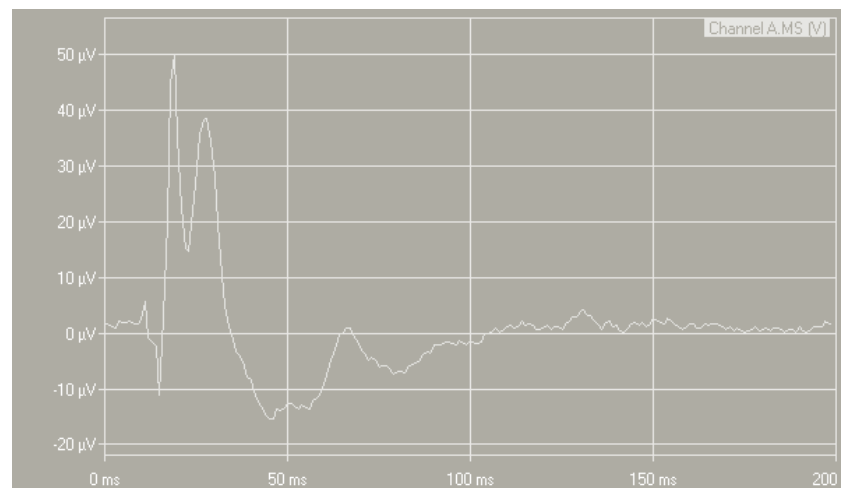

Figura 13: Representação esquemática de um potencial evocado auditivo registrado no colículo inferior de um animal tratado durante 14 dias com Cetamina $(80 \mathrm{mg} / \mathrm{kg})$. O teste foi realizado 10 minutos após a última dose do tratamento crônico, subcutânea. 


\subsection{Labirinto circular elevado: 6 dias de abstinência de Cetamina}
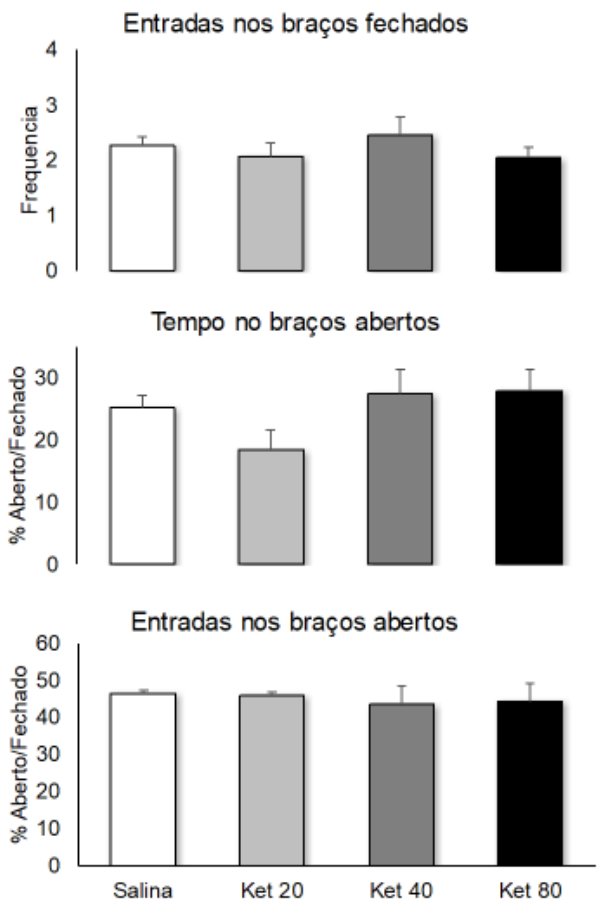

Figura 14: Frequência de entrada (acima), porcentagem de tempo nos braços abertos (figura do meio) e a porcentagem de entradas nos braços abertos (abaixo), de grupos independentes que foram submetidos ao tratamento de Cetamina por 14 dias e foram testados 6 dias após a última injeção. 
5. DISCUSSÃ̃ 
Este trabalho analisou os efeitos crônicos de diferentes doses de Cetamina na latência e na amplitude do potencial evocado auditivo em ratos, em duas fases diferentes - 24 horas e 6 dias após o término do tratamento crônico. No geral, o efeito do abuso de drogas é exercido através do aumento dos receptores dopaminérgicos nas aferências da área tegmental ventral, o qual se projeta para áreas límbicas, sobretudo, o núcleo accumbens (KOOB, 1992). Da mesma forma, a feniciclidina, assim como o derivado sintético da Cetamina, tem efeitos psicoestimulantes fortes e são capazes de induzir excitação geral, paranóia, perturbação de pensamento, alucinação e sintomas semelhantes aos da psicose, os quais remetem aos encontrados na esquizofrenia (LODGE; MERCIER, 2015).

A Cetamina aumenta de forma significativa os níveis extracelulares e as taxas do metabólico da dopamina no córtex medial pré-frontal (HONDO et al., 1994) e do núcleo accumbens (CARBONI et al., 1989). Além disso, sugere-se que receptores glutamatérgicos do tipo NMDA parecem exercer uma ação inibitória na neurotransmissão dopaminérgica nesta região (HATA et al., 1990). Portanto, por a Cetamina ser um potente antagonista NMDA e também atuar em receptores dopaminérgicos, nós investigamos a influência de injeções sistêmicas do antipsicótico atípico clozapina e de infusões intra-PrL de NMDA na latência e na amplitude dos PEAs registrados no colículo inferior (CI). A Cetamina per se não demonstrou efeito na latência ou na amplitude colicular no PEA, mesmo quando utilizada altas doses. Estudos destinados a investigar as alterações induzidas pela Cetamina no sistema auditivo são quase inexistentes, por isso, não é fácil explicar sua inabilidade.

Antagonistas de receptores NMDA, como a Cetamina, são frequentemente utilizados de forma abusiva por adolescentes, estudantes, militares e pela equipe médica. (MORGAN et al., 2010). Apesar dessas drogas produzirem alucinações e exacerbar sintomas de psicose preexistente, diversos estudos afirmam que a perturbação cognitiva é mais substancial do que as características de psicose (MALHOTRA et al., 1997; MORGAN et al., 2010). 
Embora a natureza deste déficit cognitivo tenha sido elucidada, alguns estudos têm diferenciado os efeitos da Cetamina em várias fases de processamento de informação. Este trabalho utilizou-se do potencial evocado auditivo (PEA) para examinar os efeitos agudos, crônicos e permanentes da Cetamina em diversas fases da codificação sensorial de ratos. Assim, podemos perceber o quanto um antagonista de NMDA pode afetar o processamento sensorial.

As disfunções comportamentais e cognitivas provocadas por antagonistas de NMDA, como a Cetamina, são conhecidas como modelo relevante de esquizofrenia (MALHOTRA et al., 1997; MICALLEF et al., 2002; UMBRICHT et al., 2000). Sabe-se que a redução funcional dos receptores de NMDA é um sintoma inicial do desenvolvimento da esquizofrenia (GREENE et al., 2000; NEWCOMER et al., 1999). Estudos pré-clínicos a respeito dos efeitos duradouros da Cetamina nos componentes N1 e P1 do processamento de informação auditiva são escassos. Um estudo utilizando implantes de eletrodos direcionados à área CA3 do hipocampo, mostrou que a Cetamina altera os componentes N1, P1 e P2 em humanos.

Em nosso estudo, nós encontramos que a Cetamina não é capaz de alterar a latência da N1 ou da P1, e não houve modificação na amplitude dos PEAs registradas como N1/P1 nem mesmo na administração de altas doses. Assim, os resultados indicam que as disfunções tanto no comportamento quanto na cognição, eliciadas pela Cetamina, parecem ser devido a mudanças em áreas cerebrais mais rostrais. Contudo, a influência dos efeitos crônicos da Cetamina seguidos da interrupção de exposição crônica, são evidentes e significantes. De fato, o efeito rebote da retirada foi encontrado 6 dias após a última dose aplicada, apresentando uma curva em forma de "U", aumentando a amplitude dos PEAs com as doses mais baixa e mais alta, e diminuindo nas doses intermediárias (40 mg/kg). 
Localizado no tronco encefálico, o colículo inferior $(\mathrm{CI})$ é a principal estrutura do sistema auditivo e é centro de integração de vias ascendentes e descendentes (CASSEDAY; COVEY, 1996; LI; YUE, 2002). O CI é divido em três partes principais: dorsal, externo e núcleo central (CIC). O CIC recebe a maioria das conexões aferentes do núcleo auditivo inferior (CASSEDAY; COVEY, 1996). A neurotransmissão excitatória pós sináptica do CIC é regulada pelos receptores AMPA e NMDA, com a modulação da despolarização de longa duração (HOLT et al., 2005; KELLY; ZHANG, 2002; MA et al., 2002; WYNNE et al., 1995).

A liberação de glutamato é inibida por receptores $\mathrm{GABA}_{\mathrm{B}}$ e os receptores $\mathrm{GABA}_{\mathrm{A}}$ inibem diretamente os neurônios do CIC. Considerando esta afirmação, o esperado em nosso estudo é que a Cetamina cause uma inibição nos registros dos PEAs. De fato, há muitas evidências que apontam que a neurotransmissão no CIC é regulada pelo glutamato e por receptores de glutamato (ADAMS; WENTHOLD, 1979; GREENAMYRE et al., 1984). Exemplificando, Faingold et al. (1989) destaca que o aminoácido glutamato e NMDA causam o aumento do disparo auditivo, e é suprimido pelo uso de antagonistas de NMDA. Porém, nós encontramos que a Cetamina sistêmica não é capaz de diminuir os PEAs coliculares, provavelmente devido aos efeitos adicionais que ela apresenta em outros receptores além do NMDA. Muitos estudos enfatizam a alta densidade das células GABAérgicas nesta estrutura e sugere um forte processo inibitório no CI em ratos (GERKEN, 1996; BATRA; FITZPATRICK, 2002; MERCHÁN et al., 2005; POLLAK et al., 2011).

Além disso, a interação entre as sinapses excitatórias e inibitórias podem determinar um padrão de atividade neuronial no CI. Porém, uma evidência mais pertinente seria que a ausência de efeitos eletrofisiológicos da Cetamina é devido à tolerância farmacológica. Corroborando, estudos anteriores relatam que com repetidas doses a tolerância é observada 
em macacos, humanos e ratos (BREE et al., 1967; CRONIN et al., 1972; DOUGLAS; DAGIRMANJIAN, 1975).

Um fato interessante encontrado em nosso estudo é que o efeito rebote para a tolerância é observada após 6 dias de interrupção do tratamento crônico de Cetamina. Até o momento não estamos certos que a natureza da curva em forma de "U" é resultado das diferentes doses utilizadas. Afinal, quando são avaliadas diferentes variáveis com diferentes dosagens de Cetamina as taxas de respostas seguem, usualmente, uma curva padrão de "U" invertido (MORETON et al., 1977). Estudos adicionais direcionados para os efeitos agudos, sistêmicos e locais (intra-CIC) da Cetamina, podem esclarecer este ponto.

A clozapina é um antipsicótico atípico que atua em múltiplos sistemas encefálicos. Apesar de não agir diretamente nos receptores de glutamato, continua mostrando a capacidade de modular o sistema glutamatérgico (HERESCO-LEVY, 2003), e também apresenta afinidade pela dopamina (D1, D2, D3, D4) e receptores de serotonina $\left(5 \mathrm{HT}_{2 \mathrm{~A}}\right.$, $5 \mathrm{HT}_{2 \mathrm{C}}$ ), entre outros. Além disso, acredita-se que a clozapina regula os receptores de NMDA (GIARDINO et al., 1997; OSSOWSKA et al., 1999), facilita a atividade desses receptores por alterar a glicina em múltiplos níveis (JAVITT et al., 2003) e reestrutura a disfunção de NMDA causado por feniciclidina (NINAN et al., 2003). Portanto, em nossos experimentos, foi esperado que o uso da clozapina ocasionasse uma melhora nos PEAs registrados no CIC, pelo bloqueio dos efeitos inibitórios causados pela Cetamina nos receptores NMDA. De fato, em nossos estudos, a clozapina ocasionou a melhora na amplitude dos PEAs no grupo de baixa dose de Cetamina (20 mg/kg). A ausência de efeito nos grupos de doses maiores pode ser explicada pela dose utilizada de clozapina, então, sugere-se que sua ação pode envolver diversas vias. Primeiro, o antagonismo serotoninérgico $\left(5-\mathrm{HT}_{2}\right)$, um mecanismo associado com ação de antipsicótico atípicos. Como demonstrado anteriormente, são encontrados abundantes fibras 5-HT e receptores 5-HT no CI (HURLEY, 2006; HURLEY et al., 2002; 
PERUZZI; DUT, 2004). Estas conclusões apontam para o papel exercido pela 5-HT na modulação endógena nos neurônios do CI. Além disso, como descrito previamente, a clozapina também atua na modulação da neurotransmissão glutamatérgica, então, o aminoácido excitatório, incluindo glutamato e ligantes do NMDA, ativam o sistema auditivo, e lembrando que este efeito é suprimido pelo antagonista de NMDA, o efeito esperado da clozapina é, de fato, favorecer os PEAs.

Em humanos, uma das regiões mais afetadas pela Cetamina é o córtex pré-frontal, particularmente as regiões medial (PrL) e ventral (IL) (HOLCOMB et al., 2001). Um estudo utilizando técnicas de ressonância demostrou que os efeitos dissociativos da Cetamina são fortemente correlacionados com a redução da atividade cortical mediada por glutamato (DEAKIN et al., 2008). Além disso, estudos com humanos tem mostrado que a performance em tarefas que envolvem a atividade do córtex pré-frontal é fortemente afetado pela Cetamina (HONEY et al., 2004; HONEY et al., 2005), este efeito é semelhante aos encontrados em pacientes esquizofrênicos (NEILL et al., 2010).

Os antagonistas de receptores NMDA podem alterar a atividade normal em diversas regiões cerebrais, incluindo o córtex pré-frontal medial, entre outros (O’DONNELL; GRACE, 1998). Esta região é um importante alvo, já que suas vias de eferência exercem controle top down regulatório em outras estruturas, de forma direta ou indireta (FLORESCO et al., 2009; VERTES, 2004).

No mesencéfalo, o CI exerce um papel importante no gatilho sensorial auditivo, como por exemplo, as alucinações auditivas eliciadas durante o surto psicótico são acompanhadas pela ativação dos neurônios coliculares (SHERGILL et al., 2000). Assim sendo, é possível que a neurotransmissão glutamatérgica do córtex pré-frontal module indiretamente as conexões neuronais do CI. Receptores de NMDA no CIC são responsáveis pela expressão de respostas excitatórias dos estímulos auditivos e esta ação é dependente da 
concentração extracelular de $\mathrm{Mg}^{2}$ (COTMAN; IVERSEN, 1987). Em nosso estudo, a administração de NMDA intra- PrL reduziu a amplitude colicular dos grupos pré tratados com salina e Cetamina. A diminuição dos PEAs no grupo controle foi devido, principalmente, a melhora basal da amplitude induzida pela injeção de salina (PBS); este efeito é devido a estimulação mecânica da própria microinjeção intra- PrL, tendo em vista que 24 horas após este efeito foi dissipado.

Portanto, era suposto que os efeitos das doses de NMDA usados em nosso estudo alterasse somente altas doses de Cetamina, porém, no geral, os sintomas provocados pela Cetamina são relacionados com a ação antagonista de NMDA. Inesperadamente, a administração local intra-PrL de NMDA reduziu a amplitude dos PEAs, os quais foram recuperados 24 horas após.

A exposição de um antagonista de NMDA, como a Cetamina, resulta em sintomas semelhantes aos da psicose, consequente do prejuízo do córtex pré-frontal. Em nosso caso, parece que a tolerância reestabelece os PEAs no CIC. O agonista de receptores de NMDA diminui a amplitude colicular dos PEAs.

Estes resultados demonstram que o processamento auditivo no CI está sob controle indireto do PrL, até então não há evidências da conexão direta entre PrL e CI. Portanto, nosso estudo ressalta novas evidências do efeito crônico de Cetamina no comportamento, utilizando uma medida eletrofisiológica. Além disso, nós encontramos que, assim como outras drogas de abuso, as mudanças induzidas pela Cetamina são também dependentes do nível dos mecanismos dopaminérgicos e glutamatérgicos. 
6. CONCLUSÃO 
Nossos resultados demonstram que tolerância à Cetamina reestabelece os PEAs no CIC e o agonista de receptores NMDA diminui a amplitude colicular desses potenciais, além de que o processamento auditivo no CI está sob controle indireto do PrL, e até então não há evidências da conexão direta entre eles.

Portanto, nosso estudo ressalta novas evidências do efeito crônico de Cetamina no comportamento, utilizando uma medida eletrofisiológica. Além disso, nós encontramos que, assim como em outras drogas de abuso, as mudanças induzidas pela Cetamina são também dependentes dos mecanismos dopaminérgicos e glutamatérgicos. 


\section{REFERÊNCIAS BIBLIOGRÁFICAS}


Adams, J.C., Wenthold, R.J., 1979. Distribution of putative amino acid transmitters, choline acetyltransferase and glutamate decarboxylase in the inferior colliculus. Neuroscience 4, 1947-1951. doi:10.1016/0306-4522(79)90067-8

Adams JC (1980) Crossed and descending projections to the inferior colliculus. Neurosci Lett 19: 1-5.

Aitkin L (1983) The Auditory Midbrain. New Jersey: Humana Press.

Amann LC, Halene TB, Ehrlichman RS, Luminais SN, Ma N, Abel T, Siegel SJ.(2009) Chronic ketamine impairs fear conditioning and produces long-lasting reductions in auditory evoked potentials. Neurobiol Dis. Aug;35(2):311-7

Annetta MG, Iemma D, Garisto C, Tafani C, Proietti R. (2005) Ketamine: new indications for an old drug. Curr Drug Targets. Nov;6(7):789-94.

Audi EA \& Graeff FG (1987) GABAA receptors in the midbrain central grey mediate the antiaversive action of GABA. Eur. J. Pharmacol., 135: 225-229.

Bagri, A., Sandner, G., Di Scala, G., 1989. Effects of unilateral microinjections of GABAergic drugs into the inferior colliculus on auditory evoked potentials and on audiogenic seizure susceptibility. Exp Neurol 104, 82-7

Bergman AS (1999) Ketamine: review of its pharmacology and its use in pediatric anesthesia. Anesthesia Progress, v.46, p. 10-20.

Biacabe B1, Chevallier JM, Avan P, Bonfils P (2001) Functional anatomy of auditory brainstem nuclei: application to the anatomical basis of brainstem auditory evoked potentials. Auris Nasus Larynx. Jan;28(1):85-94.

Brandão ML, Anseloni VZ, Pandossio JE, De Araujo JE, Castilho VM (1999) Neurochemical mechanisms of the defensive behavior in the dorsal midbrain. Neurosci Biobehav Rev 23: 863-875.

Brandao, M.L., Borelli, K.G., Nobre, M.J., Santos, J.M., Albrechet-Souza, L., Oliveira, A.R., Martinez, R.C., 2005. Gabaergic regulation of the neural organization of fear in the midbrain tectum. Neurosci Biobehav Rev 29, 1299-311.

Brandao ML, Coimbra NC, Osaki MY (2001) Changes in the auditory-evoked potentials induced by fear-evoking stimulations. Physiology \& behavior 72:365-372.

Brandão ML, Vasquez EC, Cabral AM, Schmitt P (1985) Chlordiazepoxide and morphine reduce pressor response to brain stimulation in awake rats. Pharmacol Biochem Behav 23: 1069-1071.

Brandão ML, De Aguiar JC \& Graeff FG (1982) GABA mediation of the antiaversive action of minor tranquilizers. Pharmacol. Biochem. Behav., 16: 397-402. 
Brandão ML, Troncoso AC, Melo LL, Sandner G (1997) Active avoidance learning using brain stimulation applied to the inferior colliculus as negative reinforcement in rats: evidence for latent inhibition. Neuropsychobiology 35: 30-35.

Bräu M, Sander F, Vogel W (1997) Blocking mechanisms in enzyimatically demyelinated peripheral nerve as revealed by single-channel experiments. Anesthesiology, v.86, n.2, p. 394-404.

Braun AA, Skelton MR, Vorhees CV, Williams MT (2010) Comparison of the elevated plus and elevated zero mazes in treated and untreated male Sprague-Dawley rats: Effects of anxiolytic and anxiogenic agents. Pharmacology, biochemistry, and behavior.

Bree, M.M., Feller, I., Corssen, G., 1967. Safety and tolerance of repeated anesthesia with CI 581 (Ketamine) in monkeys. Anesth. Analg. 46, 596-600.

Brodal P (1992) The central nervous system: structure and function. New York: Oxford University Press.

Bormann J (2000) The 'ABC' of GABA receptors. Trends Pharmacol. Sci., 21: 16-19.

Cabral A, De Ross J, Castilho VM, Brandao ML, Nobre MJ (2009) Glutamate receptor antagonism in inferior colliculus attenuates elevated startle response of high anxiety diazepam-withdrawn rats. Neuroscience 161:707-717.

Carboni, E., Imperato, A., Perezzani, L., Di Chiara, G., 1989. Amphetamine, cocaine, phencyclidine and nomifensine increase extracellular dopamine concentrations preferentially in the nucleus accumbens of freely moving rats. Neuroscience 28, 653-661.

Carlsson ML (1993) Are the disparate pharmacological profiles of competitive and uncompetitive NMDA antagonists due to different baseline activities of distinct glutamatergic pathways? (Hypothesis). Journal of neural transmission General section 94:1-10.

Casseday JH, Covey E (1996) A neuroethological theory of the operation of the inferior colliculus. Brain Behav Evol 47:311-336.

Castilho VM, Brandão ML (2001) Conditioned antinociception and freezing using electrical stimulation of the dorsal periaqueductal gray or inferior colliculus as unconditioned stimulus are differentially regulated by 5-HT2A receptors in rats. Psychopharmacology (Berl) 155: 154-162.

Chatterjee M, Ganguly S, Srivastava M, Palit G (2011) Effect of 'chronic' versus 'acute' ketamine administration and its 'withdrawal' effect on behavioural alterations in mice: implications for experimental psychosis. Behavioural brain research 216:247-254.

Chu DC, Albin RL, Young AB, Penney JB (1990) Distribution and kinetics of GABAB binding sites in rat central nervous system: a quantitative autoradiographic study. Neuroscience 34: 341-357. 
Coleman JR, Clerici WJ (1987) Sources of projections to subdivisions of the inferior colliculus in the rat. J Comp Neurol 262: 215-226.

Corazza O, Assi S, Schifano F (2013). From "Special K" to "Special M": the evolution of the recreational use of ketamine and methoxetamine. CNS Neurosci. Ther. 19, 454-460

Cotman, C.W., Iversen, L.L., 1987. Excitatory amino acids in the brain - focus on NMDA receptors. Trends Neurosci. 10, 263-265. doi:10.1016/0166-2236(87)90170-6

Cuadra G, Zurita A, Lacerra C, Molina V (1999) Chronic stress sensitizes frontal cortex dopamine release in response to a subsequent novel stressor: reversal by naloxone. Brain Res Bull 48: 303-308.

Cuadra G, Zurita A, Macedo CE, Molina VA, Brandao ML (2000) Electrical stimulation of the midbrain tectum enhances dopamine release in the frontal cortex. Brain Res Bull 52: 413-418.

Cronin, M.M., Bousfield, J. d., Hewett, E. b., McLellan, I., Boulton, T. b., 1972. Ketamine anaesthesia for radiotherapy in small children. Anaesthesia 27, 135-142. doi:10.1111/j.1365-2044.1972.tb08187.x

Deakin JF, Lees J, McKie S, Hallak JE, Williams SR, Dursun SM (2008) Glutamate and the neural basis of the subjective effects of ketamine: a pharmaco-magnetic resonance imaging study. Archives of general psychiatry 65:154-164.

Dillon P, Copeland J, Jansen K (2003) Patterns of use and harms associated with nonmedical ketamine use. Drug and alcohol dependence 69:23-28.

Douglas, B.G., Dagirmanjian, R., 1975. The effects of magnesium deficiency of ketamine sleeping times in the rat. Br. J. Anaesth. 47, 336-340.

Duval Neto GF (2004) Anestésicos Venosos. In: Manica J (eds.). Anestesiologia Princípios e Técnicas. 3th ed. Porto Alegre: Artmed, p.560-97

Faye-Lund H, Osen KK (1985) Anatomy of the inferior colliculus in rat. Anat Embryol (Berl) 171: 1-20.

Espejo EF, Minano FJ (1999) Prefrontocortical dopamine depletion induces antidepressantlike effects in rats and alters the profile of desipramine during Porsolt's test. Neuroscience 88: 609-615.

Faingold, C.L., Hoffmann, W.E., Caspary, D.M., 1989. Effects of excitant amino acids on acoustic responses of inferior colliculus neurons. Hear. Res. 40, 127-136. doi:10.1016/03785955(89)90106-8

Fay RR \& Popper AN (2000) Evolution of hearing in vertebrates: the inner ears and processing. Hear. Res., 149: 1-10. 
Feenstra MG, Botterblom MH, van Uum JF (1995) Novelty-induced increase in dopamine release in the rat prefrontal cortex in vivo: inhibition by diazepam. Neurosci Lett 189: 8184.

Ferreira PEM, Martini, RK (2001). Cocaína: lendas, história e abuso. Revista Brasileira de Psiquiatria, 23(2), 96-99. https://dx.doi.org/10.1590/S1516-44462001000200008

Floresco SB, Zhang Y, Enomoto T. (2009) Neural circuits subserving behavioral flexibility and their relevance to schizophrenia. Behav Brain Res. Dec 7;204(2):396-409

Focchi GRA (2004) Dependência de drogas: uma abordagem para leigos. Psychiatry on line Brasil, Setembro de 2004 - Vol.9 - No 9

Fuster JM (1989) The prefrontal cortex: anatomy, physiology and neuropsychology of the frontal lobe. New York: Raven Press.

Gans C (1992) An overview of the evolutionary biology of hearing. (Webster DB, Popper AN, eds).

Garcia-Cairasco N (2002) A critical review on the participation of inferior colliculus in acoustic-motor and acoustic-limbic networks involved in the expression of acute and kindled audiogenic seizures. Hear. Res., 168: 208-222.

Garcia JBS (2007) Cetamina uma nova leitura. Prática Hospitalar.53:214-6

Geyer MA (1998) Behavioral studies of hallucinogenic drugs in animals: implications for schizophrenia research. Pharmacopsychiatry 31 Suppl 2:73-79.

Glabe RS (2004) Acute toxic effects of club drugs. J Psych Drugs 36:30313.

Graeff FG, Brandao ML, Audi EA, Milani H (1986) Role of GABA in the anti-aversive action of anxiolytics. Adv Biochem Psychopharmacol 42: 79-86.

Greenamyre, J.T., Young, A.B., Penney, J.B., 1984. Quantitative autoradiographic distribution of L-[3H]glutamate-binding sites in rat central nervous system. J. Neurosci. 4, 2133-2144.

Greene, R., Bergeron, R., McCarley, R., Coyle, J.T., Grunze, H., 2000. Short-term and Longterm Effects of N-Methyl-D-Aspartate Receptor Hypofunction. Arch. Gen. Psychiatry 57, 1180-1181. doi:10.1001/archpsyc.57.12.1180

Hata, N., Nishikawa, T., Umino, A., Takahashi, K., 1990. Evidence for involvement of Nmethyl-d-aspartate receptor in tonic inhibitory control of dopaminergic transmission in rat medial frontal cortex. Neurosci. Lett. 120, 101-104. doi:10.1016/0304-3940(90)90178-C

Hall RD, Mark RG (1967) Fear and the modification of acoustically evoked potentials during conditioning. Journal of neurophysiology 30:893-910. 
Heresco-Levy, U., 2003. Glutamatergic neurotransmission modulation and the mechanisms of antipsychotic atypicality. Prog. Neuropsychopharmacol. Biol. Psychiatry, Mechanism of Atypicality of Antipsychtic Drugs 27, 1113-1123.

Holcomb HH, Lahti AC, Medoff DR, Weiler M, Tamminga CA (2001) Sequential regional cerebral blood flow brain scans using PET with H2(15)O demonstrate ketamine actions in CNS dynamically. Neuropsychopharmacology : official publication of the American College of Neuropsychopharmacology 25:165-172.

Holt, A.G., Asako, M., Lomax, C.A., MacDonald, J.W., Tong, L., Lomax, M.I., Altschuler, R.A., 2005. Deafness-related plasticity in the inferior colliculus: gene expression profiling following removal of peripheral activity. J. Neurochem. 93, 1069-1086. doi:10.1111/j.14714159.2005.03090.x

Hondo, H., Yonezawa, Y., Nakahara, T., Nakamura, K., Hirano, M., Uchimura, H., Tashiro, N., 1994. Effect of phenycyclidine on dopamine release in the rat prefrontal cortex; an in vivo microdialysis study. Brain Res. 633, 337-342. doi:10.1016/0006-8993(94)91558-X

Honey GD, Honey RA, O'Loughlin C, Sharar SR, Kumaran D, Suckling J, Menon DK, Sleator C, Bullmore ET, Fletcher PC (2005) Ketamine disrupts frontal and hippocampal contribution to encoding and retrieval of episodic memory: an fMRI study. Cereb Cortex 15:749-759.

Honey RA, Honey GD, O'Loughlin C, Sharar SR, Kumaran D, Bullmore ET, Menon DK, Donovan T, Lupson VC, Bisbrown-Chippendale R, Fletcher PC (2004) Acute ketamine administration alters the brain responses to executive demands in a verbal working memory task: an FMRI study. Neuropsychopharmacology : official publication of the American College of Neuropsychopharmacology 29:1203-1214.

Hurd YL, Suzuki M, Sedvall GC (2001) D1 and D2 dopamine receptor mRNA expression in whole hemisphere sections of the human brain. J Chem Neuroanat 22: 127-137.

Imre G, Fokkema DS, Den Boer JA, Ter Horst GJ (2006) Dose-response characteristics of ketamine effect on locomotion, cognitive function and central neuronial activity. Brain research bulletin 69:338-345.

Izquierdo I (1994) Pharmacological evidence for a role of long-term potentiation in memory. FASEB J. Nov;8(14):1139-45.

Jane JA Masterton RB \& Diamond IT (1965) The function of the tectum for attention to auditory stimuli in the cat. J. Comp. Neurol., 125: 165-191

Jansen K (2004) Ketamine: Dreams and Realities. Sarasota, FL, USA.: Multidisciplinary Association for Psychedelic Studies (MAPS).

Javitt, D.C., Balla, A., Burch, S., Suckow, R., Xie, S., Sershen, H., 2003. Reversal of Phencyclidine-Induced Dopaminergic Dysregulation by N-Methyl-D-Aspartate Receptor/Glycine-site Agonists. Neuropsychopharmacology 29, 300-307. 
Kawamura S, Sprague JM, Niimi K (1974) Corticofugal projections from the visual cortices to the thalamus, pretectum and superior colliculus in the cat. J Comp Neurol 158: 339-362.

Kelly, J.B., Zhang, H., 2002. Contribution of AMPA and NMDA receptors to excitatory responses in the inferior colliculus. Hear. Res., A collection of papers presented at the Symposium on The Inferior Colliculus: From Past To Future 168, 35-42.

Koob GF, Le Moal M (1997) Drug abuse: hedonic homeostatic dysregulation. Science 278:52-58

Koob GF (Jan 03 2017) Antireward, Compulsivity, and Addiction: Seminal Contributions of Dr. Athina Markou to Motivational Dysregulation in Addiction Psychopharmacology (Berl). DOI 10.1007/s00213-016-4484-6

Kos T, Popik P, Pietraszek M, Schafer D, Danysz W, Dravolina O, Blokhina E, Galankin T, Bespalov AY (2006) Effect of 5-HT3 receptor antagonist MDL 72222 on behaviors induced by ketamine in rats and mice. European neuropsychopharmacology : the journal of the European College of Neuropsychopharmacology 16:297-310.

Krystal JH, Karper LP, Seibyl JP, Freeman GK, Delaney R, Bremner JD, Heninger GR, Bowers MB, Jr., Charney DS (1994) Subanesthetic effects of the noncompetitive NMDA antagonist, ketamine, in humans. Psychotomimetic, perceptual, cognitive, and neuroendocrine responses. Archives of general psychiatry 51:199-214.

Lahti AC, Koffel B, LaPorte D, Tamminga CA (1995) Subanesthetic doses of ketamine stimulate psychosis in schizophrenia. Neuropsychopharmacology : official publication of the American College of Neuropsychopharmacology 13:9-19.

Lamprea MR, Cardenas FP, Vianna DM, Castilho VM, Cruz-Morales SE, Brandao ML (2002) The distribution of fos immunoreactivity in rat brain following freezing and escape responses elicited by electrical stimulation of the inferior colliculus. Brain Res 950: 186194.

Lang PJ (1998) Bradley, M.M. \& Cuthbert, B.N. 1998. Emotion, motivation, and anxiety: brain mechanisms and psychophysiology. Biol. Psychiatry, 44: 1248-1263.

Lankenau SE, Sanders B (2007) Patterns of ketamine use among young injection drug users. J Psychoactive Drugs 39:21-29.

Lankenau SE, Sanders B, Bloom JJ, Hathazi DS, Alarcon E, Tortu S, Clatts M (2007) Prevalence and Patterns of Prescription Drug Misuse among Young Ketamine Injectors. Journal of drug issues 37:717-736.

LeDoux JE, Cicchetti P, Xagoraris A, Romanski LM (1990) The lateral amygdaloid nucleus: sensory interface of the amygdala in fear conditioning. J Neurosci 10: 1062-1069. 
LeDoux JE, Ruggiero DA, Forest R, Stornetta R, Reis DJ (1987) Topographic organization of convergent projections to the thalamus from the inferior colliculus and spinal cord in the rat. J Comp Neurol 264: 123-146.

LeDoux JE, Ruggiero DA, Reis DJ (1985) Projections to the subcortical forebrain from anatomically defined regions of the medial geniculate body in the rat. J Comp Neurol 242: 182-213.

Léveillé F, E Gaamouch F, Gouix E, Lecocq M, Lobner D, Nicole O, Buisson A. (2008) Neuronial viability is controlled by a functional relation between synaptic and extrasynaptic NMDA receptors FASEB J. Dec;22(12):4258-71. doi: 10.1096/fj.08-107268. Epub 2008 Aug 18.

Li, L, Korngut LM Frost BJ \& Beninger RJ 1998 Prepulse inhibition following lesions of the inferior colliculus: prepulse intensity functions. Physiol. Behav., 65: 133- 139.

Liao Y, Tang J, Corlett PR, Wang X, Yang M, Chen H, Liu T, Chen X, Hao W, Fletcher PC (2011) Reduced dorsal prefrontal gray matter after chronic ketamine use. Biological psychiatry 69:42-48.

Li, L., Yue, Q., 2002. Auditory gating processes and binaural inhibition in the inferior colliculus. Hear. Res., A collection of papers presented at the Symposium on The Inferior Colliculus: From Past To Future 168, 98-109. doi:10.1016/S0378-5955(02)00356-8

Lodge, D., Mercier, M.S., 2015. Ketamine and phencyclidine: the good, the bad and the unexpected. Br. J. Pharmacol. 172, 4254-4276. doi:10.1111/bph.13222

Long, K.J., Allen, N., 1984. Abnormal brain-stem auditory evoked potentials following Ondine's curse. Arch Neurol 41, 1109-10.

Long KJ, Allen N (1984) Abnormal brain-stem auditory evoked potentials following Ondi ne's curse. Arch Neurol 41:1109-1110.amino acid currents in cultured neurons by ketamine. J. Neurophysiol. 58, 251-266.

Ma, C.L., Kelly, J.B., Wu, S.H., 2002. AMPA and NMDA receptors mediate synaptic excitation in the rat's inferior colliculus. Hear. Res. 168, 25-34. doi:10.1016/S03785955(02)00370-2

MacDonald, J.F., Miljkovic, Z., Pennefather, P., 1987. Use-dependent block of excitatory amino acid currents in cultured neurons by ketamine. J. Neurophysiol. 58, 251-266.

Maisonnette SS, Kawasaki MC, Coimbra NC, Brandao ML (1996) Effects of lesions of amygdaloid nuclei and substantia nigra on aversive responses induced by electrical stimulation of the inferior colliculus. Brain Res Bull 40: 93-98.

Malhotra, A.K., Pinals, D.A., Adler, C.M., Elman, I., Clifton, A., Pickar, D., Breier, A., 1997. Ketamine-Induced Exacerbation of Psychotic Symptoms and Cognitive Impairment in Neuroleptic-Free Schizophrenics. Neuropsychopharmacology 17, 141-150.

doi:10.1016/S0893-133X(97)00036-5

Mansbach RS, Geyer MA (1991) Parametric determinants in pre-stimulus modification of acoustic startle: interaction with ketamine. Psychopharmacology 105:162-168. 
Mark RG, Hall RD (1967) Acoustically evoked potentials in the rat during conditioning. Journal of neurophysiology 30:875-892.

Martins ERC, Corrêa, AK (2004) Lidar com substâncias psicoativas: o significado para o trabalhador de enfermagem. Revista Latino-americana de Enfermagem, Ribeirão Preto, v. 12,15 .

Maxwell CR, Ehrlichman RS, Liang Y, Trief D, Kanes SJ, Karp J, Siegel SJ.(2006) Ketamine produces lasting disruptions in encoding of sensory stimuli. J Pharmacol Exp Ther. Jan;316(1):315-24. Epub 2005 Sep 28.

Melo LL \& Brandão ML (1995) Role of 5-HT1A and 5HT2 receptors in the aversion induced by eletrical stimulation of inferior colliculus. Pharmacology, biochemistry, and behavior, 51, 317-321.

Micallef, J., Guillermain, Y., Tardieu, S., Hasbroucq, T., Possamaï, C., Jouve, E., Blin, O., 2002. Effects of subanesthetic doses of ketamine on sensorimotor information processing in healthy subjects. Clin. Neuropharmacol. 25, 101-106.

Moore JK Karapas F \& Moore RY (1977). Projections of the inferior colliculus in insectivores and primates. Brain Behav. Evol., 14: 301-327.

Moore RY, Goldberg JM (1963) Ascending projections of the inferior colliculus in the monkeys. Experimental Neurology 121: 109-136.

Morest DK, Oliver DL (1984) The neuronial architecture of the inferior colliculus in the cat: defining the functional anatomy of the auditory midbrain. J Comp Neurol 222: 209-236.

Moreton, J.E., Meisch, R.A., Stark, L., Thompson, T., 1977. Ketamine self-administration by the rhesus monkey. J. Pharmacol. Exp. Ther. 203, 303-309.

Morgan CJ, Curran HV (2006) Acute and chronic effects of ketamine upon human memory: a review. Psychopharmacology 188:408-424.

Morgan CJ, Curran HV (2012) Ketamine use: a review. Addiction 107:27-38.

Morgan CJ, Muetzelfeldt L, Curran HV (2010) Consequences of chronic ketamine selfadministration upon neurocognitive function and psychological wellbeing: a 1-year longitudinal study. Addiction 105:121-133.

Moriizumi T, Hattori T (1991) Pallidotectal projection to the inferior colliculus of the rat. Exp Brain Res 87: 223-226.

Morrow BA, Elsworth JD, Rasmusson AM, Roth RH (1999) The role of mesoprefrontal dopamine neurons in the acquisition and expression of conditioned fear in the rat. Neuroscience 92: 553-564. 
Muetzelfeldt L, Kamboj SK, Rees H, Taylor J, Morgan CJ, Curran HV (2008) Journey through the K-hole: phenomenological aspects of ketamine use. Drug and alcohol dependence 95:219-229.

Muthuraju S, Nobre MJ, Saito VM, Brandao ML (2014) Distinct effects of haloperidol in the mediation of conditioned fear in the mesolimbic system and processing of unconditioned aversive information in the inferior colliculus. Neuroscience 261:195-206.

Neill JC, Barnes S, Cook S, Grayson B, Idris NF, McLean SL, Snigdha S, Rajagopal L, Harte MK (2010) Animal models of cognitive dysfunction and negative symptoms of schizophrenia: focus on NMDA receptor antagonism. Pharmacology \& therapeutics 128:419-432.

Newcomer, J.W., Farber, N.B., Jevtovic-Todorovic, V., Selke, G., Melson, A.K., Hershey, T., Craft, S., Olney, J.W., 1999. Ketamine-Induced NMDA Receptor Hypofunction as a Model of Memory Impairment and Psychosis. Neuropsychopharmacology 20, 106-118. doi:10.1016/S0893-133X(98)00067-0

Ninan, I., Jardemark, K.E., Wang, R.Y., 2003. Olanzapine and clozapine but not haloperidol reverse subchronic phencyclidine-induced functional hyperactivity of $\mathrm{N}$-methyl-D-aspartate receptors in pyramidal cells of the rat medial prefrontal cortex. Neuropharmacology 44, 462472. doi:10.1016/S0028-3908(03)00033-9

Nobre MJ (2013) Changes on auditory physiology in response to the inactivation of amygdala nuclei in high anxiety rats expressing learned fear. Physiology \& behavior 118:8087.

Nobre MJ, Cabral A, Brandao ML (2010) GABAergic regulation of auditory sensory gating in low- and high-anxiety rats submitted to a fear conditioning procedure. Neuroscience 171:1152-1163.

Nobre MJ, Lopes MG, Brandao ML (2004) Defense reaction mediated by NMDA mechanisms in the inferior colliculus is modulated by GABAergic nigro-collicular pathways. Brain research 999:124-131.

Nobre MJ, Sandner G, Brandao ML (2003) Enhancement of acoustic evoked potentials and impairment of startle reflex induced by reduction of GABAergic control of the neural substrates of aversion in the inferior colliculus. Hearing research 184:82-90.

O'Donnell P, Grace AA. (1998) Dysfunctions in multiple interrelated systems as the neurobiological bases of schizophrenic symptom clusters. Schizophr Bull.;24(2):267-83.

Osen K (1973) Organization fo cat cochlear nuclei and projection of inferior colliculus. Arch Otolaryngol 98: 401-404.

Owolabi RA, Akanmu MA, Adeyemi OI (2014). Effects of ketamine and N-methyl-Daspartate on fluoxetine-induced antidepressant-related behavior using the forced swimming test. Neurosci Lett. 2014 Apr 30;566:172-6. doi: 10.1016/j.neulet.2014.01.015. 
Oye I, Paulsen O, Maurset A (1992) Effects of ketamine on sensory perception: evidence for a role of N-methyl-D-aspartate receptors. The Journal of pharmacology and experimental therapeutics 260:1209-1213.

Ozawa S, Kamiya H, Tsuzuki k (1998) Glutamate receptor in mammalian central nervous system. Progress in Neurobiology 54:581-618.

Paxinos GW, C. (2008) The Rat Brain in Stereotaxic Coordinates. New York: Academic Press.

Pollak GD, Burger RM, Klug A (2003) Dissecting the circuitry of the auditory system. Trends Neurosci 26: 33-39.

Popper, AN \& Fay RR (1997) Evolution of the ear and hearing: issues and questions. Brain Behav. Evol., 50: 213-221.

Rabiner EA (2007) Imaging of striatal dopamine release elicited with NMDA antagonists: is there anything there to be seen? J Psychopharmacol 21:253-258.

Robinson TE, Berridge KC (2003) Addiction. Annu Rev Psychol. 54:25- 53.

Roth GL, Aitkin LM, Andersen RA, Merzenich MM (1978) Some features of the spatial organization of the central nucleus of the inferior colliculus of the cat. J Comp Neurol 182: 661-680.

Sandner G, Canal NM, Brandao ML (2002) Effects of ketamine and apomorphine on inferior colliculus and caudal pontine reticular nucleus evoked potentials during prepulse inhibition of the startle reflex in rats. Behav Brain Res 128: 161-168.

Shahani R, Streutker C, Dickson B, Stewart RJ (2007) Ketamine-associated ulcerative cystitis: A new clinical entity. Urology 69:810-812.

Shepherd JK, Grewal SS, Fletcher A, Bill DJ, Dourish CT (1994) Behavioural and pharmacological characterisation of the elevated "zero-maze" as an animal model of anxiety. Psychopharmacology 116:56-64.

Shergill SS, Brammer MJ, Williams SC, Murray RM, McGuire PK (2000) Mapping auditory hallucinations in schizophrenia using functional magnetic resonance imaging. Archives of general psychiatry 57:1033-1038.

Szczepaniak WS, Moller AR (1995) Evidence of decreased GABAergic influence on temporal integration in the inferior colliculus following acute noise exposure: a study of evoked potentials in the rat. Neuroscience letters 196:77-80.

Smith MK, Larive LL, Romanelli F (2002) Club drugs: methylenedioxymethamphetamine, Flunitrazepam, ketamine hydrochloride, and $\gamma$-hydroxybutyrate. Am J Health-Syst Pharm, v.59, p.1067- 1076 . 
Tobias JD (2000) Tolerance, withdrawal, and physical dependency after long-term sedation and analgesia of children in the pediatric intensive care unit. Critical care medicine 28:21222132.

Tokunaga A, Sugita S, Otani K (1984) Auditory and non-auditory subcortical afferents to the inferior colliculus in the rat. J Hirnforsch 25: 461-472.

Tricklebank MD, Singh L, Oles RJ, Preston C, Iversen SD (1989) The behavioural effects of MK-801: a comparison with antagonists acting non-competitively and competitively at the NMDA receptor. European journal of pharmacology 167:127-135.

Troncoso AC, Osaki MY, Mason S, Borelli KG, Brandao ML (2003) Apomorphine enhances conditioned responses induced by aversive stimulation of the inferior colliculus. Neuropsychopharmacology 28: 284-291.

Umbricht, D., Schmid, L., Koller, R., Vollenweider, F.X., Hell, D., Javitt, D.C., 2000. Ketamine-Induced Deficits in Auditory and Visual Context-Dependent Processing in Healthy Volunteers: Implications for Models of Cognitive Deficits in Schizophrenia. Arch. Gen. Psychiatry 57, 1139-1147. doi:10.1001/archpsyc.57.12.1139

Vertes RP (2006) Interactions among the medial prefrontal cortex, hippocampus and midline thalamus in emotional and cognitive processing in the rat. Neuroscience. Sep 29;142(1):120 .

Wamsley JK, Gehlert DR, Filloux FM, Dawson TM (1989) Comparison of the distribution of D-1 and D-2 dopamine receptors in the rat brain. J Chem Neuroanat 2: 119-137.

Winer JA \& Schreiner CE (2005) The Inferior Colliculus. Springer, New York.

Woolard HH, Harpman JA (1940) The Connections of the inferior colliculus and the dorsal nucleus of lateral lemniscus. Journal of Anatomy 74: 458.

Wynne, B., Harvey, A.R., Robertson, D., Sirinathsinghji, D.J.S., 1995. Neurotransmitter and neuromodulator systems of the rat inferior colliculus and auditory brainstem studied by in situ hybridization. J. Chem. Neuroanat. 9, 289-300. doi:10.1016/0891-0618(95)00095-X 
8. ANEXOS 
Systemic dopamine and cortical glutamate receptors modulate the rebound excitation of collicular auditory evoked potentials elicited in rats under ketamine withdrawal

Roberta Monteiro Incrocci $^{b, c}$ and Manoel Jorge Nobre ${ }^{a, b, c}$

a Departamento de Psicologia, Faculdade de Filosofia, Ciências e Letras de Ribeirão Preto, Universidade de São Paulo (USP), 14040-901 Ribeirão Preto, SP, Brasil.

${ }^{b}$ Departamento de Psicologia, Uni-FACEF, 14401-135, Franca, SP, Brasil.

c Instituto de Neurociências e Comportamento-INeC, Campus USP, 14040-901 Ribeirão Preto, SP, Brasil.

Corresponding author: M.J. Nobre

Laboratório de Psicobiologia, Faculdade de Filosofia, Ciências e Letras de Ribeirão Preto, Universidade de São Paulo, Av. Bandeirantes, 3900, 14090-901, Ribeirão Preto, SP, Brasil.

Phone: 551636023788

Fax: 551636024830

E-mail: mjnes@usp.br 


\section{INTRODUCTION}

Due to its reinforcing and rewarding properties, the non-medical use of ketamine has grown progressively worldwide in the past decades, with the drug becoming increasingly popular among youths, especially clubbers and ravers. Ketamine is a non-competitive NMDA receptors antagonist and a dissociative anesthetic that shares the ability to intensify sensory experiences (Dillon et al., 2003). Similar to other non-competitive N-methyl-Daspartate glutamate receptors (NMDA) antagonists, like phencyclidine and MK-801, ketamine is commonly used as an experimental model of schizophrenia in clinical and preclinical studies (Geyer, 1998). Ketamine also increases the psychotic state of schizophrenic patients (Lahti et al., 1995). Besides to alter behavioral and cognitive functions (Malhotra et al., 1997; Micallef et al., 2002; Umbricht et al., 2000), the acute administration of ketamine has also the ability to induce physiological auditory evoked potentials (AEPs) changes consistent with schizophrenia (Maxwell et al., 2006).

Ketamine administration elicits sensory and motor disturbances, memory deficits (Imre et al., 2006; Kos et al., 2006), hypermotility (Carlsson, 1993), stereotyped behavior and ataxia (Tricklebank et al., 1989). Similar to other NMDA receptor antagonists, ketamine prompts hallucinations and delusions, exacerbates previous installed psychosis (Krystal et al., 1994; Moghaddam and Krystal, 2012), and has the ability to produce neurological and peripheral toxicity (Gable, 2004; Morgan et al., 2010). In addition, NMDA antagonists, including ketamine, disturb coherent personality by inducing sensory overload through breaking homeostasis of sensory-motor gating processes (Mansbach and Geyer, 1989; Maxwell et al., 2006; Sandner et al., 2002). For example, ketamine changes the reactivity of several brain regions to a variety of sensory inputs including the auditory ones, despite the drug does not promote exactly a true sensory blockade, an effect that has been called "dissociative" anesthesia (Domino et al., 1965).

From the auditory system, the inferior colliculus (IC) is a midbrain region reputed to be one of the most important. For example, sound localization and the prepulse inhibition (PPI) of the startle reflex, which is considered a model of sensorimotor gating (Braff and Geyer, 1990; Fendt et al., 2001; Li and Yue, 2002) being detected even in decerebrate rats (Li and Frost, 2000), are highly modulated in the IC ( $\mathrm{Li}$ and Yue, 2002). In addition, preattentive event-related potentials such as mismatch negativity is also dependent from collicular auditory mechanisms (Patel et al., 2012). Deficits on these mechanisms are frequently observed following systemic or local infusion of NMDA antagonists, including 
ketamine, showing that unconscious auditory attentional processes are modulated by glutamatergic neurotransmission at this midbrain level.

Pharmacologically, ketamine stimulates specific neurons to release dopamine (Farber et al., 2002), an effect probably associated with its potential of abuse. Brain dopamine concentration was found to be increased in rat brain tissue after chronic intraperitoneal infusion of ketamine from lower to higher doses ( $\mathrm{Li}$ et al., 2015). The rewarding effects of ketamine has been demonstrated in several animal models including the conditioned place preference (Suzuki et al., 2000; van der Kam et al., 2009) and selfadministration procedures (Caffino et al., 2016; Venniro et al., 2015). Importantly, besides the well-known antagonistic action of ketamine on NMDA receptors, the drug also acts enhancing the GABA inhibitory neurotransmission in the central nervous system (Irifune et al., 2000). However, despite all these finds, little is known about the impact of the repeated use of ketamine on the neural pharmacology and physiology of auditory gating. In addition, ketamine dependence or a possible withdrawal syndrome following the interruption of its chronic use, as well as the dose regimen to promote it, are questions not defined yet. Therefore, taking into account that ketamine disrupts the midbrain auditory gating, mainly through NMDA receptors hypofunction, and bearing in mind that the IC plays a role on the processing of auditory sensory information, the aim of the study was to assess the effects of ketamine on the latency and amplitude of AEPs elicited in the IC of rats tested during ketamine effects and following withdrawal from chronic administration. In this study, the chronic method of daily ketamine injections was selected to model chronic ketamine abuse, as usually seen in humans.

In humans, one of the brain regions most affected by ketamine is the prefrontal cortex, particularly its medial (PrL) and ventral (IL) regions (Holcomb et al., 2001). Human studies have been showed that the performance in tasks that is related to prefrontal activity is strongly affected by acute ketamine (Honey et al., 2004, Honey et al., 2005), comparable to those found in schizophrenic patients (Neill et al., 2010). The NMDA receptors antagonism may led to changes on normal activity of several brain regions, including the medial prefrontal cortex (O’Donnell and Grace, 1998). Efferents from this region exert a top-down regulatory control of other structures either directly or indirectly (Floresco et al., 2009; Vertes, 2004). In the midbrain, the IC plays an important role on the auditory sensory gating. As an example, auditory hallucinations elicited during psychotic outbreak are accompanied by IC neural activation (Shergill et al., 2000). Therefore, it is possible that 
glutamate neurotransmission in the prefrontal cortex, mainly the prelimbic region (PrL) using NMDA itself indirectly modulates IC neuronial firing. Finally, unlike typical neuroleptics, the atypical antipsychotic clozapine (CLZ) potently blocks the disruption of the sensorimotor gating induced by NMDA antagonists (Bakshi et al., 1994). Therefore, the effects of ketamine on AEPs were challenged with a systemic injection of CLZ. Possible changes on emotionality induced by chronic ketamine were evaluated with the use of the elevated zero maze (EZM)

\section{MATERIALS AND METHODS}

\subsection{Animals and housing conditions}

In this study, we used 96 new-born male Wistar rats from the campus of Ribeirão Preto, University of São Paulo. The (weaned) animals were three weeks old, weighing $50 \pm 10 \mathrm{~g}$, at the beginning of the experiments. They were provided with food and water ad libitum and maintained in a colony in a temperature-controlled $\left(24 \pm 1^{\circ} \mathrm{C}\right)$ room, under a 12:12 h light-dark cycle (lights on at 7 a.m.). The present study was conducted under the guidelines of the US National Institute of Health: Guide for the Care and Use of Laboratory Animals (NIH Publications, 8th Edition, 2010). The number of animals used was the minimum required to allow for the reliability of the results. In keeping with accepted practice, every effort was made to minimise animal stress and suffering.

\subsection{Surgery}

The animals underwent surgical implantation of electrode assemblies. They were intraperitoneally anesthetized with a mix of $100 \mathrm{mg} / \mathrm{kg}$ ketamine $/ 4.5 \mathrm{mg} / \mathrm{kg}$ xylazine (Agener, Brazil) and fixed in a digital stereotaxic frame. Lidocaine $(20 \mathrm{mg} / \mathrm{ml}, 1 \mathrm{ml})$ was injected around the surgical field as a local complement to general anesthesia. For recording of the extracellular field potentials, one bipolar twisted electrode (12.0 mm length), made of stainless steel enameled wires (Plastic-One products, Roanoke, VA, USA), $150 \square \mathrm{m}$ in diameter, insulated except at the cross section of the tip, was aimed at the CIC (8.6 posterior, \pm 1.5 lateral, -4.0 deep relative to bregma). The assembly was fixed to the skull by means of acrylic resin and the three stainless steel screws. 


\subsection{Experimental box}

An experimental cage (external dimensions: $19 \times 9 \times 9 \mathrm{~cm}$; internal dimensions: 16 $\times 6 \times 7 \mathrm{~cm}$ ), located inside a Faraday insulated system and surrounded by a ventilated plywood sound-attenuating chamber $(64 \times 60 \times 40 \mathrm{~cm})$, was used. A $7.5 \mathrm{~W}$ red bulb at the top of the testing box was switched on during the experimental sessions. The floor of the cage consisted of six $3.0 \mathrm{~mm}$ diameter stainless steel bars spaced $1.5 \mathrm{~mm}$ apart. A loudspeaker, located $10 \mathrm{~cm}$ behind the cage, delivered continuous background noise $(55 \mathrm{~dB}$ sound pressure level). Software and an appropriate interface (Lynx, São Paulo, Brazil) controlled the presentation and sequencing of the acoustic stimuli. Sound pressure levels were measured at the level of the ears of the animals using a 0.125-inch microphone and a type 2636 measuring amplifier DK-2580 (Bruel and Kjaer, Naerum, Denmark).

Acoustic stimuli, presented at a rate of $0.33 \mathrm{~Hz}$, were delivered via two piezoelectric speakers (12 $\Omega, 200 \mathrm{~W}$, LeSon, Brazil) mounted on the lateral walls of the sound-insulating box, $15 \mathrm{~cm}$ from the wire-mesh cage. Stimuli were pure tone clicks (50 ms duration; 3000 $\mathrm{Hz}$ square-wave pulses) with $105 \mathrm{~dB}$ sound pressure level (SPL). The animals were previously habituated to the behavioral restraining promoted by the experimental cage, that limited their movements except for a small gap, until that the aversive effects of the restriction ceased. The experimental cage was placed in the middle of Faraday cage, centered exactly between the two piezoelectric speakers in order to ensure equivalent sensitivities during sessions.

\subsection{Measuring collicular auditory-evoked potentials (AEP)}

The ketamine administration and AEP recording parameters were comparable to previous studies (Maxwell et al., 2006; Nobre, 2013). The very small electrical voltage AEPs were recorded from electrodes unilaterally implanted in the central nucleus of the inferior colliculus. These AEPs occur in response to a repetitive stimulus along a specific brainstem auditory pathway, which are well-known to reflect neuronial activity in the auditory complex, mainly in the cochlear nucleus, superior olive, and IC (Long and Allen, 1984). Stimuli were generated and controlled by a biological data-acquisition system (Sysdin, Lynx, São Paulo, Brazil). The average value was obtained at the end of the sessions. AEP were recorded after each of the 100 auditory stimuli as the voltage difference between the tips of a bipolar insulated wire electrode $(150 \mu \mathrm{m})$. This voltage difference was fed into an amplifier (Lynx, TX001, bandwidth set to 20-200 Hz) through two noiseless shielded cables (passed 
through a hole in the roof of the Faraday cage). The output of the amplifier was connected to an analog/digital converter (CAD 12/36) plugged into a microcomputer. Filtering, amplification, and digitalization of the signals were performed with the Sysdin system (Lynx, São Paulo, Brazil). The potential signals were sampled at a rate of $0.33 \mathrm{kHz}$ and filtered (high-pass filter, $20 \mathrm{~Hz}$; low-pass filter, $200 \mathrm{~Hz}$ ). Sysdin software was programmed to sum up individual AEP amplitudes. The data-acquisition sweep began $10 \mathrm{~ms}$ before the onset of the sound stimulus (latency to switch on the sound plus sound propagation) and continued until $200 \mathrm{~ms}$ after termination of the sound stimulus. During the recording, animals were monitored via a camera system placed in the experimental room. The positive peak P1 is considered an early component of the collicular response. Its amplitude is measured peak to peak, with peak latency between 5 and 10 msec (Hall and Mark, 1967; Mark and Hall, 1967). The AEP elicited from the CIC were recorded from the ventro-caudal portions of the nucleus. This way of analysis is similar to that observed in previous studies of our and other laboratories that used similar protocols (Hall and Mark, 1967; Mark and Hall, 1967; Nobre et al., 2010, 2003; Szczepaniak and Moller, 1995). Peak amplitudes were defined as the maximum amplitude measured between N1 and the end of P1, similar as other previous studies of our laboratory (Brandao et al., 2005, 2001a; Nobre et al., 2003). This set of data was monitored on the computer screen. The computer output was graphically displayed on an XY plotter (Hewlett-Packard 1100, Palo Alto, CA, USA). AEP data were stored on a computer hard disk and transferred to Microsoft Excel (Microsoft Corp., Mountain View, CA, USA) tables for off-line visualization and analysis.

\subsection{Changes in anxiety induced by chronic ketamine}

For this purpose, the elevated zero maze (EZM) was used. This apparatus consisted of a custom-made Plexiglas circular runaway that were $10 \mathrm{~cm}$ wide $(95 \mathrm{~cm}$ diameter $\times 50$ $\mathrm{cm}$ height), equally divided into two open ( $1 \mathrm{~cm}$ walls) and two enclosed arms $(50 \mathrm{~cm}$ walls $)$. Trials were conducted under 100 lux luminosity during five minutes. In this study seven animals of each group were used. Each rat was tested only once. The animals were placed individually in one of the closed arms and were allowed five minutes of free exploration. The choice of the EZM as the major predictor of anxiety-like behavior was made to avoid ambiguity in the interpretation of the time spent in the central square of the traditional elevated-plus design, allowing uninterrupted exploration (Kulkarni et al., 2007). Behavioural data from the EZM were inputted to hard disc for later analysis using a digital 
video camera system. Experimental sessions were conducted between 4p.m. and 6p.m. The maze was cleaned with $20 \%$ ethanol and deionised water before each test.

\subsection{Drugs}

The following drugs were used: Ketamine chloridrate $(20,40$, and $80 \mathrm{mg} / \mathrm{kg}$ s.c. Agener, Brasil), the typical antipsychotic Clozapine (10 mg/kg i.p. - Sigma-Aldrich, USA). Physiological saline served as vehicle control for IP injections. The dose of clozapine used was based on the study of Chatterjee et al. (2011).

\subsection{Experimental procedure}

The method for chronic ketamine administration used in our study (14 daily and repeated intraperitonial injections) was selected to model the procedure that is usually employed by ketamine abuser, where individuals self-administer acute doses continually over time. Starting at one day after surgery, the animals were daily handled for $10 \mathrm{~min}$ and later submitted to a single daily subcutaneous injection of one of the doses of ketamine, during fourteen days. After each injection, the animals returned to the home cage until the next day. In the day fourteen, immediately after the last ketamine administration, each rat was placed in the testing cage, inside the experimental chamber, and was connected to the recording system. The animals were allowed an additional 10 min period of habituation in the enclosure. Ended this period AEP recordings began. Clozapine (Leponex, Novartis, Brazil) was obtained in a commercial form. It was dissolved with physiological saline solution $(0.9 \%$ sodium chloride), to obtain the required concentration of $10 \mathrm{mg} / \mathrm{ml}$ in a volume of $1 \mathrm{ml} / \mathrm{kg}$ body weight. Solution was cleaned with a syringe filter (Whatman GD/XP filter nylon $0.45 \mathrm{~mm}$, Maidstone, UK). Clozapine was administered 25 minutes before ketamine injection.

\subsection{Histology}

Upon completion of the experiments, the animals were deeply anaesthetized with urethane and perfused intracardially with saline $0.9 \%$ followed by formalin solution (4\%). Seven days later the brains were frozen. Serial $60 \square \mathrm{m}$ frontal brain sections were stained in order to localize the actual recording sites, which were drawn on corresponding planes of the Paxinos and Watson atlas (1997).

\subsection{Statistical Analysis}


The waves of the auditory evoked potentials (AEPs) were labeled as in previous works (Bagri et al., 1989; Brandao et al., 2005, 2001b; Nobre, 2013). Data are reported as means \pm SEM. Drug effects on the on the latency for the first negative (N1) and the second positive wave (P1), and on the amplitude of AEP was analyzed through a two-way repeated measures ANOVA in a treatments $\mathrm{x}$ time schedule design. Follow-up comparisons were made with the one-way ANOVA. When necessary, comparisons between group treatments were performed with the Student T-test (bicaudal). Significance level was set at $\mathrm{p}<0.05$.

\section{RESULTS}

A microphotograph of a representative injection site is shown in the first panel of figure 1. The locations of the electrodes implanted in the IC are depicted in the remaining panels. In order to analyze the effects of chronic daily ketamine injections on latency and amplitude of AEPs, two-way ANOVA was used. Statistical analysis showed that ketamine effects or ketamine withdrawal does not change latency, no matter the dose used (N1: $\left.F_{3,98}=1,66 ; p=0,08, P 1: F_{3,98}=1,90 ; p=0,21\right)$. Rats tested under ketamine effects $\left(F_{3,31}=1,059\right.$; $\mathrm{p}=0.38$ ) showed no changes on the amplitude of AEPs. After 24-hours withdrawal, AEPs significantly changed $\left(\mathrm{F}_{3,27}=3,52 ; \mathrm{p}<0.03\right)$. The same was found after 6 days after ended ketamine treatment $\left(\mathrm{F}_{3,32}=6,14 ; \mathrm{p}<0.002\right)$. Follow-up analysis with Student $\mathrm{T}$-test for comparisons between drug treatment and controls revealed that 20 and $80 \mathrm{mg} / \mathrm{kg}$ of ketamine decreases AEPs on 24-hours withdrawal. In addition, control AEPs is significantly enhanced at this point and this the reason why $40 \mathrm{mg} / \mathrm{kg}$ ketamine seems to decrease this measure. Six days after, a rebound enhancement on AEPs amplitude induced by 20 and $80 \mathrm{mg} / \mathrm{kg}$ ketamine is noted. The influence of clozapine on the effects of ketamine on latency was absent $\left(\mathrm{N} 1: \mathrm{F}_{4,67}=1,35 ; \mathrm{p}=0.25, \mathrm{P} 1: \mathrm{F}_{4,67}=2,51 ; \mathrm{p}=0.14\right)$, despite the histograms showed a tendency of clozapine to enhance the influence of $80 \mathrm{mg} / \mathrm{kg}$-ketamine on P1-latency. AEPs was selectively affected by clozapine. Changes within groups were absent by ketamine $\left(\mathrm{F}_{4,35}=2,18 ; \mathrm{p}=0.09\right)$ and ketamine withdrawal $\left(\mathrm{F}_{4,33}=1,98 ; \mathrm{p}=0.12\right)$. However, clozapine enhanced the AEPs amplitude of controls and ketamine $20 \mathrm{mg} / \mathrm{kg}$ groups, tested on 24-hours withdrawal period. NMDA antagonism on IC showed no influence on N1 $\left(F_{4,56}=0,844.85\right.$; $\mathrm{p}=0.51)$ or $\mathrm{P} 1\left(\mathrm{~F}_{4,56}=1,20 ; \mathrm{p}=0.63\right)$ latency. ANOVA detected significant changes on AEPs $\left(F_{4,59}=6,68 ; p<0.005\right)$. These differences were mainly due to decreases on AEPs when the antagonist was challenged with ketamine effects. In addition, NMDA almost entirely blocked the AEP in 40mg/kg-ketamine group tested on withdrawal. 


\section{DISCUSSION}

The current study analyzed the effects of chronic escalated doses of ketamine, and two different phases of ketamine withdrawal (24 hours and six days after the last injection), on the latency and amplitude of auditory evoked potentials (AEPs) in rats.

In general, drugs of abuse exert their effects through increasing dopamine receptors firing from afferents of the mesenchephalic ventral tegmental area (VTA) functioning that project to limbic areas, mainly the nucleus accumbens (Koob, 1992). In the same way, phencyclidine as well as its synthetic derivative ketamine have strong psychostimulant effects being able to induce general excitation, paranoia, thinking disturbances, hallucinations and an overall psychosis-like symptoms that resemble schizophrenia (Lodge and Mercier, 2015). Ketamine has the ability to significantly increase the extracellular levels and metabolite rates of dopamine in the medial prefrontal cortex (Hondo et al., 1994) and nucleus accumbens (Carboni et al., 1989). Besides, it was suggested that NMDA glutamate receptors seems to exert an inhibitory action into dopamine neurotransmission at this region (Hata et al., 1990). Therefore, taking into account that ketamine is a potent

NMDA antagonist and also acts in dopamine receptors we investigated the influence of the systemic injections of the atypical antipsychotic clozapine and the local intra-PrL infusion of NMDA on the latency and amplitude of AEPs recorded into the central nucleus of the inferior colliculus (cIC). Ketamine per se showed no effect on latency or on the amplitude of collicular AEP, even in the higher dose used. Studies aimed to investigating changes in the auditory system elicited by ketamine is almost non-existent. Therefore, it is not easy to explain the effects of ketamine on the the variables in study.

N-Methyl-d-aspartate receptor antagonists such as ketamine are frequently abused by adolescents, college students, and military and medical personnel (Gahlinger, 2004; Morgan et al., 2004). Although these drugs produce hallucinations and delusions as well as exacerbating preexisting psychosis, several studies have argued that the psychotic and dissociative features are less prominent than the lasting cognitive disruptions (Malhotra et al., 1997; Morgan et al., 2004). Indeed, the nature of these lasting cognitive deficits remains unclear, and few studies have distinguished the effects of ketamine on the multiple phases of information processing. The current study uses auditory evoked potentials (AEPs) to examine the acute, chronic, and lasting effects of ketamine on various phases of sensory 
encoding in mice. In so doing, we will further elucidate the precise phases of information processing during which $\mathrm{N}$-methyl-d-aspartate antagonists affect sensory processing.

Behavioral and cognitive dysfunctions elicited N-methyl-d-aspartate antagonists like ketamine are reputed as relevant models of schizophrenia (Malhotra et al., 1997; Micallef et al., 2002; Umbricht et al., 2000). As such, it has been proposed that the functional reduction of NMDA receptors is symptomatic of the onset of schizophrenia (Greene et al., 2000; Newcomer et al., 1999). Regarding preclinical studies little is known about the lasting effects of ketamine on the role of $\mathrm{N} 1$ and $\mathrm{P} 1$ components on auditory information processing was changed by ketamine (Maxwell et al., 2006, p. 200). Other study using electrodes aimed to the CA3 hippocampal area showed that ketamine changes gating of the human N1, P1 and P2 components (van Berckel et al., 1998). In our study we found we found that ketamine is unable to change N1 or P1 latency. The amplitude of AEPs recorded as the N1/P1 amplitude was found to be insensitive even to the higher dose of ketamine used, as well. In addition, chronic ketamine was unable to induce any change on emotionality, as revealed by the EZM test. This is suggestive for the tolerance to the effects of ketamine on emotional behavior, as discussed elsewhere. Therefore, these results indicate that the behavioral and cognitive dysfunctions elicited by ketamine effects seem to be due to changes in more rostral brain regions. However, the influence of chronic ketamine effects following withdrawal from chronic exposure were visible and significant. In fact, a rebound effect of ketamine interruption was found 6 days after the last injection with the data assuming a U-shaped curve, with the lowest and higher dose used increasing AEPs amplitude and the intermediate dose $(40 \mathrm{mg} / \mathrm{mg})$ reducing this variable.

Located at the dorsal midbrain, the inferior colliculus (IC) is a major auditory structure and the center of integration for the ascending and descending auditory pathways (Casseday and Covey, 1996; Li and Yue, 2002). The IC is divided in three main parts named dorsal, external and central nucleus (cIC) with the cIC receiving the majority of the afferent inputs from the inferior auditory nuclei (Casseday and Covey, 1996). In this midbrain region, both excitatory and inhibitory neurotransmitters are involved in processing of auditory stimuli (Holt et al., 2005; Kelly and Zhang, 2002; Ma et al., 2002; Wynne et al., 1995). Postsynaptic excitatory drives in the cIC are regulated by AMPA and NMDA receptors, with NMDA modulating long-lasting depolarization. Glutamate release is under inhibition of presynaptic $\mathrm{GABA}_{\mathrm{B}}$ receptors. In addition, $\mathrm{GABA}_{\mathrm{A}}$ receptors directly inhibit cIC neurons. Taking this configuration into account is was expected that in our study systemic ketamine 
led to an inhibition of the AEPs recorded in the cIC. Indeed, several evidences pointed out that the excitatory auditory neurotransmission in the cIC is regulated by glutamate and glutamate receptors (Adams and Wenthold, 1979, p. 19; Greenamyre et al., 1984). As an example, Faingold et al. (Faingold et al., 1989) highlighted that in the cIC excitatory amino acids including glutamate and NMDA enhanced increased auditory firing, an effect suppressed by NMDA antagonists. We found that systemic ketamine was not able to decrease collicular AEPs. This may be due to additional effects of ketamine on other receptors than de NMDA ones. Several studies have emphasized that the the high density of GABAergic cells in this structure in the rat suggests the presence of strong inhibitory processes in the IC (Gerken, 1996; Batra and Fitzpatrick, 2002; Merchán et al., 2005; Pollak et al., 2011). Therefore, the interaction of excitatory and inhibitory synapses could determine the pattern of neural activity in cIC. More appropriately, the absence of eletrophysiological effects of ketamine could may be due to pharmacological tolerance. In fact, earlier studies have documented that, following repeated administration, tolerance to ketamine ensues in monkeys, humans and rats (Bree et al., 1967; Cronin et al., 1972; Douglas and Dagirmanjian, 1975). We argue that rebound to this tolerance underlies the increased amplitude of AEPs noted 6 days after ketamine interruption. At this moment, we are not certain about the nature of the U-shaped curve resulted from the escalated doses of ketamine. However, when evaluating different variables with different approaches ketamine response rate was showed to obey an inverted U-shaped function pattern (Moreton et al., 1977). Additional studies focusing on the acute effects of systemic and local (intra-cIC) ketamine in the range of doses used here could clarify this point.

Clozapine is an atypical antipsychotic that shares the ability to act on multiple neural systems. Despite does not directly target glutamatergic receptors, clozapine still showed the ability to modulate the glutamatergic system (Heresco-Levy, 2003) but also have different affinities for dopamine (D1, D2, D3, D4) and serotonin receptors (5-HT2A, 5-HT2C), among others. Also, clozapine is believed to up-regulate NMDA receptors binding (Giardino et al., 1997; Ossowska et al., 1999), facilitates NMDA receptors activity, by affecting glycine at multiple levels (Javitt et al., 2003) and restores NMDA dysfunction induced by phencyclidine (Ninan et al., 2003). Taking this information into account it is expected that clozapine enhances the AEPs elicited in the cIC by blocking ketamine inhibitory effects on NMDA receptors. In fact, in our study clozapine enhanced the collicular AEPs amplitude in rats pre-treated with the lower dose of ketamine $(20 \mathrm{mg} / \mathrm{kg})$. The absence of the effects of 
clozapine in higher doses is believed to be due to the dose of clozapine used. It is supposed that the action of clozapine could involve several pathways. First, through 5-HT2 antagonism; a mechanism associated with the action of atypical antipsychotics. As demonstrated previously, plentiful 5-HT fibers and 5-HT receptors have been found in the IC (Hurley, 2006; Hurley et al., 2002; Peruzzi and Dut, 2004). These findings point out the role of 5-HT on the endogenous modulation of IC neurons. In addition, as described elsewhere, clozapine also shares the ability to modulate glutamate neurotransmission. Taking into account that excitatory amino acids including glutamate and NMDA ligands increase cIC auditory firing, and bearing in mind that this effect is suppressed by NMDA antagonists, it makes sense that the effects of clozapine were to strengthen AEPs.

In humans, one of the brain regions most affected by ketamine is the prefrontal cortex, particularly its medial (PrL) and ventral (IL) regions (Holcomb et al., 2001). For instance, in a study using the resonance imaging technique it was showed that the dissociative effect of ketamine correlated significantly with a reduction in the cortical activity mediated by glutamate (Deakin et al., 2008). Besides, human studies have been showed that the performance in tasks that is related to prefrontal activity is strongly affected by acute ketamine in humans (Honey et al., 2004, Honey et al., 2005), an effect comparable to those found in schizophrenic patients (Neill et al., 2010). The NMDA receptors antagonism may led to changes on normal activity of several brain regions, including the medial prefrontal cortex, among others (O'Donnell and Grace, 1998). This region is an important target since its efferent pathways exert a top-down regulatory control of other structures either directly or indirectly (Floresco et al., 2009; Vertes, 2004). In the midbrain, the IC plays an important role on the auditory sensory gating. As an example, auditory hallucinations elicited during psychotic outbreak are accompanied by IC neural activation (Shergill et al., 2000). Therefore, it is possible that glutamate neurotransmission in the prefrontal cortex indirectly modulates IC neuronial firing. NMDA receptors in the cIC are responsible for the expression of excitatory responses to auditory stimuli and this action is dependent on the concentration of extracellular $\mathrm{Mg}^{2}$ (Cotman and Iversen, 1987). Ketamine, is a non-competitive NMDA antagonist (Anis et al., 1983) that acts by an open channel block mechanism (MacDonald et al., 1987). In our study, administration of NMDA into the PrL reduced the collicular AEPs amplitude of control and ketamine pre-treated rats. The decrease of AEPs in control rats was mainly due to the enhancement of the basal amplitude induced by PBS injection; an effect due to the mechanistic stimulation due microinjection of PBS 
into PrL neurons. This effect dissipated 24 hours later. Thus, the effects of the dose of NMDA used in our study is supposed to challenge only the higher doses of ketamine. However, the overall symptoms evoked by ketamine are related to their ability to antagonize NMDA. Unexpectedly, the local administration into PrL of NMDA itself reduced auditory amplitude, which restores to basal levels on the next day. Systemic exposure to NMDA antagonists like ketamine results in the appearance of psychosis-like symptoms consequent to prefrontal impairments. In this case, it seems that tolerance to ketamine reestablishes AEPs in the cIC. The NMDA receptors agonism in the PrL depress the amplitude of collicular AEPs. This result showed that the auditory gating in the cIC is under indirect control of PrL, since to our knowledge there is no direct connection between Prl and IC. Therefore, our study point out new evidences on the effects of chronic ketamine on behavior, using an electrophysiological measure. In addition, we found that, like other drugs of abuse, changes induced by ketamine is also dependent on some level to dopaminergic and glutamatergic mechanisms.

\section{ACKNOWLEDGMENTS}

This work was supported by FAPESP (Proc. no. 02/03705-0) and CNPq (301069/816). M.J. Nobre is recipient of a doctor scholarship from CAPES. R.M Incrocci holds a master scholarship from CAPES. 
LEGENDS AND FIGURES 


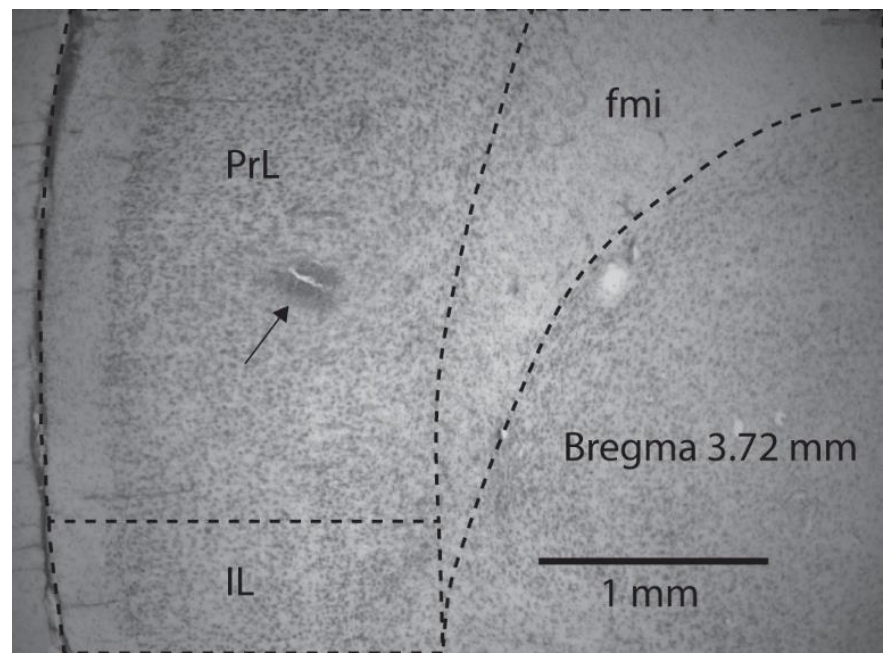

Figure 1. Fotomicrophotograph of a representative site of drug injection in the prelimbic cortex (PrL). fmi- forceps minor, IL- infralimbic cortex. 


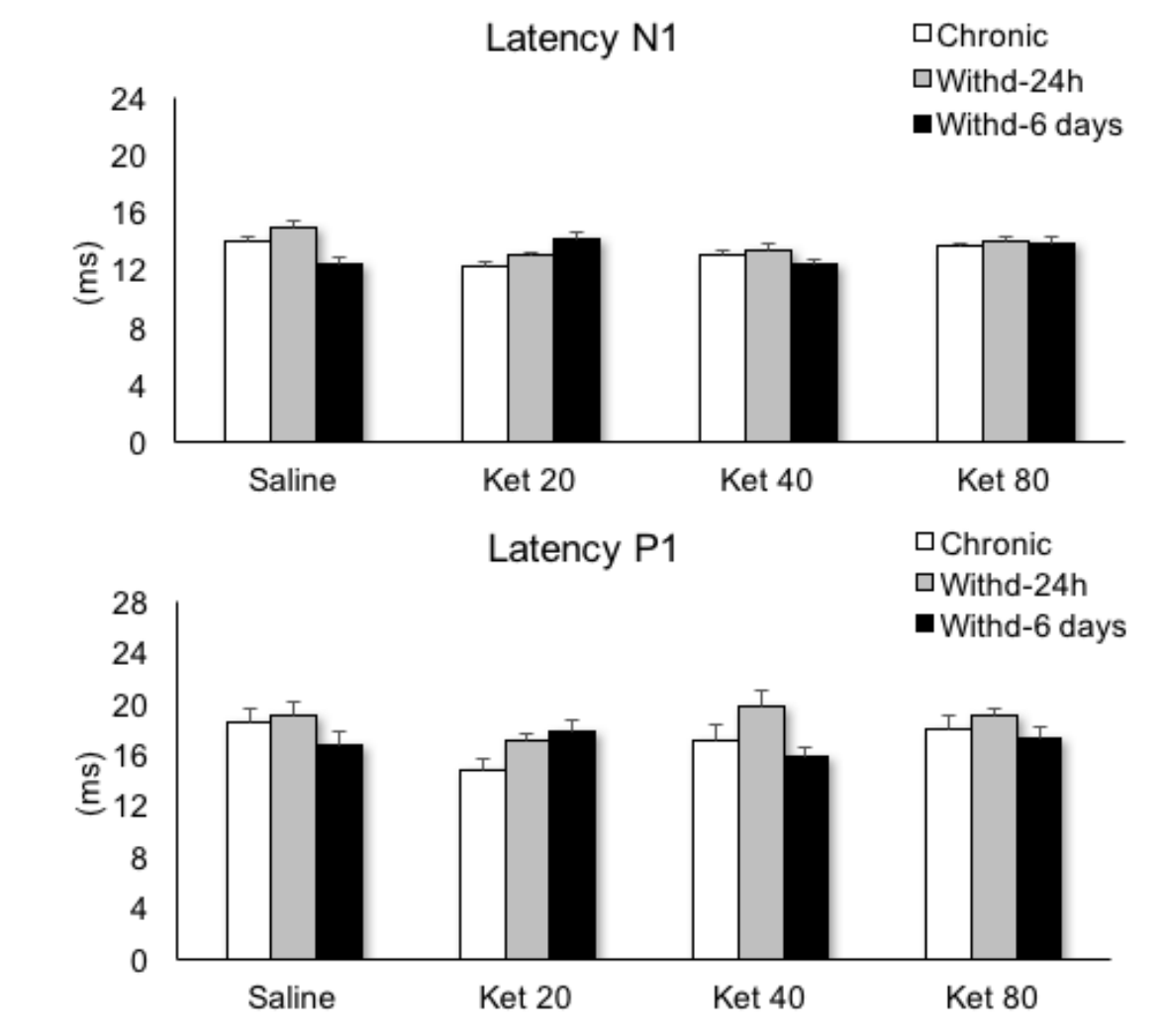

Figure 2. Latency for the first negative (N1) and first positive (P1) components of the collicular auditory evoked potentials (AEPs) depicted in milliseconds (ms). Three doses of ketamine were used. The animals were tested under ketamine effects (Chronic) or after 24 hours or 6 days of withdrawal. 

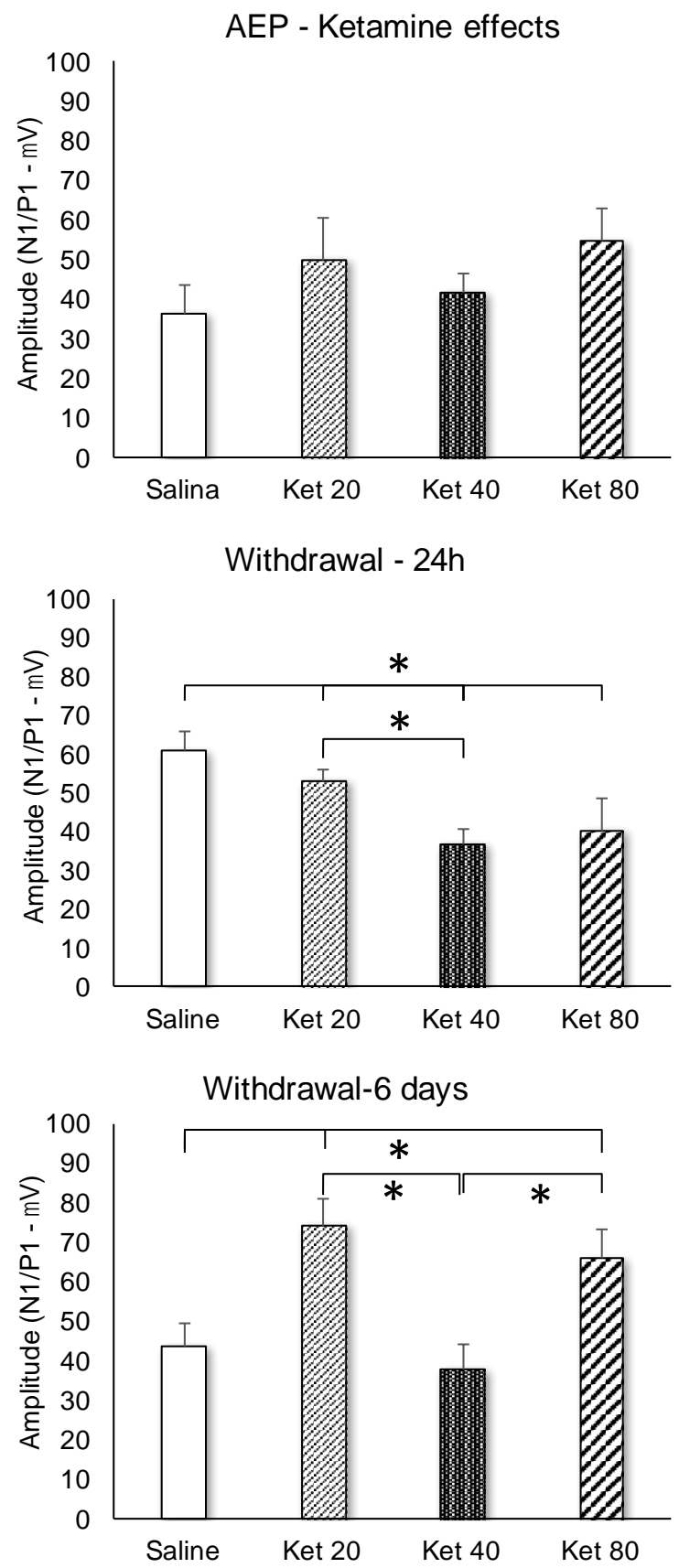

Figure 3. Mean \pm SEM of the amplitude of the collicular auditory evoked potentials (AEPs). Amplitudes are showed as the peak between N1 and P1 components. Three doses of ketamine were used. The animals were tested under ketamine effects (Chronic) or after 24 hours or 6 days of withdrawal. 

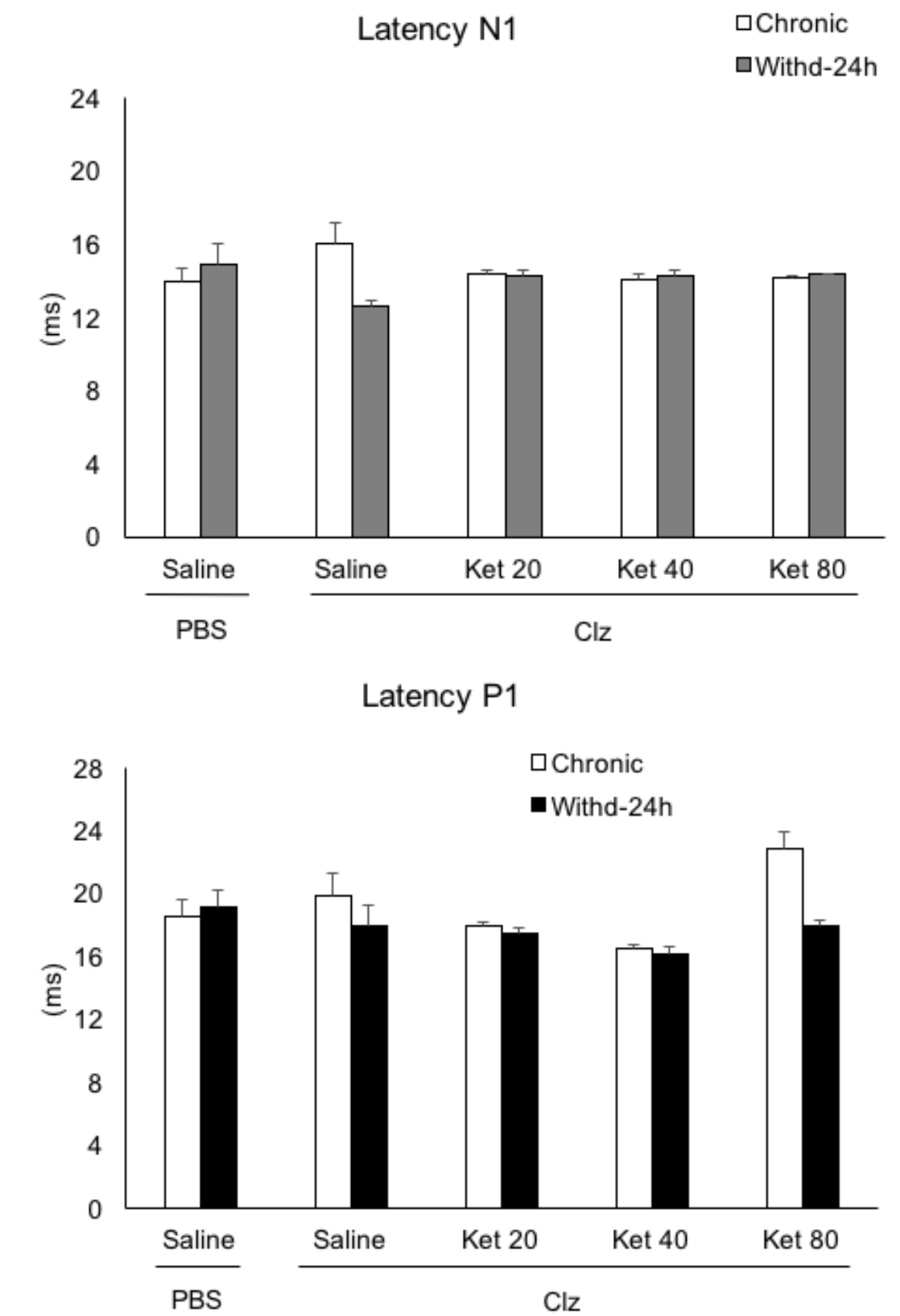

Figure 4. Latency for the first negative (N1) and first positive (P1) components of the collicular auditory evoked potentials (AEPs) depicted in milliseconds (ms). Three doses of ketamine were used. The chronic effect of ketamine was challenged with a systemic injection of the atypical antipsychotic clozapine. The animals were also tested after 24 hours of withdrawal. 


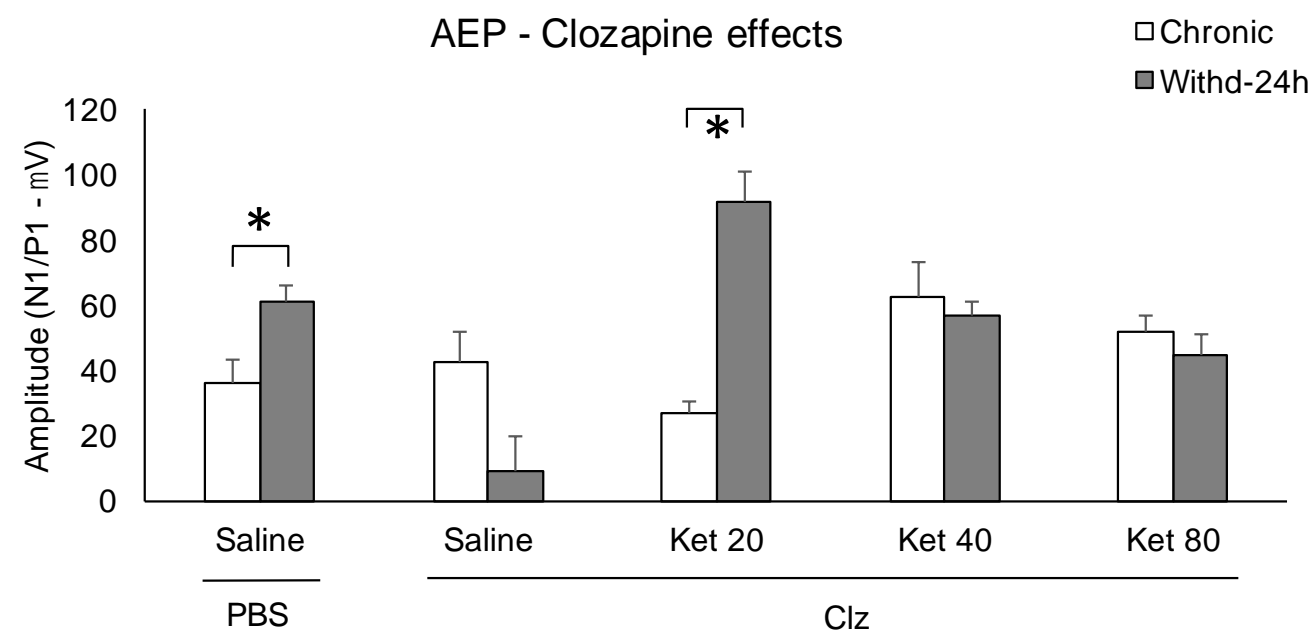

Figure 5. Mean \pm SEM of the amplitude of the collicular auditory evoked potentials (AEPs). Amplitudes are showed as the peak between N1 and P1 components. Three doses of ketamine were used. The chronic effect of ketamine on AEPs was challenged with a systemic injection of the atypical antipsychotic clozapine. The animals were also tested after 24 hours of withdrawal. 


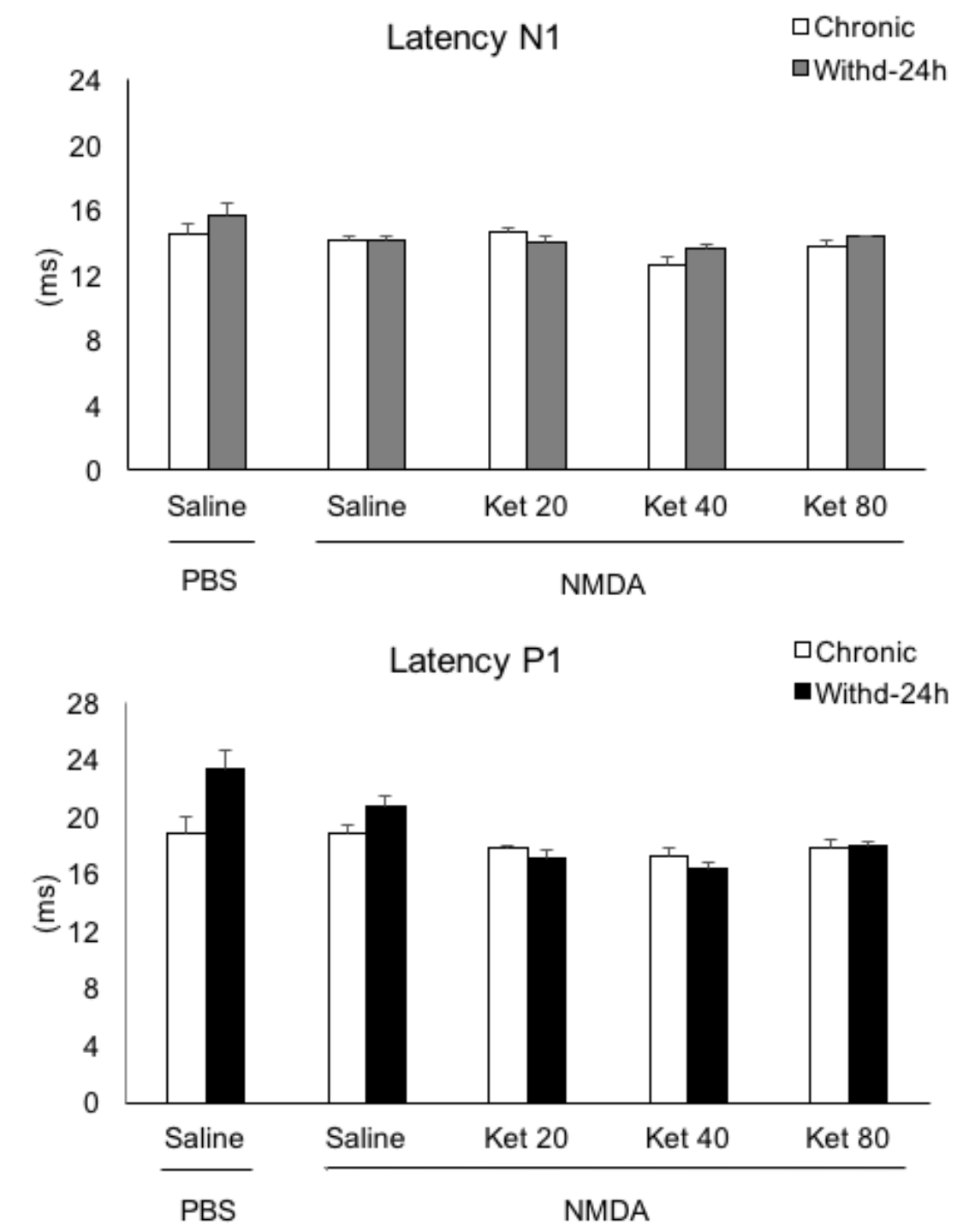

Figure 6. Latency for the first negative (N1) and first positive (P1) components of the collicular auditory evoked potentials (AEPs) depicted in milliseconds (ms). Three doses of ketamine were used. The chronic effect of ketamine was challenged with an intraprelimbic injection of NMDA. The animals were also tested after 24 hours of withdrawal. 


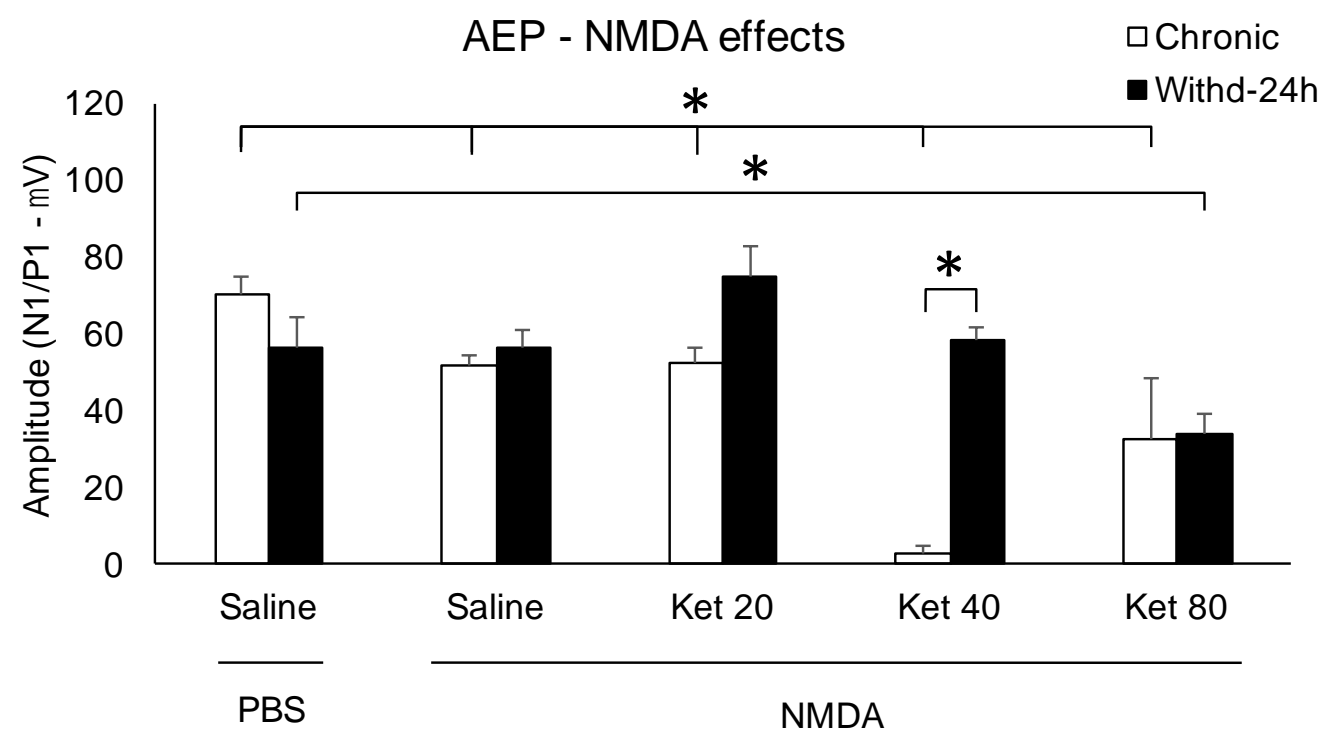

Figure 7. Mean \pm SEM of the amplitude of the collicular auditory evoked potentials (AEPs). Amplitudes are showed as the peak between N1 and P1 components. Three doses of ketamine were used. The chronic effect of ketamine was challenged with an intraprelimbic injection of NMDA. The animals were also tested after 24 hours of withdrawal. 


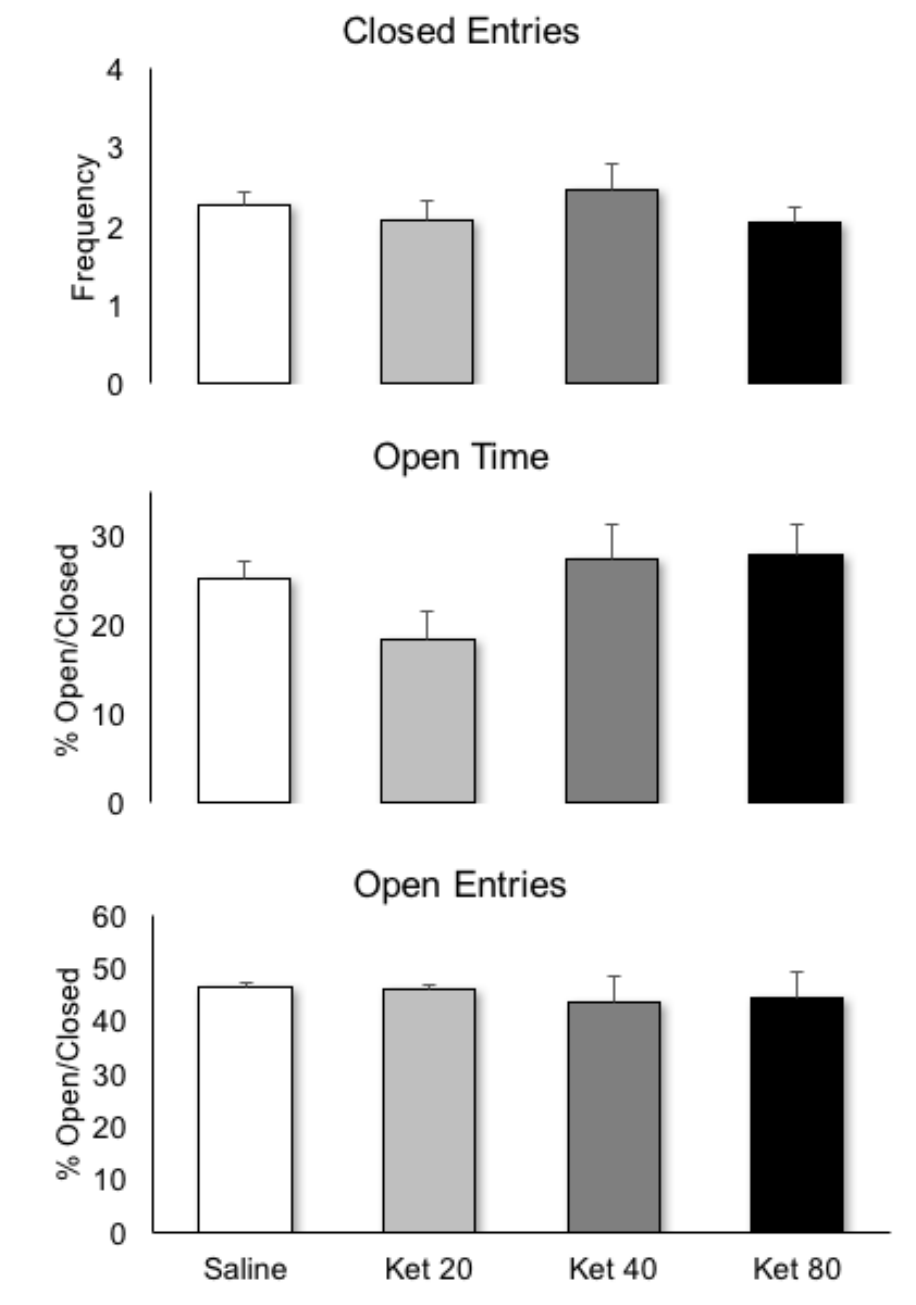

Figure 8. Frequency of entries (top), percentage of the time spent in the open arms (middle), and percentage of entries in the open arms (bottom), of independent groups of rats maintained in a regimen of a single daily 14-days ketamine and tested 30 minutes after the last injection. 


\section{REFERENCES}

Adams, J.C., Wenthold, R.J., 1979. Distribution of putative amino acid transmitters, choline acetyltransferase and glutamate decarboxylase in the inferior colliculus. Neuroscience 4, 1947-1951. doi:10.1016/0306-4522(79)90067-8

Anis, N.A., Berry, S.C., Burton, N.R., Lodge, D., 1983. The dissociative anaesthetics, ketamine and phencyclidine, selectively reduce excitation of central mammalian neurones by N-methyl-aspartate. Br. J. Pharmacol. 79, 565-575. doi:10.1111/j.14765381.1983.tb11031.x

Bagri, A., Sandner, G., Di Scala, G., 1989. Effects of unilateral microinjections of GABAergic drugs into the inferior colliculus on auditory evoked potentials and on audiogenic seizure susceptibility. Exp Neurol 104, 82-7.

Bakshi, V.P., Swerdlow, N.R., Geyer, M.A., 1994. Clozapine antagonizes phencyclidineinduced deficits in sensorimotor gating of the startle response. J. Pharmacol. Exp. Ther. 271, 787-794.

Braff, D.L., Geyer, M.A., 1990. Sensorimotor Gating and Schizophrenia: Human and Animal Model Studies. Arch. Gen. Psychiatry 47, 181-188. doi:10.1001/archpsyc.1990.01810140081011

Brandao, M.L., Borelli, K.G., Nobre, M.J., Santos, J.M., Albrechet-Souza, L., Oliveira, A.R., Martinez, R.C., 2005. Gabaergic regulation of the neural organization of fear in the midbrain tectum. Neurosci Biobehav Rev 29, 1299-311.

Brandao, M.L., Coimbra, N.C., Osaki, M.Y., 2001a. Changes in the auditory-evoked potentials induced by fear-evoking stimulations. Physiol Behav 72, 365-72.

Brandao, M.L., Coimbra, N.C., Osaki, M.Y., 2001b. Changes in the auditory-evoked potentials induced by fear-evoking stimulations. Physiol Behav 72, 365-72.

Bree, M.M., Feller, I., Corssen, G., 1967. Safety and tolerance of repeated anesthesia with CI 581 (Ketamine) in monkeys. Anesth. Analg. 46, 596-600.

Caffino, L., Piva, A., Giannotti, G., Chio, M.D., Mottarlini, F., Venniro, M., Yew, D.T., Chiamulera, C., Fumagalli, F., 2016. Ketamine Self-Administration Reduces the Homeostasis of the Glutamate Synapse in the Rat Brain. Mol. Neurobiol. 1-8. doi:10.1007/s12035-016-0231-6

Carboni, E., Imperato, A., Perezzani, L., Di Chiara, G., 1989. Amphetamine, cocaine, phencyclidine and nomifensine increase extracellular dopamine concentrations preferentially in the nucleus accumbens of freely moving rats. Neuroscience 28, 653-661.

Carlsson, M.L., 1993. Are the disparate pharmacological profiles of competitive and uncompetitive NMDA antagonists due to different baseline activities of distinct glutamatergic pathways? (Hypothesis). J Neural Transm Gen Sect 94, 1-10.

Casseday, J.H., Covey, E., 1996. A neuroethological theory of the operation of the inferior colliculus. Brain Behav Evol 47, 311-36.

Chatterjee, M., Ganguly, S., Srivastava, M., Palit, G., 2011. Effect of "chronic" versus "acute" ketamine administration and its "withdrawal" effect on behavioural alterations in mice: implications for experimental psychosis. Behav Brain Res 216, 247-54. doi:10.1016/j.bbr.2010.08.001

Cotman, C.W., Iversen, L.L., 1987. Excitatory amino acids in the brain - focus on NMDA receptors. Trends Neurosci. 10, 263-265. doi:10.1016/0166-2236(87)90170-6

Cronin, M.M., Bousfield, J. d., Hewett, E. b., McLellan, I., Boulton, T. b., 1972. Ketamine anaesthesia for radiotherapy in small children. Anaesthesia 27, 135-142. doi:10.1111/j.1365-2044.1972.tb08187.x

Dillon, P., Copeland, J., Jansen, K., 2003. Patterns of use and harms associated with nonmedical ketamine use. Drug Alcohol Depend 69, 23-8. 
Domino, E.F., Chodoff, P., Corssen, G., 1965. PHARMACOLOGIC EFFECTS OF CI-581, A NEW DISSOCIATIVE ANESTHETIC, IN MAN. Clin. Pharmacol. Ther. 6, 279-291.

Douglas, B.G., Dagirmanjian, R., 1975. The effects of magnesium deficiency of ketamine sleeping times in the rat. Br. J. Anaesth. 47, 336-340.

Faingold, C.L., Hoffmann, W.E., Caspary, D.M., 1989. Effects of excitant amino acids on acoustic responses of inferior colliculus neurons. Hear. Res. 40, 127-136. doi:10.1016/03785955(89)90106-8

Farber, N.B., Kim, S.H., Dikranian, K., Jiang, X.P., Heinkel, C., 2002. Receptor mechanisms and circuitry underlying NMDA antagonist neurotoxicity. Mol. Psychiatry 7, 32-43. doi: $10.1038 / \mathrm{sj} / \mathrm{mp} / 4000912$

Fendt, M., Li, L., Yeomans, J.S., 2001. Brain stem circuits mediating prepulse inhibition of the startle reflex. Psychopharmacology (Berl.) 156, 216-224. doi:10.1007/s002130100794 Floresco, S.B., Zhang, Y., Enomoto, T., 2009. Neural circuits subserving behavioral flexibility and their relevance to schizophrenia. Behav Brain Res 204, 396-409. doi:10.1016/j.bbr.2008.12.001

Gable, R.S., 2004. Acute toxic effects of club drugs. J. Psychoactive Drugs 36, 303-13. doi:10.1080/02791072.2004.10400031

Geyer, M.A., 1998. Behavioral studies of hallucinogenic drugs in animals: implications for schizophrenia research. Pharmacopsychiatry 31 Suppl 2, 73-9. doi:10.1055/s-2007-979350 Giardino, L., Bortolotti, F., Orazzo, C., Pozza, M., Monteleone, P., Calzà, L., Maj, M., 1997. Effect of chronic clozapine administration on $[3 \mathrm{H}] \mathrm{MK} 801$-binding sites in the rat brain: a side-preference action in cortical areas. Brain Res. 762, 216-218. doi:10.1016/S00068993(97)00478-2

Greenamyre, J.T., Young, A.B., Penney, J.B., 1984. Quantitative autoradiographic distribution of L-[3H]glutamate-binding sites in rat central nervous system. J. Neurosci. 4, 2133-2144.

Greene, R., Bergeron, R., McCarley, R., Coyle, J.T., Grunze, H., 2000. Short-term and Longterm Effects of N-Methyl-D-Aspartate Receptor Hypofunction. Arch. Gen. Psychiatry 57, 1180-1181. doi:10.1001/archpsyc.57.12.1180

Hall, R.D., Mark, R.G., 1967. Fear and the modification of acoustically evoked potentials during conditioning. J Neurophysiol 30, 893-910.

Hata, N., Nishikawa, T., Umino, A., Takahashi, K., 1990. Evidence for involvement of Nmethyl-d-aspartate receptor in tonic inhibitory control of dopaminergic transmission in rat medial frontal cortex. Neurosci. Lett. 120, 101-104. doi:10.1016/0304-3940(90)90178-C Heresco-Levy, U., 2003. Glutamatergic neurotransmission modulation and the mechanisms of antipsychotic atypicality. Prog. Neuropsychopharmacol. Biol. Psychiatry, Mechanism of Atypicality of Antipsychtic Drugs 27, 1113-1123. doi:10.1016/j.pnpbp.2003.09.007

Holt, A.G., Asako, M., Lomax, C.A., MacDonald, J.W., Tong, L., Lomax, M.I., Altschuler, R.A., 2005. Deafness-related plasticity in the inferior colliculus: gene expression profiling following removal of peripheral activity. J. Neurochem. 93, 1069-1086. doi:10.1111/j.14714159.2005.03090.x

Hondo, H., Yonezawa, Y., Nakahara, T., Nakamura, K., Hirano, M., Uchimura, H., Tashiro, N., 1994. Effect of phenycyclidine on dopamine release in the rat prefrontal cortex; an in vivo microdialysis study. Brain Res. 633, 337-342. doi:10.1016/0006-8993(94)91558-X Hurley, L.M., 2006. Different Serotonin Receptor Agonists Have Distinct Effects on SoundEvoked Responses in Inferior Colliculus. J. Neurophysiol. 96, 2177-2188. doi:10.1152/jn.00046.2006

Hurley, L.M., Thompson, A.M., Pollak, G.D., 2002. Serotonin in the inferior colliculus. Hear. Res., A collection of papers presented at the Symposium on The Inferior Colliculus: 
From Past To Future 168, 1-11. doi:10.1016/S0378-5955(02)00365-9

Imre, G., Fokkema, D.S., Den Boer, J.A., Ter Horst, G.J., 2006. Dose-response characteristics of ketamine effect on locomotion, cognitive function and central neuronial activity. Brain Res Bull 69, 338-45. doi:10.1016/j.brainresbull.2006.01.010

Irifune, M., Sato, T., Kamata, Y., Nishikawa, T., Dohi, T., Kawahara, M., 2000. Evidence for $\mathrm{GABA}(\mathrm{A})$ receptor agonistic properties of ketamine: convulsive and anesthetic behavioral models in mice. Anesth. Analg. 91, 230-236.

Javitt, D.C., Balla, A., Burch, S., Suckow, R., Xie, S., Sershen, H., 2003. Reversal of

Phencyclidine-Induced Dopaminergic Dysregulation by N-Methyl-D-Aspartate

Receptor/Glycine-site Agonists. Neuropsychopharmacology 29, 300-307. doi:10.1038/sj.npp.1300313

Kelly, J.B., Zhang, H., 2002. Contribution of AMPA and NMDA receptors to excitatory responses in the inferior colliculus. Hear. Res., A collection of papers presented at the Symposium on The Inferior Colliculus: From Past To Future 168, 35-42. doi:10.1016/S0378-5955(02)00372-6

Koob, G.F., 1992. Drugs of abuse: anatomy, pharmacology and function of reward pathways. Trends Pharmacol Sci 13, 177-84.

Kos, T., Popik, P., Pietraszek, M., Schafer, D., Danysz, W., Dravolina, O., Blokhina, E., Galankin, T., Bespalov, A.Y., 2006. Effect of 5-HT3 receptor antagonist MDL 72222 on behaviors induced by ketamine in rats and mice. Eur Neuropsychopharmacol 16, 297-310. doi:10.1016/j.euroneuro.2005.10.001

Krystal, J.H., Karper, L.P., Seibyl, J.P., Freeman, G.K., Delaney, R., Bremner, J.D., Heninger, G.R., Bowers, M.B., Charney, D.S., 1994. Subanesthetic effects of the noncompetitive NMDA antagonist, ketamine, in humans. Psychotomimetic, perceptual, cognitive, and neuroendocrine responses. Arch Gen Psychiatry 51, 199-214.

Kulkarni, S.K., Singh, K., Bishnoi, M., 2007. Elevated zero maze: a paradigm to evaluate antianxiety effects of drugs. Methods Find. Exp. Clin. Pharmacol. 29, 343-8. doi:10.1358/mf.2007.29.5.1117557

Lahti, A.C., Holcomb, H.H., Medoff, D.R., Tamminga, C.A., 1995. Ketamine activates psychosis and alters limbic blood flow in schizophrenia. Neuroreport 6, 869-72.

Li, B., Liu, M.-L., Wu, X.-P., Jia, J., Cao, J., Wei, Z.-W., Wang, Y.-J., 2015. Effects of ketamine exposure on dopamine concentrations and dopamine type 2 receptor mRNA expression in rat brain tissue. Int. J. Clin. Exp. Med. 8, 11181-11187.

Li, L., Frost, B.J., 2000. Azimuthal directional sensitivity of prepulse inhibition of the pinna startle reflex in decerebrate rats. Brain Res. Bull. 51, 95-100. doi:10.1016/S03619230(99)00215-4

Li, L., Yue, Q., 2002. Auditory gating processes and binaural inhibition in the inferior colliculus. Hear. Res., A collection of papers presented at the Symposium on The Inferior Colliculus: From Past To Future 168, 98-109. doi:10.1016/S0378-5955(02)00356-8

Lodge, D., Mercier, M.S., 2015. Ketamine and phencyclidine: the good, the bad and the unexpected. Br. J. Pharmacol. 172, 4254-4276. doi:10.1111/bph.13222

Long, K.J., Allen, N., 1984. Abnormal brain-stem auditory evoked potentials following Ondine's curse. Arch Neurol 41, 1109-10.

MacDonald, J.F., Miljkovic, Z., Pennefather, P., 1987. Use-dependent block of excitatory amino acid currents in cultured neurons by ketamine. J. Neurophysiol. 58, 251-266.

Ma, C.L., Kelly, J.B., Wu, S.H., 2002. AMPA and NMDA receptors mediate synaptic excitation in the rat's inferior colliculus. Hear. Res. 168, 25-34. doi:10.1016/S03785955(02)00370-2

Malhotra, A.K., Pinals, D.A., Adler, C.M., Elman, I., Clifton, A., Pickar, D., Breier, A., 
1997. Ketamine-Induced Exacerbation of Psychotic Symptoms and Cognitive Impairment in Neuroleptic-Free Schizophrenics. Neuropsychopharmacology 17, 141-150. doi:10.1016/S0893-133X(97)00036-5

Mansbach, R.S., Geyer, M.A., 1989. Effects of phencyclidine and phencyclidine biologs on sensorimotor gating in the rat. Neuropsychopharmacol. Off. Publ. Am. Coll. Neuropsychopharmacol. 2, 299-308.

Mark, R.G., Hall, R.D., 1967. Acoustically evoked potentials in the rat during conditioning. J Neurophysiol 30, 875-92.

Maxwell, C.R., Ehrlichman, R.S., Liang, Y., Trief, D., Kanes, S.J., Karp, J., Siegel, S.J., 2006. Ketamine Produces Lasting Disruptions in Encoding of Sensory Stimuli. J. Pharmacol. Exp. Ther. 316, 315-324. doi:10.1124/jpet.105.091199

Micallef, J., Guillermain, Y., Tardieu, S., Hasbroucq, T., Possamaï, C., Jouve, E., Blin, O., 2002. Effects of subanesthetic doses of ketamine on sensorimotor information processing in healthy subjects. Clin. Neuropharmacol. 25, 101-106.

Moghaddam, B., Krystal, J.H., 2012. Capturing the angel in "angel dust": twenty years of translational neuroscience studies of NMDA receptor antagonists in animals and humans. Schizophr. Bull. 38, 942-949. doi:10.1093/schbul/sbs075

Moreton, J.E., Meisch, R.A., Stark, L., Thompson, T., 1977. Ketamine self-administration by the rhesus monkey. J. Pharmacol. Exp. Ther. 203, 303-309.

Morgan, C.J.A., Muetzelfeldt, L., Curran, H.V., 2010. Consequences of chronic ketamine self-administration upon neurocognitive function and psychological wellbeing: a 1-year longitudinal study. Addict. Abingdon Engl. 105, 121-133. doi:10.1111/j.13600443.2009.02761.x

Neill JC, Barnes S, Cook S, Grayson B, Idris NF, McLean SL, Snigdha S, Rajagopal L, Harte MK (2010) Animal models of cognitive dysfunction and negative symptoms of schizophrenia: focus on NMDA receptor antagonism. Pharmacology \& therapeutics 128:419-432.

Newcomer, J.W., Farber, N.B., Jevtovic-Todorovic, V., Selke, G., Melson, A.K., Hershey, T., Craft, S., Olney, J.W., 1999. Ketamine-Induced NMDA Receptor Hypofunction as a Model of Memory Impairment and Psychosis. Neuropsychopharmacology 20, 106-118. doi:10.1016/S0893-133X(98)00067-0

Ninan, I., Jardemark, K.E., Wang, R.Y., 2003. Olanzapine and clozapine but not haloperidol reverse subchronic phencyclidine-induced functional hyperactivity of $\mathrm{N}$-methyl-D-aspartate receptors in pyramidal cells of the rat medial prefrontal cortex. Neuropharmacology 44, 462472. doi:10.1016/S0028-3908(03)00033-9

Nobre, M.J., 2013. Changes on auditory physiology in response to the inactivation of amygdala nuclei in high anxiety rats expressing learned fear. Physiol Behav 118, 80-7. doi:10.1016/j.physbeh.2013.05.007

Nobre, M.J., Cabral, A., Brandao, M.L., 2010. GABAergic regulation of auditory sensory gating in low- and high-anxiety rats submitted to a fear conditioning procedure. Neuroscience 171, 1152-63.

Nobre, M.J., Sandner, G., Brandao, M.L., 2003. Enhancement of acoustic evoked potentials and impairment of startle reflex induced by reduction of GABAergic control of the neural substrates of aversion in the inferior colliculus. Hear Res 184, 82-90.

O'Donnell, P., Grace, A.A., 1998. Dysfunctions in multiple interrelated systems as the neurobiological bases of schizophrenic symptom clusters. Schizophr. Bull. 24, 267-283.

Ossowska, K., Pietraszek, M., Wardas, J., Nowak, G., Wolfarth, S., 1999. Chronic haloperidol and clozapine administration increases the number of cortical NMDA receptors in rats. Naunyn. Schmiedebergs Arch. Pharmacol. 359, 280-287. 
Patel, C.R., Redhead, C., Cervi, A.L., Zhang, H., 2012. Neural sensitivity to novel sounds in the rat's dorsal cortex of the inferior colliculus as revealed by evoked local field potentials. Hear. Res. 286, 41-54. doi:10.1016/j.heares.2012.02.007

Peruzzi, D., Dut, A., 2004. GABA, serotonin and serotonin receptors in the rat inferior colliculus. Brain Res. 998, 247-250. doi:10.1016/j.brainres.2003.10.059

Sandner, G., Canal, N.M., Brandao, M.L., 2002. Effects of ketamine and apomorphine on inferior colliculus and caudal pontine reticular nucleus evoked potentials during prepulse inhibition of the startle reflex in rats. Behav Brain Res 128, 161-8.

Shergill, S.S., Brammer, M.J., Williams, S.C., Murray, R.M., McGuire, P.K., 2000. Mapping auditory hallucinations in schizophrenia using functional magnetic resonance imaging. Arch Gen Psychiatry 57, 1033-8.

Suzuki, T., Kato, H., Aoki, T., Tsuda, M., Narita, M., Misawa, M., 2000. Effects of the noncompetitive NMDA receptor antagonist ketamine on morphine-induced place preference in mice. Life Sci. 67, 383-389. doi:10.1016/S0024-3205(00)00639-1

Szczepaniak, W.S., Moller, A.R., 1995. Evidence of decreased GABAergic influence on temporal integration in the inferior colliculus following acute noise exposure: a study of evoked potentials in the rat. Neurosci Lett 196, 77-80.

Tricklebank, M.D., Singh, L., Oles, R.J., Preston, C., Iversen, S.D., 1989. The behavioural effects of MK-801: a comparison with antagonists acting non-competitively and competitively at the NMDA receptor. Eur J Pharmacol 167, 127-35.

Umbricht, D., Schmid, L., Koller, R., Vollenweider, F.X., Hell, D., Javitt, D.C., 2000. Ketamine-Induced Deficits in Auditory and Visual Context-Dependent Processing in Healthy Volunteers: Implications for Models of Cognitive Deficits in Schizophrenia. Arch. Gen. Psychiatry 57, 1139-1147. doi:10.1001/archpsyc.57.12.1139

van Berckel, B.N., Oranje, B., van Ree, J.M., Verbaten, M.N., Kahn, R.S., 1998. The effects of low dose ketamine on sensory gating, neuroendocrine secretion and behavior in healthy human subjects. Psychopharmacology (Berl.) 137, 271-281.

van der Kam, E.L., De Vry, J., Tzschentke, T.M., 2009. 2-Methyl-6(phenylethynyl)-pyridine (MPEP) potentiates ketamine and heroin reward as assessed by acquisition, extinction, and reinstatement of conditioned place preference in the rat. Eur. J. Pharmacol. 606, 94-101. doi:10.1016/j.ejphar.2008.12.042

Venniro, M., Mutti, A., Chiamulera, C., 2015. Pharmacological and non-pharmacological factors that regulate the acquisition of ketamine self-administration in rats. Psychopharmacology (Berl.) 232, 4505-4514. doi:10.1007/s00213-015-4077-9

Vertes, R.P., 2004. Differential projections of the infralimbic and prelimbic cortex in the rat. Synapse 51, 32-58.

Wynne, B., Harvey, A.R., Robertson, D., Sirinathsinghji, D.J.S., 1995. Neurotransmitter and neuromodulator systems of the rat inferior colliculus and auditory brainstem studied by in situ hybridization. J. Chem. Neuroanat. 9, 289-300. doi:10.1016/0891-0618(95)00095-X 